US Army Corps of Engineers $S_{\circledast}$

Engineer Research and

Development Center

Analysis of the Effect of Environmental Conditions in Conducting Amphibious Assaults Using a Ship Simulator/Vessel-Response Model Proof-of-Concept Study

Mary A. Cialone, David J. Mark, S. Keith Martin,

Dennis W. Webb, Mary C. Allison, Rhonda D. Taylor,

Thomas A. McKenna, and James R. Hill

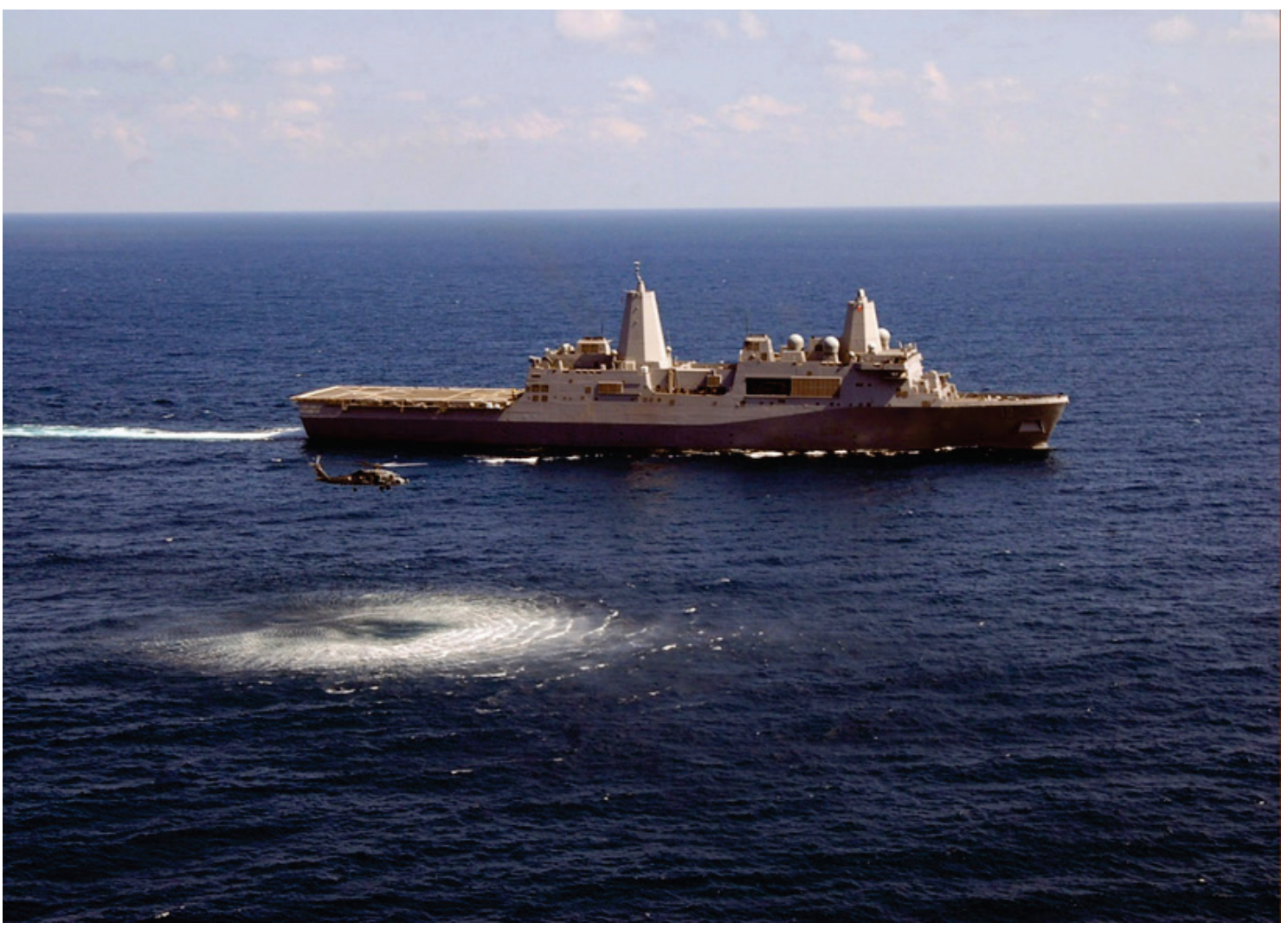


The U.S. Army Engineer Research and Development Center (ERDC) solves the nation's toughest engineering and environmental challenges. ERDC develops innovative solutions in civil and military engineering, geospatial sciences, water resources, and environmental sciences for the Army, the Department of Defense, civilian agencies, and our nation's public good. Find out more at www.erdc.usace.army.mil.

To search for other technical reports published by ERDC, visit the ERDC online library at http://acwc.sdp.sirsi.net/client/default. 


\section{Analysis of the Effect of Environmental Conditions in Conducting Amphibious Assaults Using a Ship Simulator/Vessel-Response Model Proof-of-Concept Study}

Mary A. Cialone, David J. Mark, S. Keith Martin, Dennis W. Webb, and Mary C. Allison

Coastal and Hydraulics Laboratory

U.S. Army Engineer Research and Development Center 3909 Halls Ferry Road

Vicksburg, MS 39180-6199

Rhonda D. Taylor

Office of Research and Technology Transfer

U.S. Army Engineer Research and Development Center 3909 Halls Ferry Road

Vicksburg, MS 39180-6199

Thomas A. McKenna and James R. Hill

U.S. Marine Corps Intelligence Activity

2033 Barnett Avenue

Quantico, VA 22134-5011

Final report

Approved for public release; distribution is unlimited.

Prepared for U.S. Army Corps of Engineers

Washington, DC 20314-1000

Under Marine Corps Intelligence Activity and 219 funding from ERDC 


\section{Abstract}

Significant technological advances have been made in estimating tidal current and water levels using numerical models as well as in estimating vessel maneuverability using ship/tow simulators. Benefits in applying these technologies to planning an amphibious assault include: 1) minimizing operational risk by testing the feasibility of the navigability of an area; 2) determining the capacity and timing of that operation; 3) defining the optimal axes-of-assault that best ensures navigational safety; and 4) developing a training platform for executing a particular plan.

This report summarizes a proof-of-concept study for demonstrating the application of these technologies to allow commanders to determine the feasibility of surface amphibious operations and their use in a virtual amphibious assault near the Port of Anchorage, Alaska. This site was chosen because the environmental conditions at this location dictate that only a narrow window of time is available for conducting surface ship-toshore operations.

The vessel used in the virtual assault is the 1646-class Landing Craft Utility (LCU). The U.S. Navy (USN) provided two experienced craftmasters for piloting the LCU. Their assessment was that the simulator provided a realistic environment and the handling of the virtual LCU closely resembled that of a standard displacement landing craft.

DISCLAIMER: The contents of this report are not to be used for advertising, publication, or promotional purposes. Citation of trade names does not constitute an official endorsement or approval of the use of such commercial products. All product names and trademarks cited are the property of their respective owners. The findings of this report are not to be construed as an official Department of the Army position unless so designated by other authorized documents. 


\section{Contents}
Abstract ii

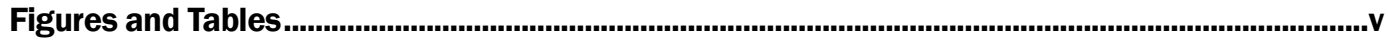

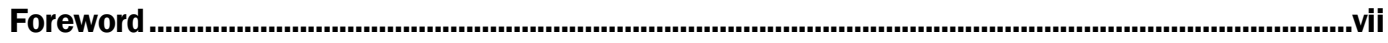

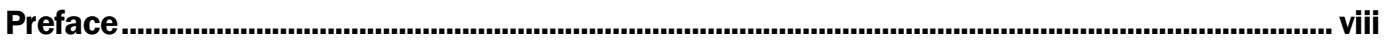

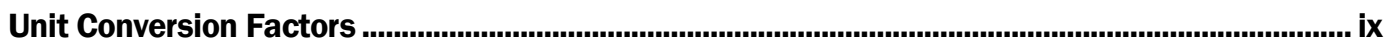

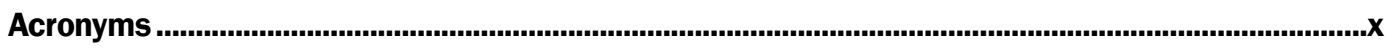

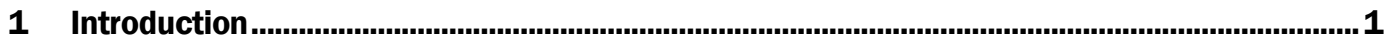

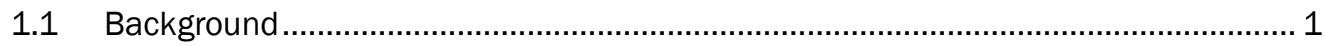

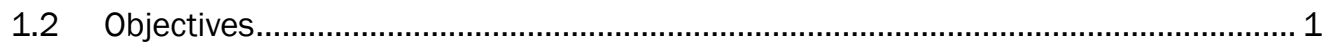

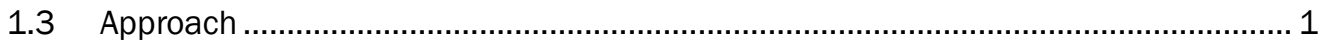

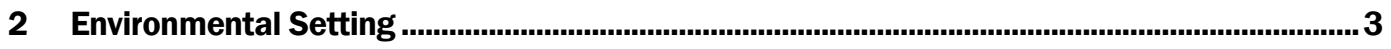

2.1 Physical characteristics of Anchorage, Alaska ....................................................... 3

2.2 Physical characteristics of Inchon, Korea ......................................................... 7

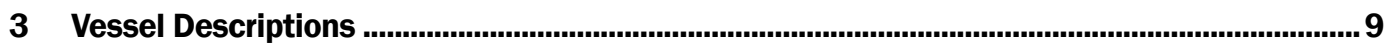

3.1 Amphibious transport dock ......................................................................... 9

3.2 Landing Craft Utility (LCU) ............................................................................ 12

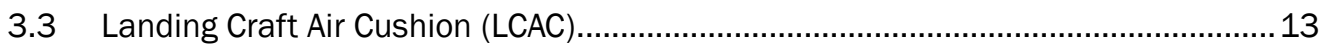

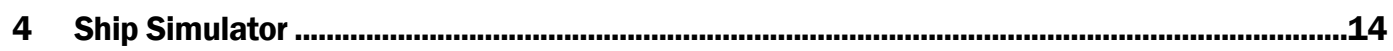

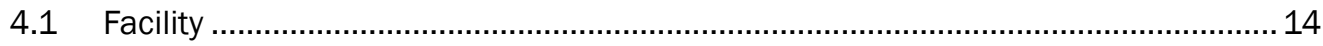

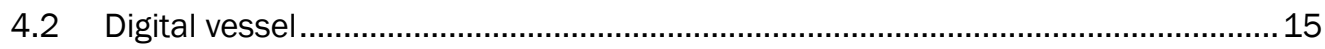

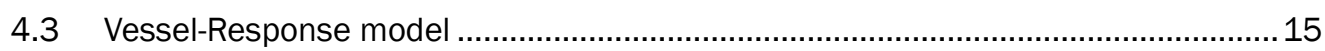

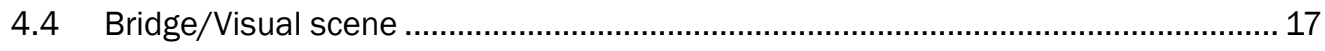

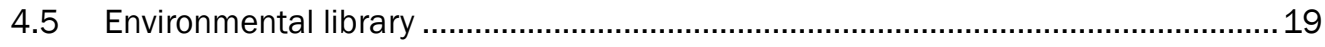

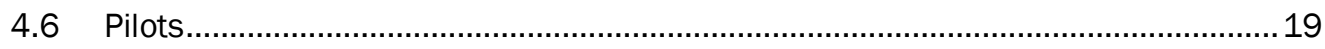

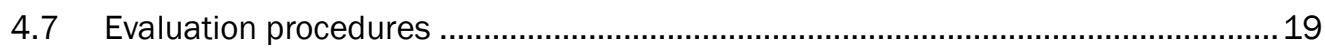

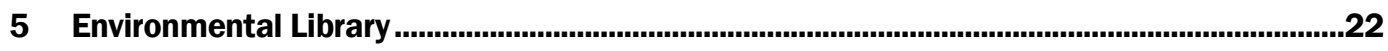

5.1 ADCIRC Model........................................................................................ 22

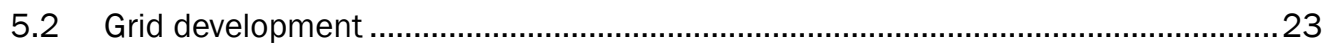

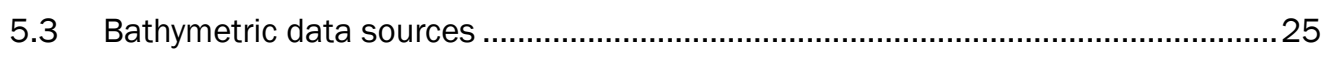

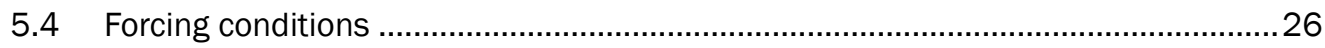

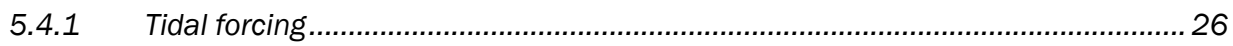

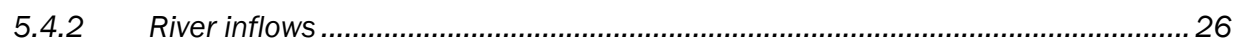

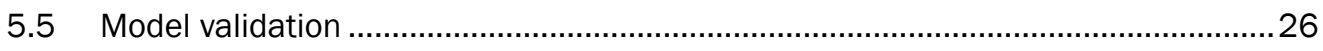

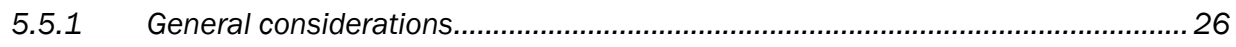




\begin{tabular}{|c|c|}
\hline 5.5 .2 & 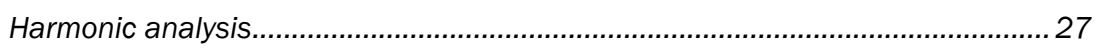 \\
\hline 5.5 .3 & 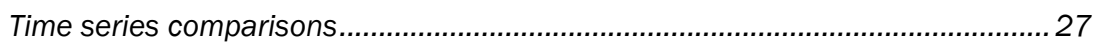 \\
\hline 5.5 .4 & Transect comparisons .............. \\
\hline 5.5 .5 & 30 \\
\hline
\end{tabular}

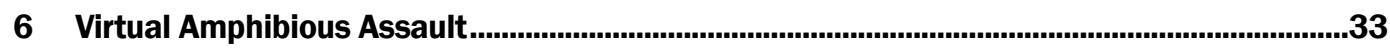

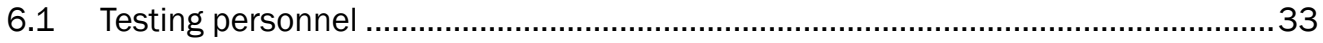

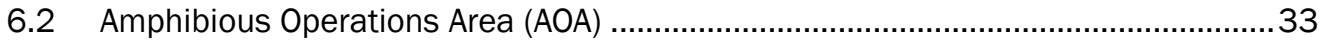

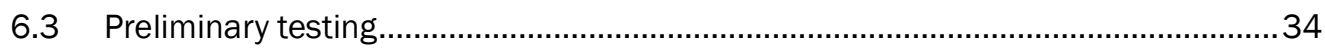

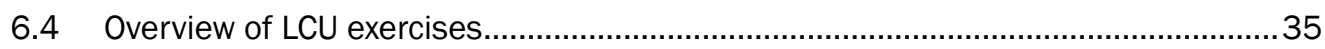

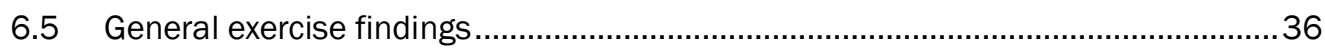

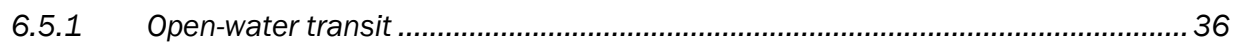

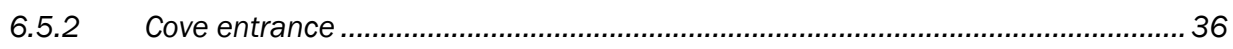

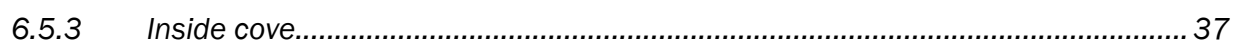

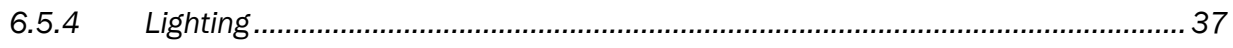

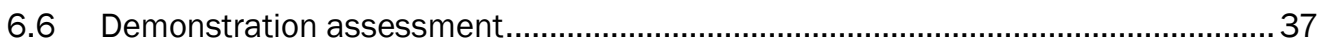

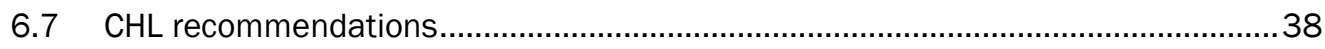

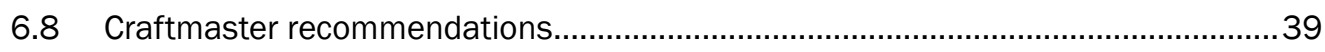

7 Geographic Information System (GIS) Model......................................................................40

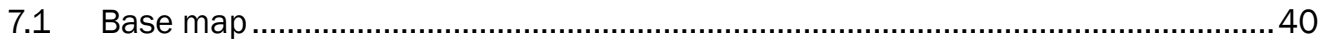

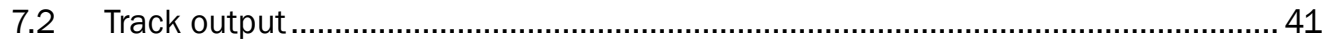

7.3 Environmental conditions .............................................................................. 42

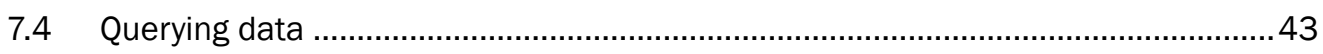

8 Summary

References .....................................................................................................................................47

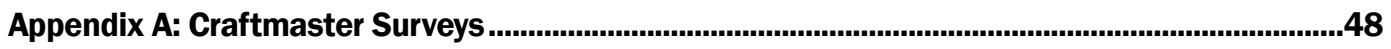

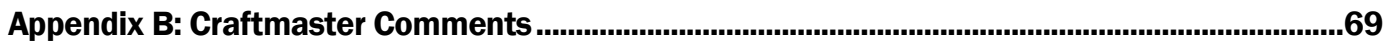

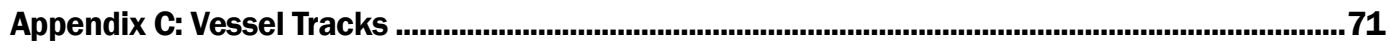

\section{Report Documentation Page}




\section{Figures and Tables}

\section{Figures}

Figure 1. Location of Anchorage, Alaska...................................................................................... 4

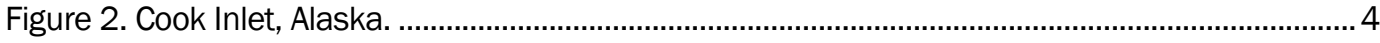

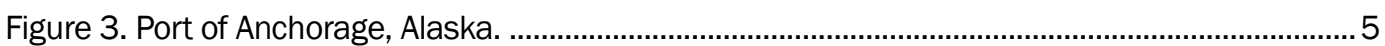

Figure 4. Mudflat in upper Knik Arm, Alaska.............................................................................. 6

Figure 5. Landing site at the Port of Anchorage, Alaska.................................................................. 6

Figure 6. Coastal region in vicinity of Inchon, Republic of Korea (Google Earth Pro $\left.{ }^{\circledR}\right)$.........................

Figure 7. Starboard view of the USS Mesa Verde (LPD 19) (Image courtesy of U.S. Navy)................10

Figure 8. Cutaway illustration of the LPD (Image courtesy of the Naval Sea Systems

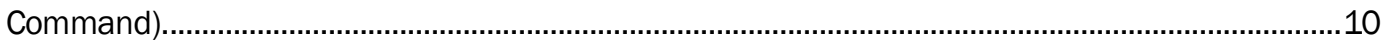

Figure 9. Lower well deck of the USS San Antonio (LPD 17) (Image courtesy of U.S. Navy). ............11

Figure 10. 1600-series LCU (Image courtesy of U.S. Navy)...............................................................12

Figure 11. Landing Craft Air Cushion (LCAC) (Image courtesy of U.S. Navy)......................................13

Figure 12. Schematic displaying environmental and pilot-controlled forces on vessel.......................15

Figure 13. Schematic displaying the 6-degrees of ship motion computed by the vessel-

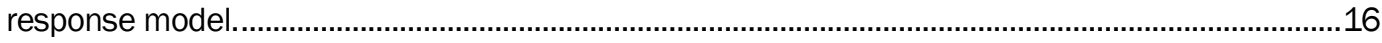

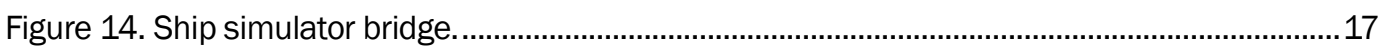

Figure 15. Port of Anchorage visual scene at high water. ……......................................................

Figure 16. Port of Anchorage visual scene at low water...............................................................18

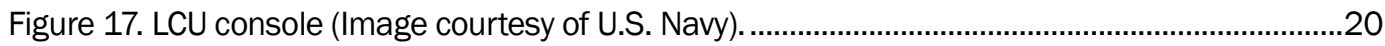

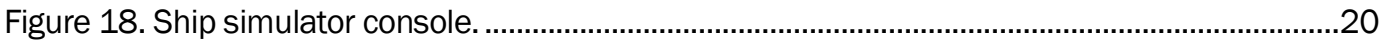

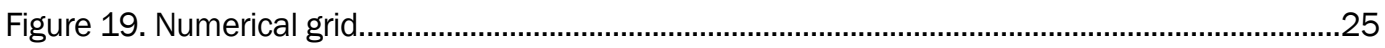

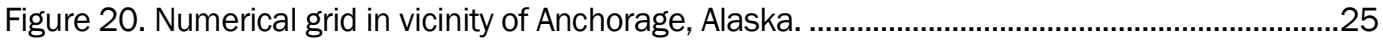

Figure 21. Comparison of ADCIRC-generated and NOS-published tidal constituents........................28

Figure 22. Comparison of ADCIRC-generated and measured water-surface elevations. ..................29

Figure 23. Comparison of measured and ADCIRC-generated water transport. ..................................30

Figure 24. Comparison of ADCIRC-computed and ADCP-measured gyre. ..........................................31

Figure 25. Tidal current on 11 August 2006 at 16:15 Zulu................................................................32

Figure 26. Amphibious operations area.....................................................................................34

Figure 27. Landing site south of the Port of Anchorage (Google Earth Pro $\left.{ }^{\circledR}\right)$......................................34

Figure 28. Example LCU track.....................................................................................................

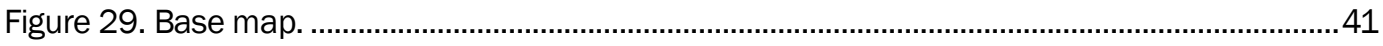

Figure 30. Traffic contours along coastline. ………………...................................................... 43

Figure 31. HTML capability to display vessel performance.............................................................44

Figure C1. Exercise P01AA11. ............................................................................................... 71

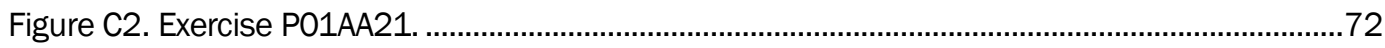

Figure C3. Exercise P01BA11 .................................................................................................. 
Figure C4. Exercise P01BB11

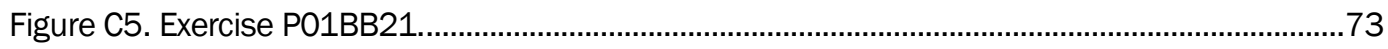

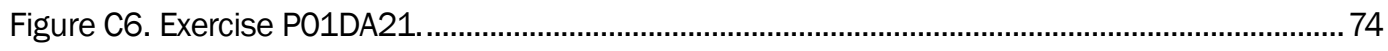

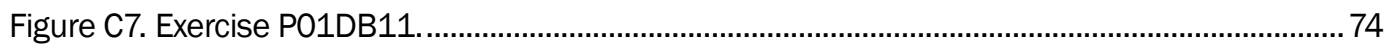

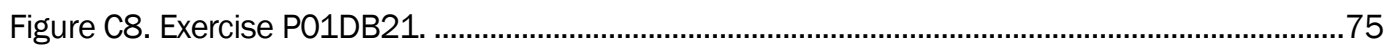

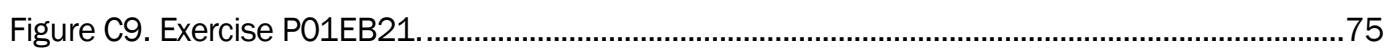

\section{Tables}

Table 1. Environmental conditions defining “Go/No-Go” decision......................................................39

Table 2. Track output parameters..................................................................................................42 


\section{Foreword}

General Joseph Dunford, United States Marine Corps (USMC), the $3^{6^{\text {th }}}$ Commandant of the Marine Corps, in his planning guidance stated that the Marine Corps must "win today's battles while evolving, innovating and adapting to win tomorrow's fight." The challenges that United States (U.S.) maritime forces face will increasingly be in an uncertain, complex and decentralized operating environment. Rapid and detailed understanding of the effects of the environment on the conduct of maritime employment and deployment of maritime forces will be required to enable decision makers to effectively assess risk. This proof-of-concept study was designed to build a capability not previously exploited; to enable the analysis of planned landing craft operations in a controlled environment to assess the risk that the environment poses to proposed operations.

The successful creation of a Landing Craft Utility 1646 model was verified by qualified craftmasters and further meets the intent of providing the means to plan and rehearse prior to execution of operations in support of a crisis where little opportunity is available to familiarize the craftmasters and planners with the location and its associated challenges. Foundational geospatial, climatological, meteorological, astronomical, and oceanographic data is the key to establishing the most accurate environment to test the proposed plan. Further development enhances the capability as a training tool at the school house, as well as a means to improve fleet readiness.

The USMC is charged with being the Nation's Crisis Response Force. Operating with the U.S. Navy and U.S. Coast Guard, they are charged with providing the Nation with a credible, flexible, scalable, force to meet our national security objectives, be they responding to humanitarian assistance or deterring aggression. Providing decision makers with the tools capable of objectively assessing operational risk moves the force towards greater readiness and the capability to determine what is in the realm of the possible. 


\section{Preface}

This study was conducted for the Marine Corps Intelligence Activity (MCIA) under funding by the USMC Intelligence Activity and supplemental 219 funding by the U.S. Army Corps of Engineers (USACE), Engineer Research and Development Center (ERDC) Coastal and Hydraulics Laboratory (CHL).Tidal circulation modeling, together with the development of the environmental library and GIS database, was performed by the Coastal Processes Branch (HF-C), and the Estuarine Engineering Branch (HF-E). Both branches reside in the Flood and Storm Protection Division (HF), CHL. Ms. Ashley E. Frey was Chief, HF-C, and Dr. Robert T. McAdory was Chief, HF-E. General supervision of this component of the study was provided by Dr. Cary A. Talbot, Chief, HF.

Development and application of the Ship/Tow Simulator was conducted by the Navigation Branch (HN-N). Direct supervision was provided by Mr. Timothy W. Shelton, Chief, HN-N. General supervision was provided by Dr. Jackie S, Pettway Chief, Navigation Division (HN).

The Technical Director for the Military Engineering Program was Dr. Kevin M. Barry. The Deputy Director and Director for the CHL were COL Jeffery R. Eckstein (Ret.) and Mr. José E. Sánchez, SES, respectively.

Craftmasters who piloted the virtual LCU were: BMCS(SW) Daniel Chavez, Assault Craft Unit Two, and QM1(SW) Brandon M. Nelson, Assault Craft Unit One. BMCS Chavez's commanding officer was CDR Michael B. O'Driscoll, whereas QM1 Nelson's commanding officer was CDR Julie Grunwell.

COL Brian S. Green was the Commander of ERDC, and Dr. David W. Pittman, SES, was the Director. 


\section{Unit Conversion Factors}

\begin{tabular}{|l|l|l|}
\hline Multiply & By & To Obtain \\
\hline feet & 0.3048 & meters \\
\hline knots & 0.514 & meters per second \\
\hline miles & 1.609 & kilometers \\
\hline square miles & 2.59 & square kilometers \\
\hline
\end{tabular}




\section{Acronyms}

AAV Assault Amphibious Vehicles

ADCP Acoustic Doppler Current Profiler

ADCRIC ADvanced CIRCulation

AOA Amphibious Operations Area

CHL Coastal Hydraulics Laboratory

DNC Digital Nautical Chart

ERDC Engineer Research and Development Center

ESRI Environmental Systems Research Institute

GIS Geographic Information System

HTML Hyper-Text Markup Language

LCAC Landing Craft Air Cushion

LCU Landing Craft Utility

LOTS Logistics Over The Shore

LPD Landing Platform Dock

LSD Dock Landing Ship

MCIA Marine Corps Intelligence Activity

NED National Elevation Dataset

NGA National Geospatial-Intelligence Agency 


$\begin{array}{ll}\text { NOAA } & \text { National Oceanic and Atmospheric Administration } \\ \text { NOS } & \text { National Ocean Service } \\ \text { ROMO } & \text { Range of Military Operations } \\ \text { RPM } & \text { Revolutions Per Minute } \\ \text { SES } & \text { Senior Executive Service } \\ \text { USACE } & \text { U.S. Army Corps of Engineers } \\ \text { USGS } & \text { United States Geological Survey } \\ \text { USMC } & \text { United States Marine Corps } \\ \text { USN } & \text { United States Navy }\end{array}$




\section{Introduction}

\subsection{Background}

In 2003, the U.S. Marine Corps Intelligence Activity (MCIA) instituted an initiative to improve the rigor of its analyses in the littoral zone, which included using state-of-the-art tidal circulation models for estimating tides and current for planning amphibious operations. Prior to this initiative, operational plans were developed in much the same manner as during World War II, using a high tide elevation at the beachhead and a crudely estimated peak current along the axis-of-assault. Factors addressed by using tidal circulation models to improve amphibious operational planning are the following: 1) estimating tidal range and current at a particular site, 2) determining whether that site is appropriate for an amphibious assault landing; and, 3) determining the time during which tidal conditions are favorable for conducting an operation.

\subsection{Objectives}

The above initiative does not address two critical factors: 1) the navigability of waters from the sea echelon area to the beachhead by the landing craft and, 2) the capacity and timing of that operation. These factors become most acute in areas of extreme tidal range, strong current and shear zones, and in areas having limited maneuverability. The goal of this study is to evaluate whether the ship simulator can help address these factors.

Additional benefits in applying these technologies to planning of an amphibious assault are the following: 1) minimizing operational risk by testing the feasibility of the navigability of an area, 2) determining the capacity and timing of that operation, 3) defining the optimal axes-ofassault that best ensures navigational safety; and, 4) developing a training platform for executing a particular plan.

\subsection{Approach}

This proof-of-concept study demonstrates the combined use of a highresolution tidal circulation model and a ship simulator for developing and evaluating operational plans via a virtual amphibious assault near the Port of Anchorage, Alaska. This site was chosen because the environmental conditions at the Port are as challenging as those experienced during 
Operation CHROMITE, the Invasion of Inchon, Republic of Korea, in September 1950. Currents in Knik Arm, where the Port of Anchorage resides, exceed $2 \mathrm{~m} / \mathrm{s}$ (4 kts) during spring tide and the tidal range exceeds $10 \mathrm{~m}$ (32 ft). Massive mudflats front the Port, and at lower-low water are about $500 \mathrm{~m}$ ( $1640 \mathrm{ft})$ wide. These environmental conditions, as at Inchon, dictate that only a narrow window of time is available for conducting an amphibious operation.

This report is composed of eight chapters and three appendices, the first chapter being the introduction. Chapter 2 provides a description of the environmental setting of the Port of Anchorage and also provides details of the Invasion of Inchon. Chapter 3 describes the vessels used in this study, whereas Chapter 4 provides an overview of the Ship Simulator components. Chapter 5 describes the tidal circulation model whose water levels and current compose the environmental library. Chapter 6 describes the virtual assaults, and Chapter 7 provides an overview of the GIS-based model composed of the track output and environmental conditions recorded during each exercise. Chapter 8 provides a summary of this study.

Appendix A contains the surveys each craftmaster wrote at the conclusion of each simulation, as well as the exit interview conducted at the conclusion of the testing period. Appendix B summarizes the recommendations the craftmasters made for improving the simulator's capabilities. Appendix C displays the vessel tracks recorded during each exercise. 


\section{Environmental Setting}

The Port of Anchorage, Alaska was chosen as the landing site for the virtual amphibious assault because the environmental conditions in Knik Arm, where the Port is located, are as challenging as those encountered during Operation CHROMITE, the Invasion of Inchon, Korea in September 1950. The virtual assault of the Port of Anchorage was conducted under spring tide conditions when the tidal range is about $11 \mathrm{~m}$ ( $36 \mathrm{ft}$ ). Maximum current during spring tide is about $2 \mathrm{~m} / \mathrm{s}$ ( 4 knots) on flood and ebb. At low water, a massive mudflat fronting the Port is exposed. Its width at lower-low water is about $500 \mathrm{~m}(1640 \mathrm{ft})$.

Also, the Engineer Research and Development Center (ERDC) has conducted several comprehensive studies for the U.S. Army Corps of Engineers (USACE) Alaska District to support its mission in maintaining our Nation's navigable waters. Components of these studies include field data collection, measurement and monitoring programs, tidal circulation modeling, sediment transport modeling, and navigation modeling using the ship simulator. As such, the models used in this study have been validated against measured data to ensure their accuracy, leaving piloting of the vessels as the sole variable in this application.

The following sections describe the physical characteristics of the area surrounding the Port of Anchorage, as well a brief description of Operation CHROMITE.

\subsection{Physical characteristics of Anchorage, Alaska}

The environmental setting selected for this study was the Port of Anchorage, located in south central Alaska at approximately 61.2 deg N latitude, 149.9 deg W longitude, or over $3200 \mathrm{~km}$ (2000 mi) northeast of the eastern tip of the Aleutian Island chain (Figure 1). The water approach to Anchorage from the Gulf of Alaska is through Cook Inlet (Figure 2). The Municipality of Anchorage is at the southernmost portion of Knik Arm and the Port of Anchorage is $3.2 \mathrm{~km}$ (2 mi) north of the Municipality (Figure 3). 
Figure 1. Location of Anchorage, Alaska.

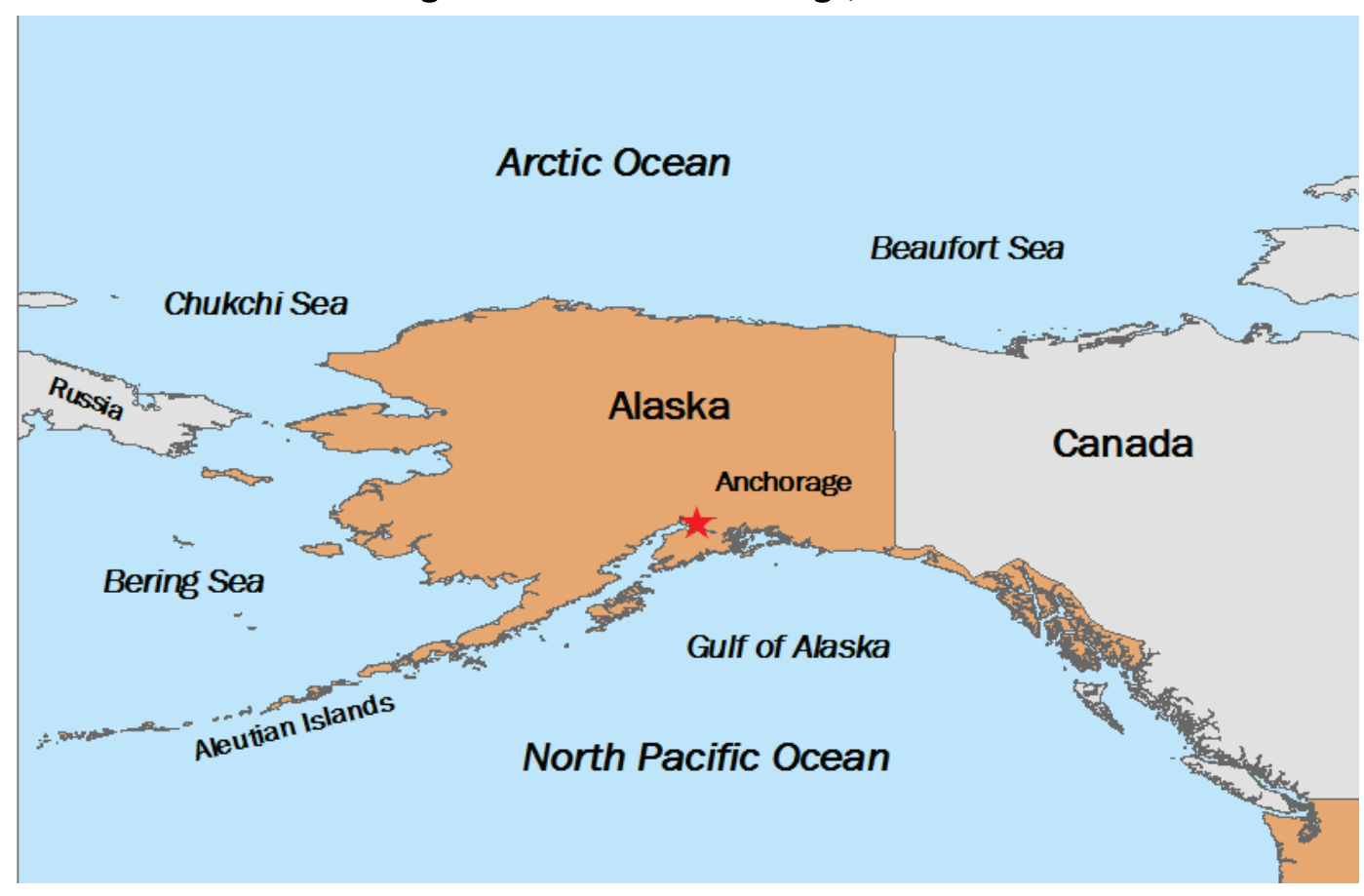

Figure 2. Cook Inlet, Alaska.

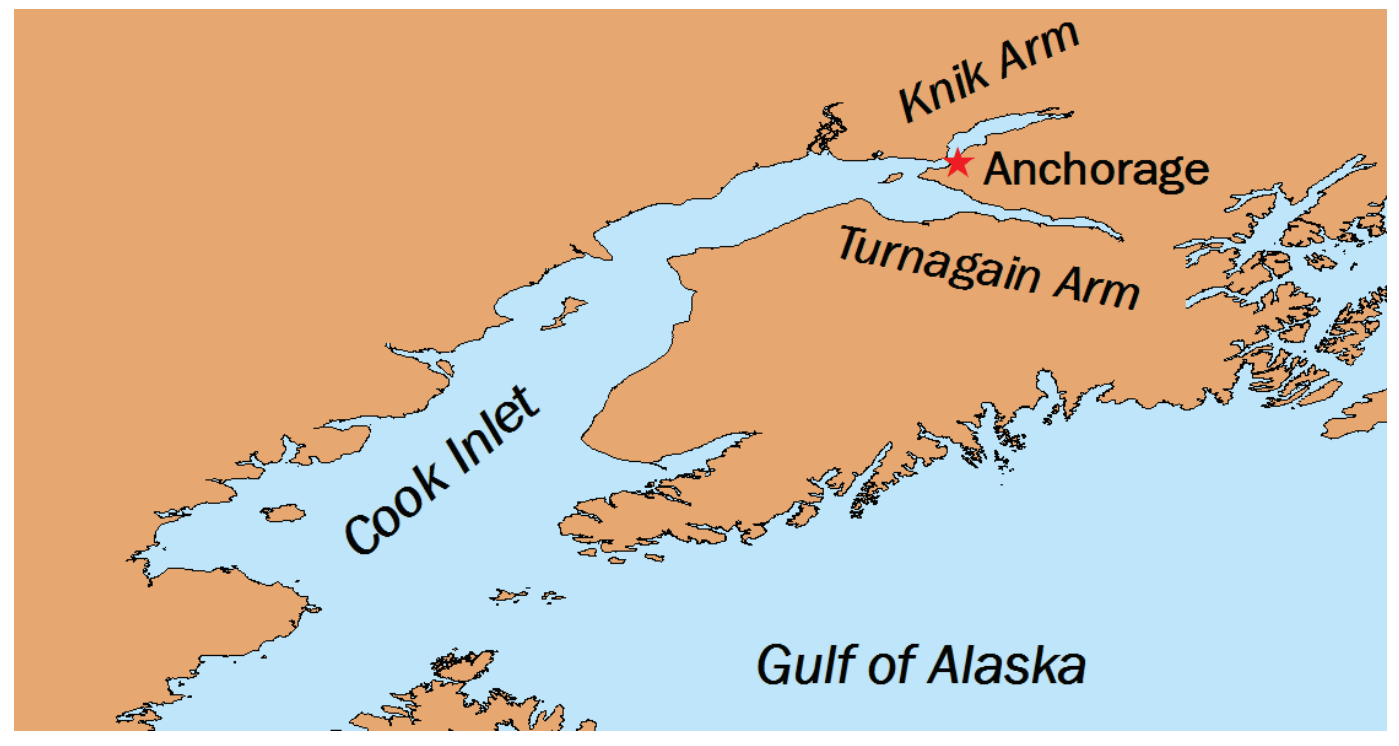


Figure 3. Port of Anchorage, Alaska.

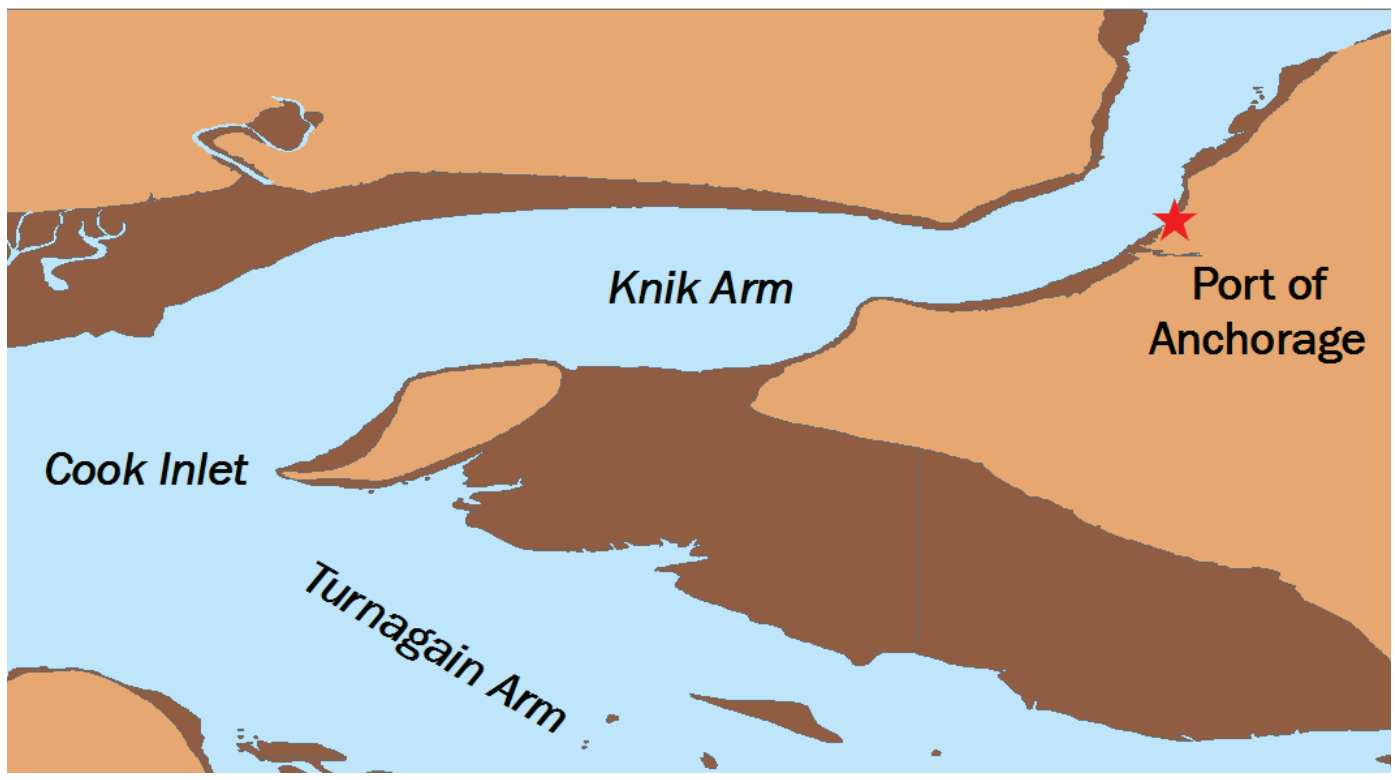

The Municipality is located predominantly on a strip of coastal lowlands near the Chugach Mountains; however, the city limits extend eastward into the alpine territory of Chugach State Park. The western boundary of the city is Point Woronzof, located at the northern terminus of Cook Inlet which splits into two fjords: Turnagain Arm running west to east and Knik Arm running south to north. The tidal ranges in these fjords are some of the largest in the world. The coastal region consists mainly of expansive mudflats of fine glacial silt and these regions become wet and dry with each tidal cycle (Figure 4 and Figure 5). This combination of conditions (extreme tide range, exposed solid ground that can quickly become inundated with the incoming tide, and silty material that becomes mud when wetted) can be treacherous to those that are unaware of these dangers. 
Figure 4. Mudflat in upper Knik Arm, Alaska.

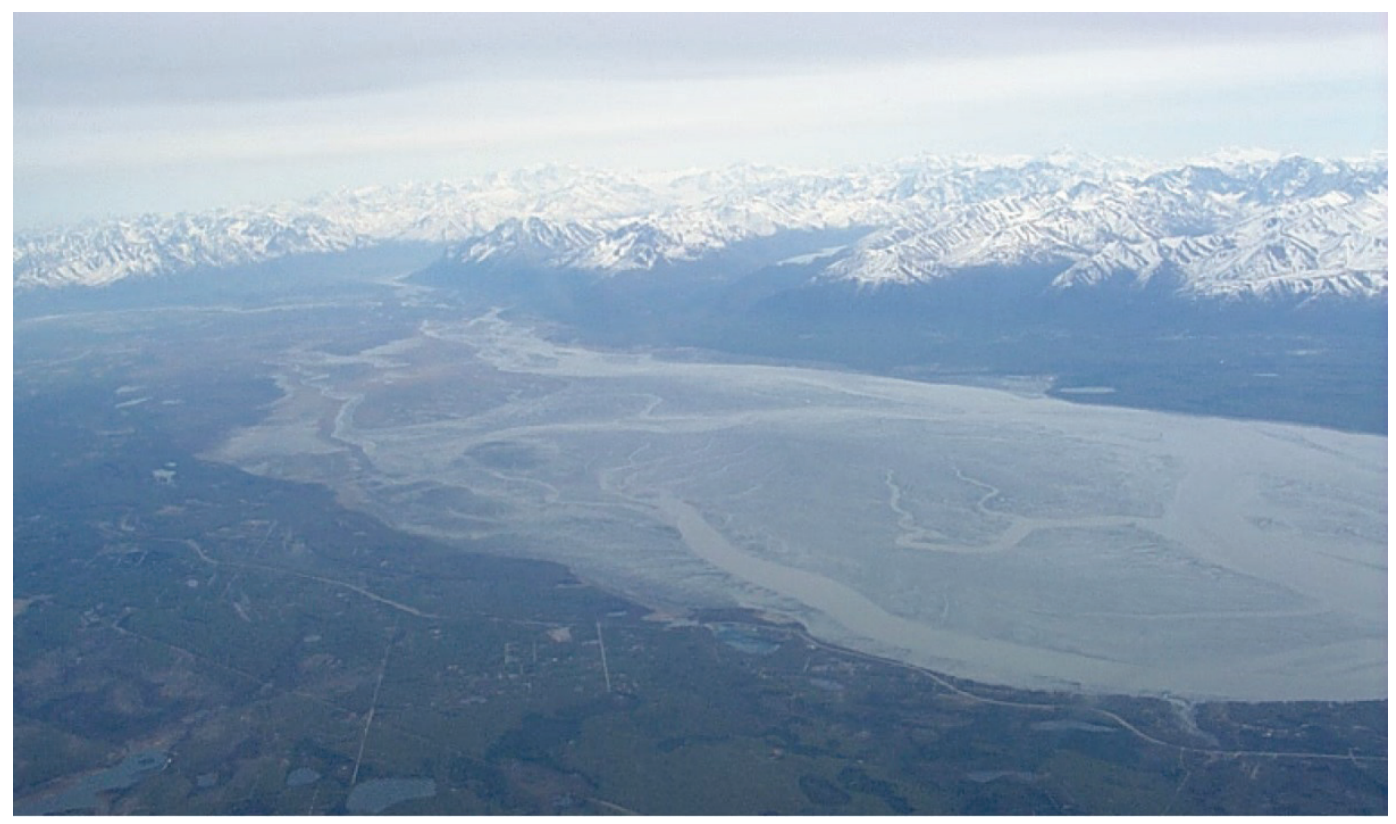

Figure 5. Landing site at the Port of Anchorage, Alaska.

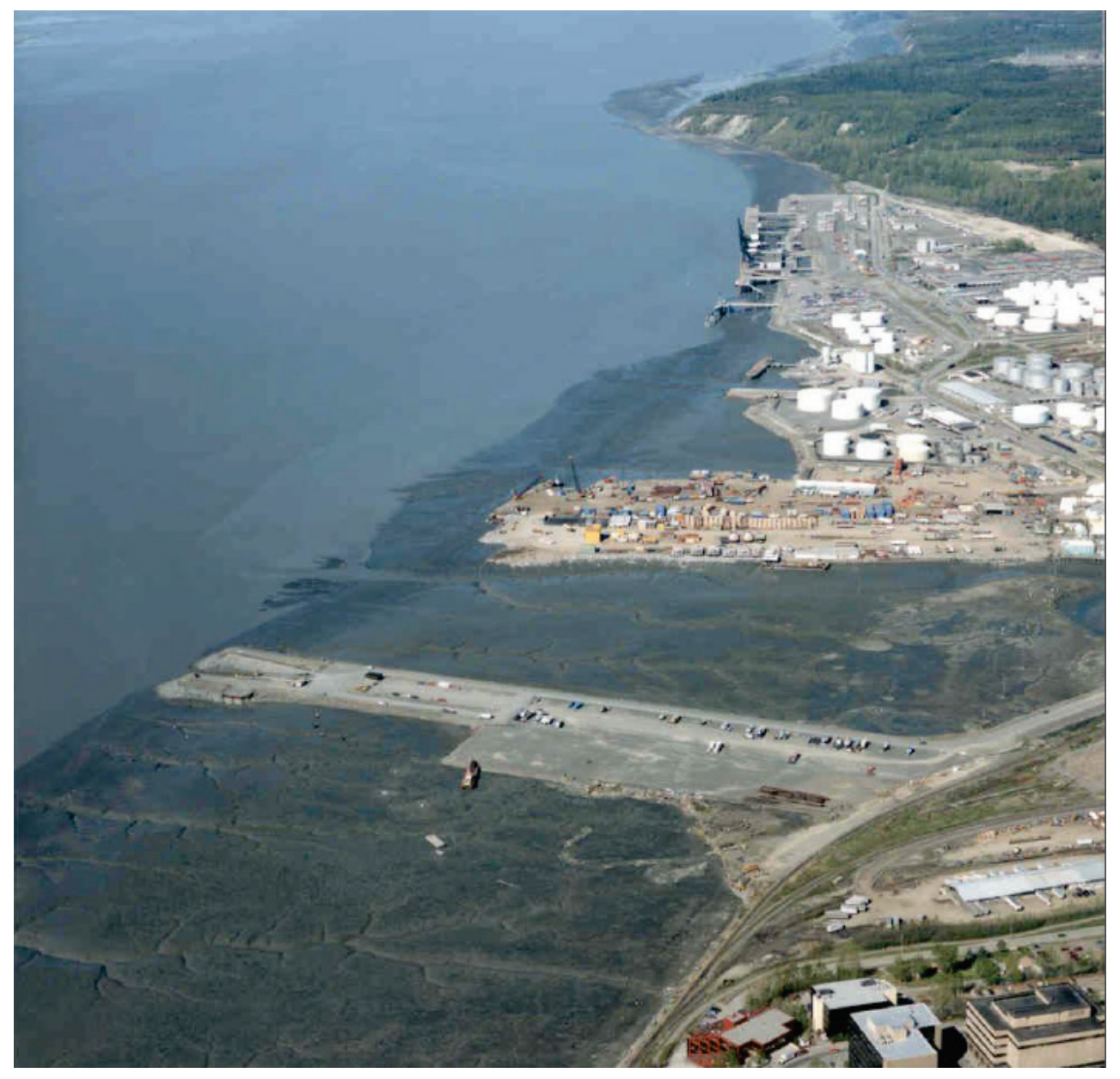




\subsection{Physical characteristics of Inchon, Korea}

Inchon is a coastal city located on the Yellow Sea in northwestern South Korea near the capital city, Seoul (Figure 6). With a population of nearly 3 million people, it is the third most populated city in Korea. Its growth is attributed to its coastal location, the development of Inchon Harbor, and its proximity to the capital. Similar to Anchorage, Alaska, Inchon has one of the world's largest tide ranges, with an average range of $8.8 \mathrm{~m} \mathrm{(29 \textrm {ft } )}$

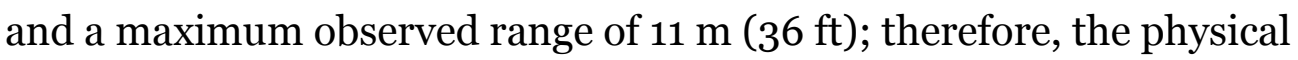
characteristics of either of these two locations provide a demonstration of the operational environment for assessing the timing of amphibious assaults under extreme tide conditions. Another similarity is the expansive mudflats in Anchorage and Inchon. There are approximately $2850 \mathrm{~km}^{2}$ $\left(1100 \mathrm{mi}^{2}\right)$ of intertidal mudflats in western Korea which are not fronted by barrier beaches, swash bars, large-scale intertidal drainage networks, or well-developed landward salt marshes (Frey et al. 1988). The intertidal mudflats at Inchon are made of clayey silt and sand (Kim and Park 1985; Frey et al. 1988) and extend $18 \mathrm{~km}$ (11 mi) from the shoreline at Inchon and some $50 \mathrm{~km}(31 \mathrm{mi})$ from the shore just north of Inchon. The narrow river channel at Inchon and wide mudflats restrict shipping operations in this region (Schwartz 2005).

Figure 6. Coastal region in vicinity of Inchon, Republic of Korea (Google Earth Pro ${ }^{\circledR}$ ).

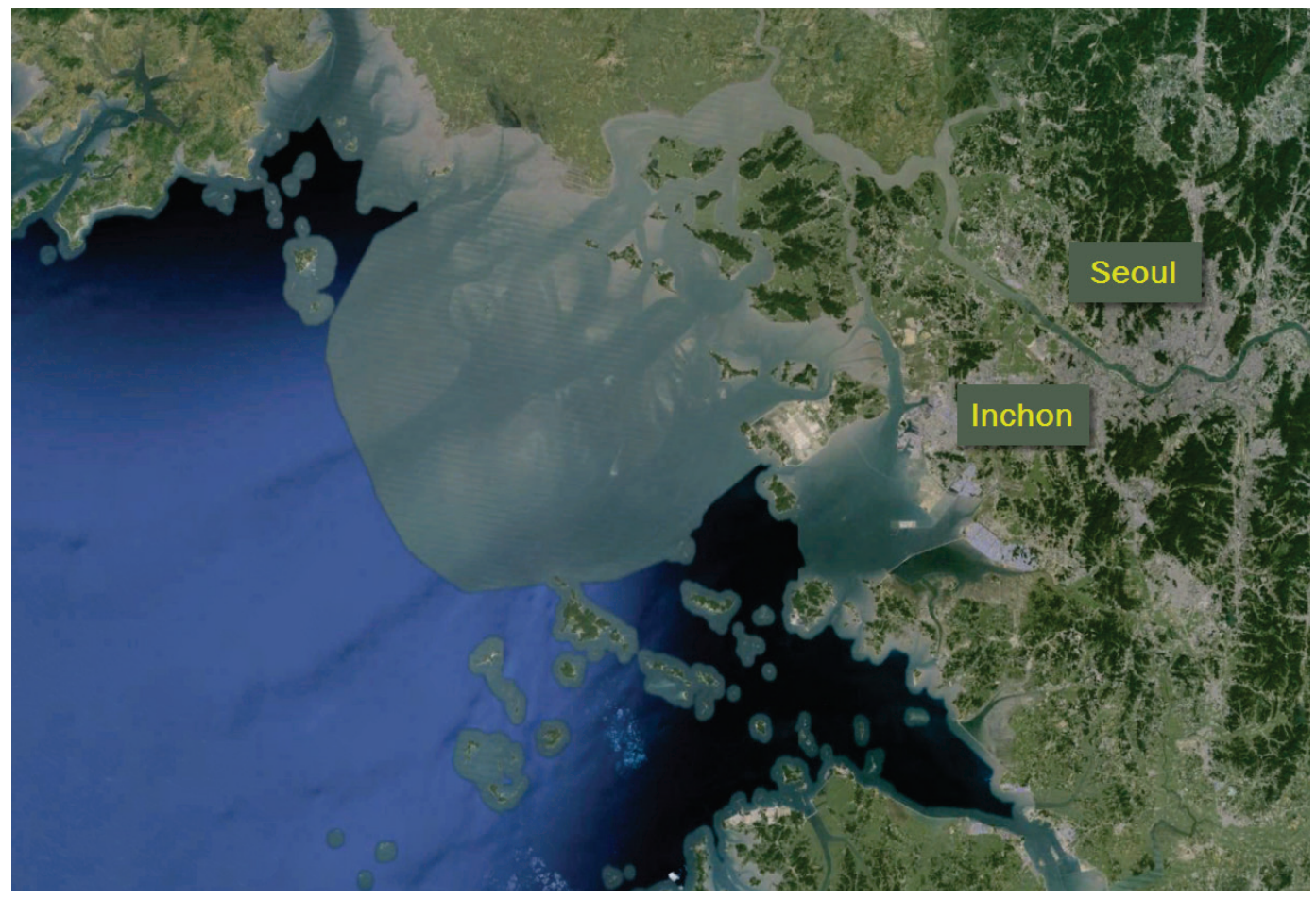


The conditions in Anchorage, Alaska, also serve as a reminder of the conditions during the amphibious assault on Inchon, Korea in 1950 led by General Douglas McArthur (Builder et al. 1999). During that time period, without the tide modeling and ship simulator capabilities of today, the plan of action was to conduct timing drills elsewhere on the Korean coastline and have military intelligence gather physical data prior to the attack by placing forces on an island in Inchon Harbor, Operation TRUDY JACKSON (Boose 2008; Clark 2002). Selecting neap tide conditions would have avoided the extreme tide range and ensure some depth of water at low tide, but those conditions were not selected. Operation planners chose a time period of spring high tide so the amphibious shipping could be close to the beach/seawall and enable the assault landing craft to get to the seawall without getting stuck in the mud (Schwartz 2005). During spring tide in Inchon Harbor, flood tidal currents are $0.9 \mathrm{~m} / \mathrm{sec}$ (1.8 knots) to $1.8 \mathrm{~m} / \mathrm{sec}$ (3.6 knots) and ebb currents are $1.2 \mathrm{~m} / \mathrm{sec}$ ( 2.4 knots) to $2.3 \mathrm{~m} / \mathrm{sec}$ (4.6 knots) (Frey et al. 1988). Schwartz (2005) noted that the tidal currents at Inchon also had an influence on the timing of assault because the range of current speeds is similar to the maximum assault vessel speeds. The planners required a time period of two high tides in daylight, which restricted the landing to a few days each month (Schwartz 2005). This planning was critical because poor knowledge of the tides on other assaults, namely Operation GALVANIC, the Invasion of Tarawa, Gilberts Islands during World War II, had led to assault craft running aground on the coral reef, forcing the Marines to wade over 1000 yards to the beach. 


\section{Vessel Descriptions}

The MCIA selected three vessels for testing in this proof-of-concept study, the: San Antonio-class Amphibious Transport Dock or Landing Platform Dock (LPD); 1646- class Landing Craft Utility (LCU); and the Landing Craft Air Cushion (LCAC). At the time of this report, testing has only been completed for the LCU. Testing of the other vessels was completed in spring 2017. A general description of each is provided below.

\subsection{Amphibious transport dock}

Shown in Figure 7, the LPD is an amphibious warfare ship which embarks, transports, and lands elements of a landing force for a variety of expeditionary warfare missions. Elements include 700 to 900 Marines, heavy combat equipment, and supplies. Heavy combat equipment can consist of Assault Amphibious Vehicles (AAV), tanks, bulldozers, and a variety of light and heavy duty trucks. This equipment is stowed in the ship's vehicle stowage areas, which is divided into an upper and lower section. The surface connectors (LCAC and LCU) are embarked in the well deck and may be pre-loaded with a combination of the trucks and heavy equipment. The LPD can be ballasted down in the water, flooding the lower well section, launching the LCACs, LCUs, and AAVs during expeditionary operations. Figure 8 is a cutaway illustration of the ship displaying the stern gate to the well deck, located on the stern of the ship; the lower vehicle storage deck, located aft; and the upper vehicle storage deck, located mid-ship. Shown are two LCACs in the lower well deck with assorted equipment in the upper well deck. Figure 9 is a photo of the USS San Antonio's (LPD 17) lower well deck; two AAVs are shown in the photo.

The ship also has a helicopter landing deck and a hangar facility aft. The landing deck supports vertical take-off and landing aircraft, such as the MV-22B Osprey, as well as standard assault and assault support helicopters such as the CH-53K Super Stallion. As such, the LPD can provide air support for the range of military operations (ROMO) from special operations through expeditionary warfare missions. The landing deck also provides a means for the ship to be replenished with personnel and supplies by air while at sea. 
Figure 7. Starboard view of the U.S.S. Mesa Verde (LPD 19) (Image courtesy of U.S. Navy).

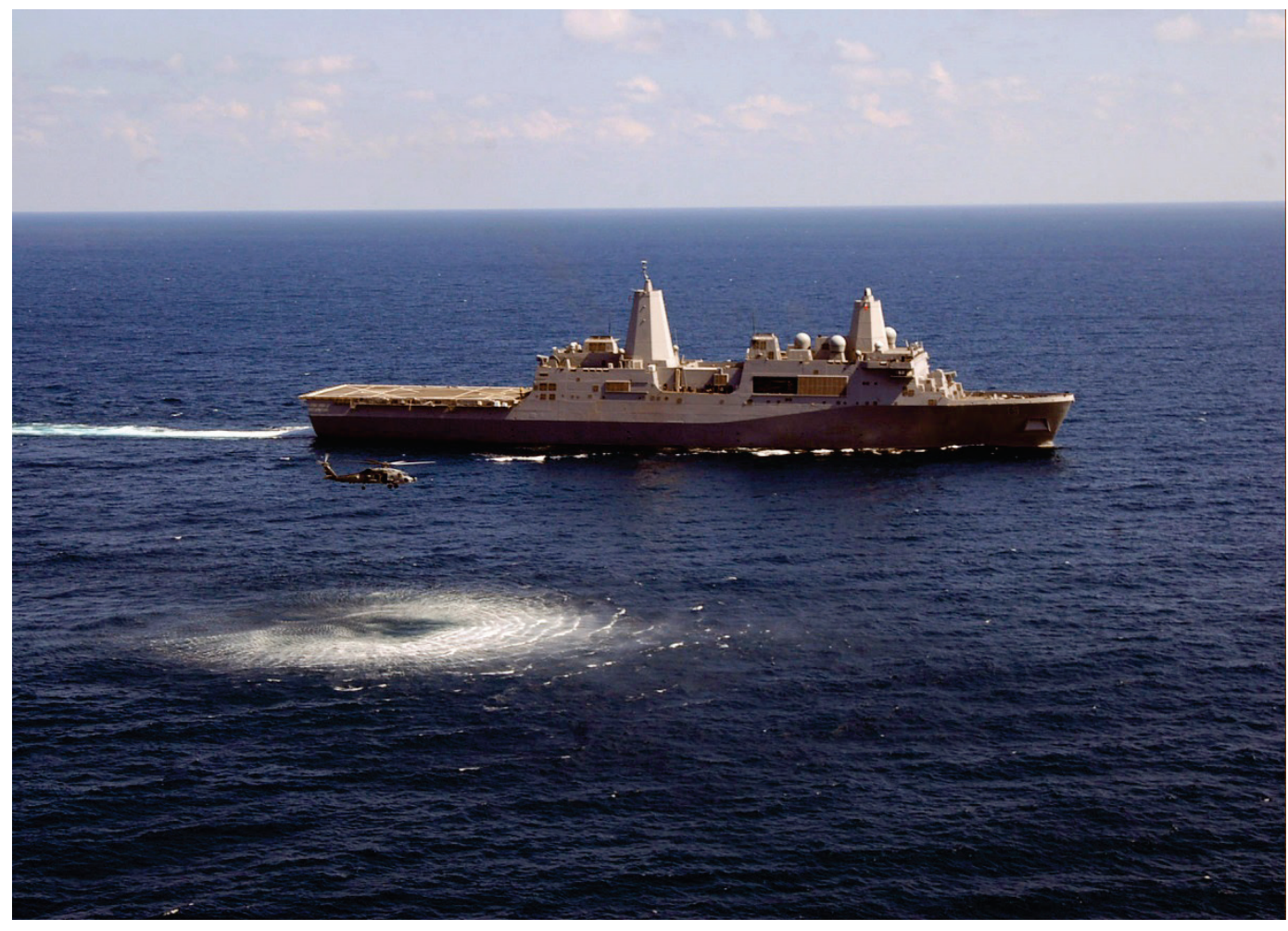

Figure 8. Cutaway illustration of the LPD (Image courtesy of the Naval Sea Systems Command).

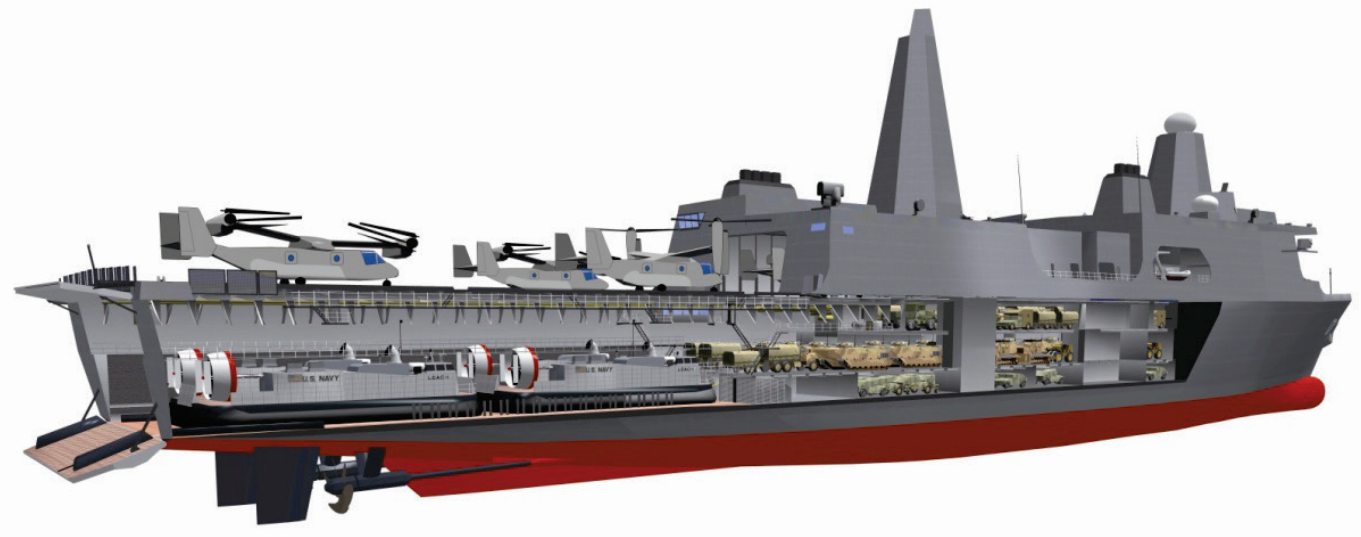


Figure 9. Lower well deck of the U.S.S. San Antonio (LPD 17) (Image courtesy of U.S. Navy).

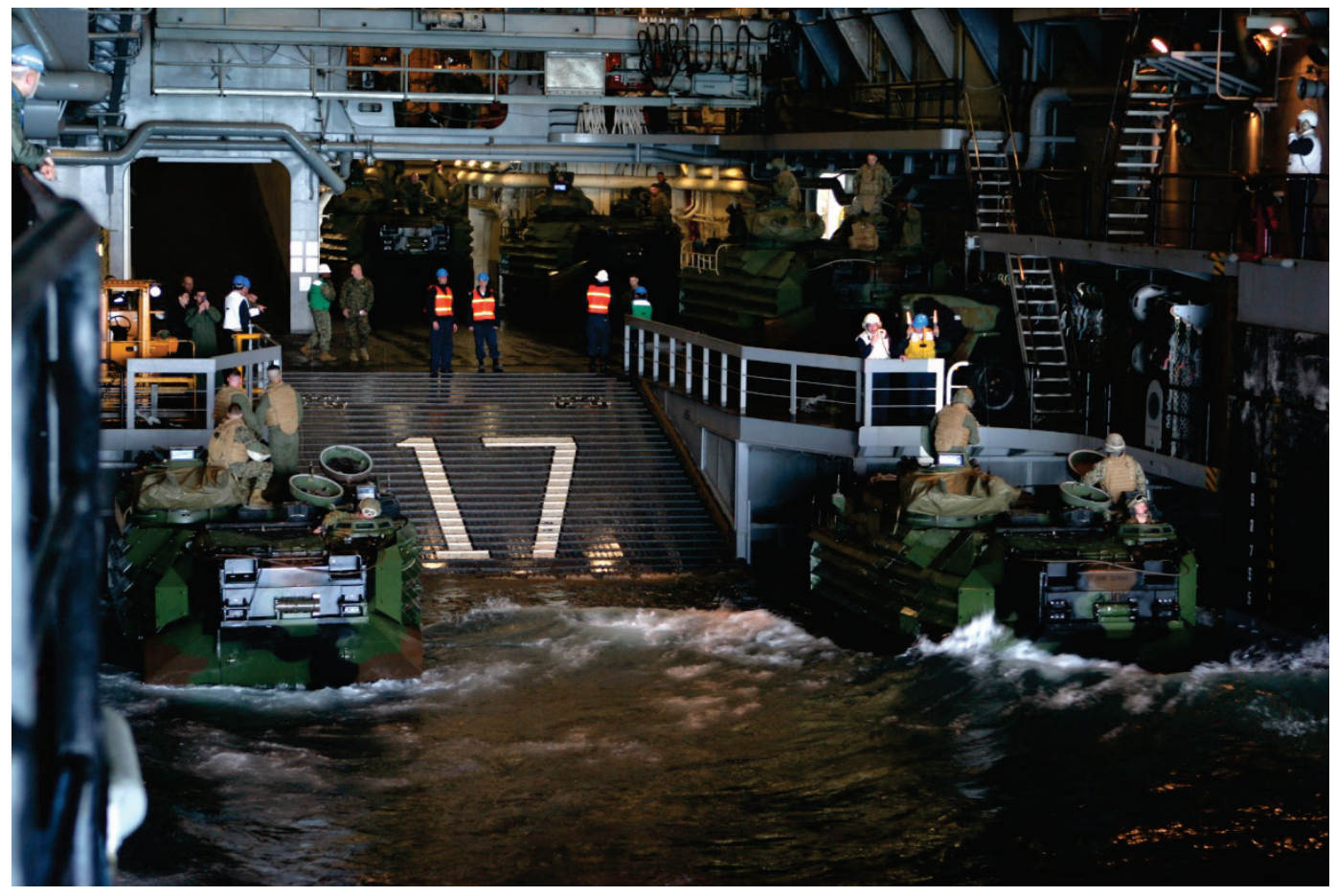

There is currently one class of LPD: the San Antonio class. The remaining ship of the Austin class, U.S.S. Ponce (AFSB 15) is used as an afloat forward staging base in the U.S. Central Command area of operations.

The San Antonio-class of LPDs provides the U.S. Navy (USN) and USMC with modern, sea-based platforms that are networked, survivable, and built to operate with 21st century transformational platforms. They are $684 \mathrm{ft}$ long, with a $105 \mathrm{ft}$ beam and have a published maximum speed of 22 knots. The full-load displacement is 24,900 tons. The ship holds a crew of 377 , an embarked landing force of 699 , and a surge capacity of 800 . The ship is fitted with Two Bushmaster II $30 \mathrm{~mm}$ Close-in Guns, two Rolling Airframe Missile launchers, and ten .50 caliber machine guns.

For air support, the San Antonio-class LPD can launch two $\mathrm{CH}_{53} \mathrm{E}$ Super Stallion helicopters; two MV-22 Osprey tilt-rotor aircraft; or, four, AH-1, or UH-1 helicopters.

The San Antonio class includes the U.S.S. San Antonio (LPD 17), U.S.S. New Orleans (LPD 18), U.S.S. Mesa Verde (LPD 19), U.S.S. Green Bay (LPD 20), U.S.S. New York (LPD 21), U.S.S. San Diego (LPD 22), U.S.S. Anchorage (LPD 23), U.S.S. Arlington (LPD 24), and the U.S.S. Somerset (LPD 25). 


\subsection{Landing Craft Utility (LCU)}

The LCU class of vessels was first used in supporting amphibious assaults during World War II, most notably in the Operations OVERLORD and SHINGLE, the invasions of Normandy and Italy, respectively, and in the Pacific Theatre. The LCUs provide support in Logistic-Over-The-Shore (LOTS) operations as well as in landings in remote areas having austere shore facilities or unimproved beaches. It is used for transporting combatequipped Marines, general cargo, and vehicles from amphibious shipping to the beachhead. Bow and stern ramps provide a roll on/roll off capability for tracked and wheeled vehicles.

There are three classes of LCUs in the 1600 series: the 1610 , the 1627 , and the 1646, all with similar characteristics. Figure 10 shows a photo of a 1600 -series LCU. It is $134.75 \mathrm{ft}$ long with a $29.8 \mathrm{ft}$ beam, a full-load displacement of 375 tons and a maximum speed of 11 knots. The 1646class LCU has living facilities to support its crew of 13 for up to 10 days at sea. Its lift capability is 2 M1A1 tanks; 10 LAVs; or, about 400 combatequipped Marines. The vessel is equipped with two $12.7 \mathrm{~mm} \mathrm{MGs}$ and two 7.62 mm MGs as well as Furuno radar navigation.

Figure 10. 1600-series LCU (Image courtesy of U.S. Navy).

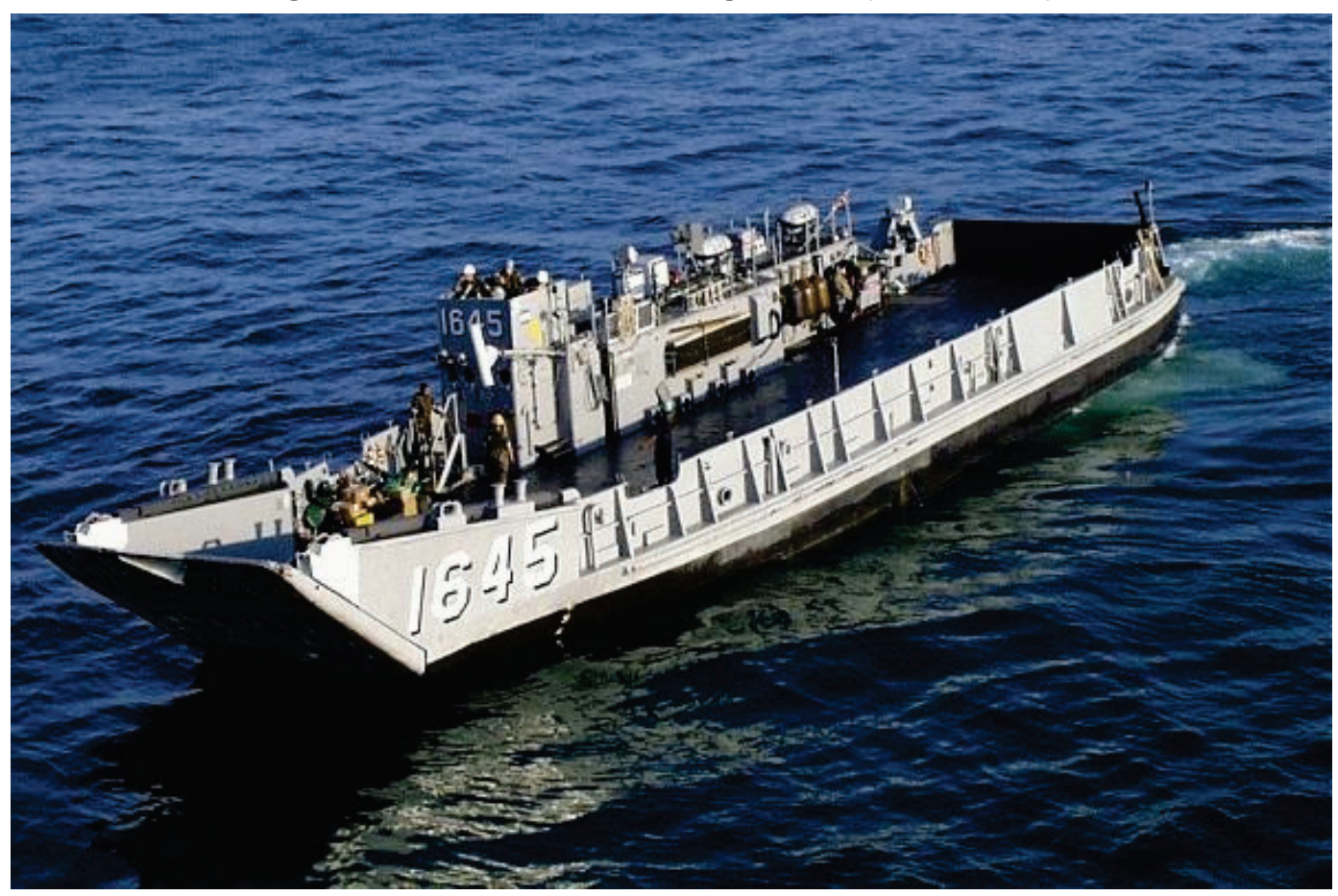




\subsection{Landing Craft Air Cushion (LCAC)}

The LCAC is an air cushion, non-displacement landing craft used for transporting combat-equipped Marines and heavy equipment from ship to shore (Figure 11). Equipment includes artillery, armor, and general supplies. With its ability to ride over the water surface and low-lying terrain, it can access the majority of the world's coastlines. It can be launched up to 50 nautical miles from the beachhead, providing an overthe-horizon capability. It also has a maximum speed of about 40 milesper-hour, permitting LCACs and helicopters to operate in tandem in amphibious assaults.

Figure 11. Landing Craft Air Cushion (LCAC) (Image courtesy of U.S. Navy).

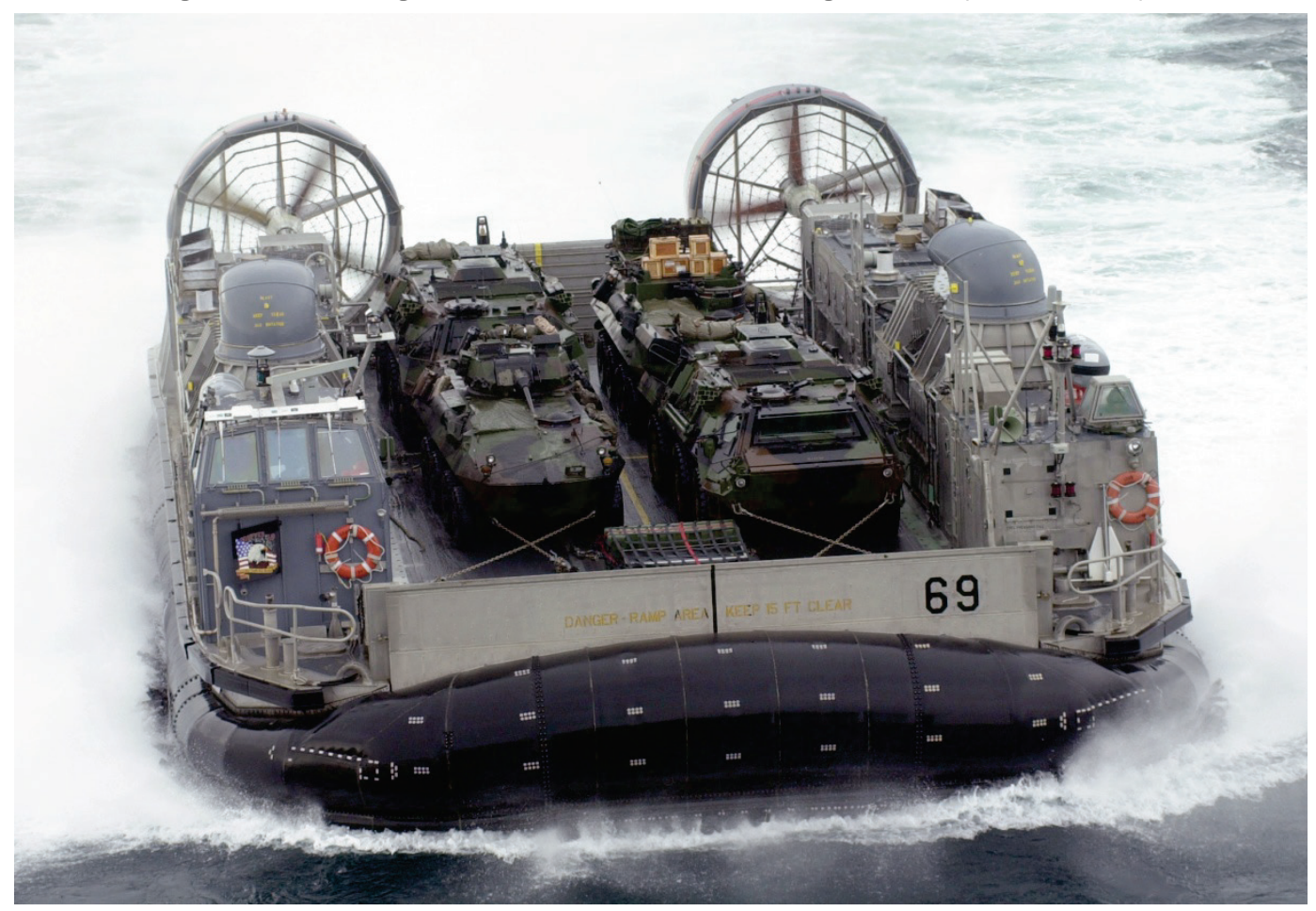

All LCACs are transported to deployment locations in USN amphibious ships, including LPDs, Amphibious Assault Ships - LHD/LHA and Dock Landing Ships (LSD).

Lift and propulsion of the LCAC are generated with four engines, but can continue operating at reduced capacity with two engines. Because the LCAC rides on the water surface, it is less susceptible to naval mines than other assault craft or vehicles. The capacity of the LCAC includes 180 combatequipped Marines, $1809 \mathrm{sq} \mathrm{ft}$ of cargo, 60 ton payload (up to 75 tons in an overload condition), or one M-1 Abrams tank. 


\section{Ship Simulator}

CHL has supported the USACE Civil Works mission in evaluating federally-maintained navigation channels since the early 1980 s with its ship simulator/vessel-response facility. Tidal circulation and wave models, developed in-house, provide the environmental conditions needed by the simulator. A sampling of federally-maintained channels that have been evaluated by CHL include; Port of Alaska, San Diego Harbor, Mayport, Florida, and Chesapeake Bay (Thimble Shoals Channel and Elizabeth River Reach).

The ship simulator is comprised of four distinct components: vesselresponse model; bridge/visual scenes; environmental library; and pilots. In USACE Civil Works applications, only licensed pilots with years of experience in navigating the federal channel being studied are selected for sailing the virtual ship or tow in the simulator. For this proof-of-concept study, two certified USN craftmasters, each having deployed, operational experience in a variety of weather conditions and well deck operations, piloted the virtual vessel. As in USACE applications, having experienced craftmasters operate the vessels helps ensure they are being expertly handled and evaluated.

\subsection{Facility}

The ship simulator was purchased by CHL from Kongsberg Maritime, the same manufacturer of trainers used in USN training facilities. Simulator data files developed by CHL can be disseminated to the USN and used directly without modification. As such, once testing of an operation plan is completed, files can be transitioned to the USN for training purposes.

The CHL facility is accredited for processing classified information up to the SECRET level. Computer disks containing the environmental library, described in Section 4.5, are removed from the simulator's servers and stored in a GSA-approved safe when simulations are not being conducted. Components of the simulator, as well as evaluation procedures, are discussed below. 


\subsection{Digital vessel}

A digital vessel is a database containing the physical and performance parameters/characteristics of a particular vessel. The vessel-response model, described in Section 4.3, uses these data in computing the forces acting on the vessel to estimate its track and motion. A small sampling of physical parameters include the vessel's length, beam, draft, distance from stern to bridge wing, length of water line, width of water line, and extreme height.

Digital vessels that ERDC presently have in inventory are San Antonioclass LPD, loaded and ballasted versions; LCAC, loaded and ballasted; 1646-class LCU, loaded; and the AAV7A1.

\subsection{Vessel-Response model}

The heart of the ship simulator is the vessel-response model used in calculating ship motion as produced by the variety of forces that can be exerted on a vessel (Figure 12). Forces causing ship motion are both environmental and pilot controlled. Environmental forces include current, bank effects, wind, and waves, whereas pilot-controlled forces include rudder angle, propeller revolution, tugs, and bow and stern thrusters. The six degrees of ship motion are composed of three degrees of motion in both the horizontal and vertical planes (Figure 13).

Figure 12. Schematic displaying environmental and pilot-controlled forces on vessel.

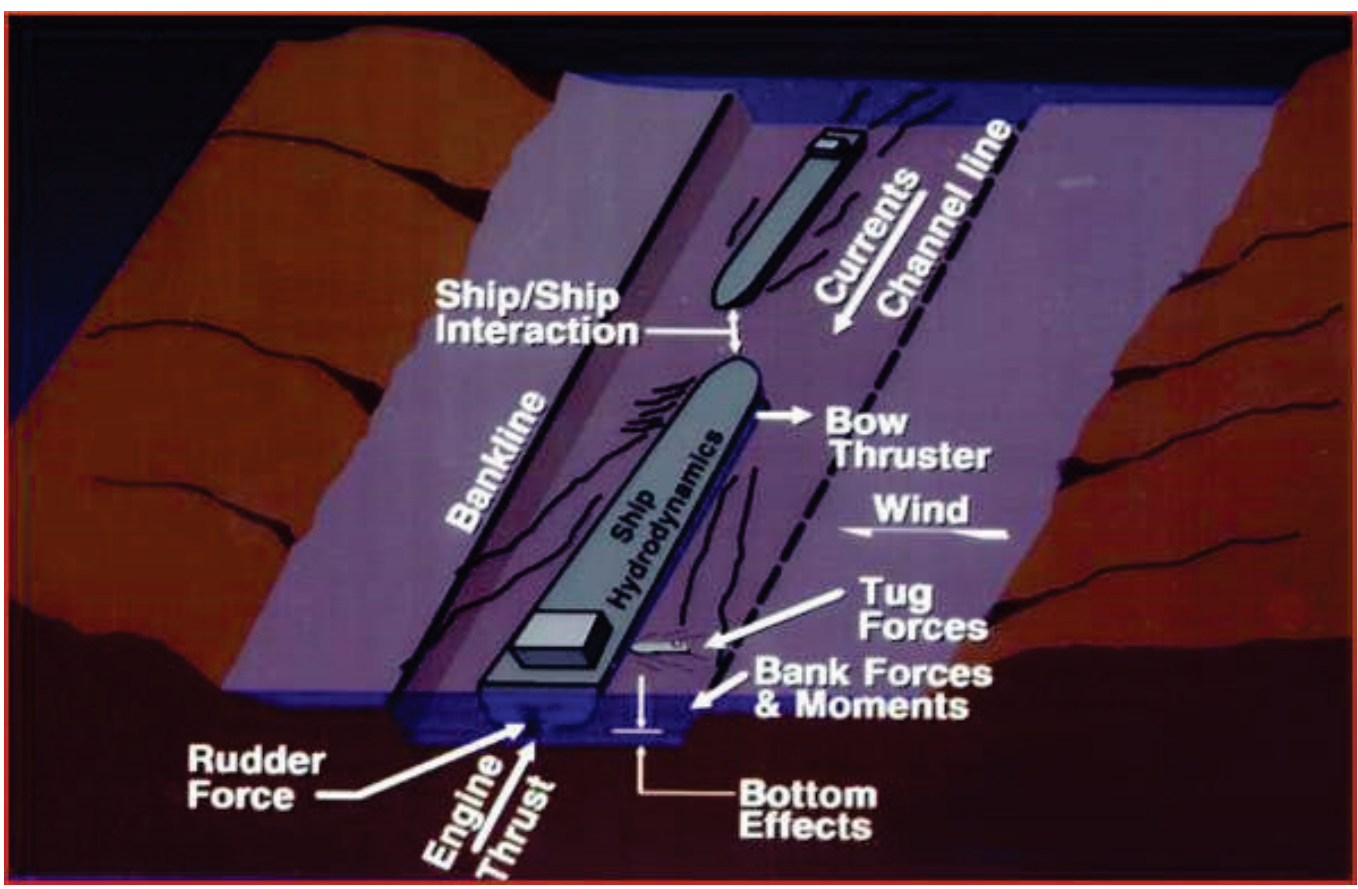


Figure 13. Schematic displaying the 6-degrees of ship motion computed by the vesselresponse model.

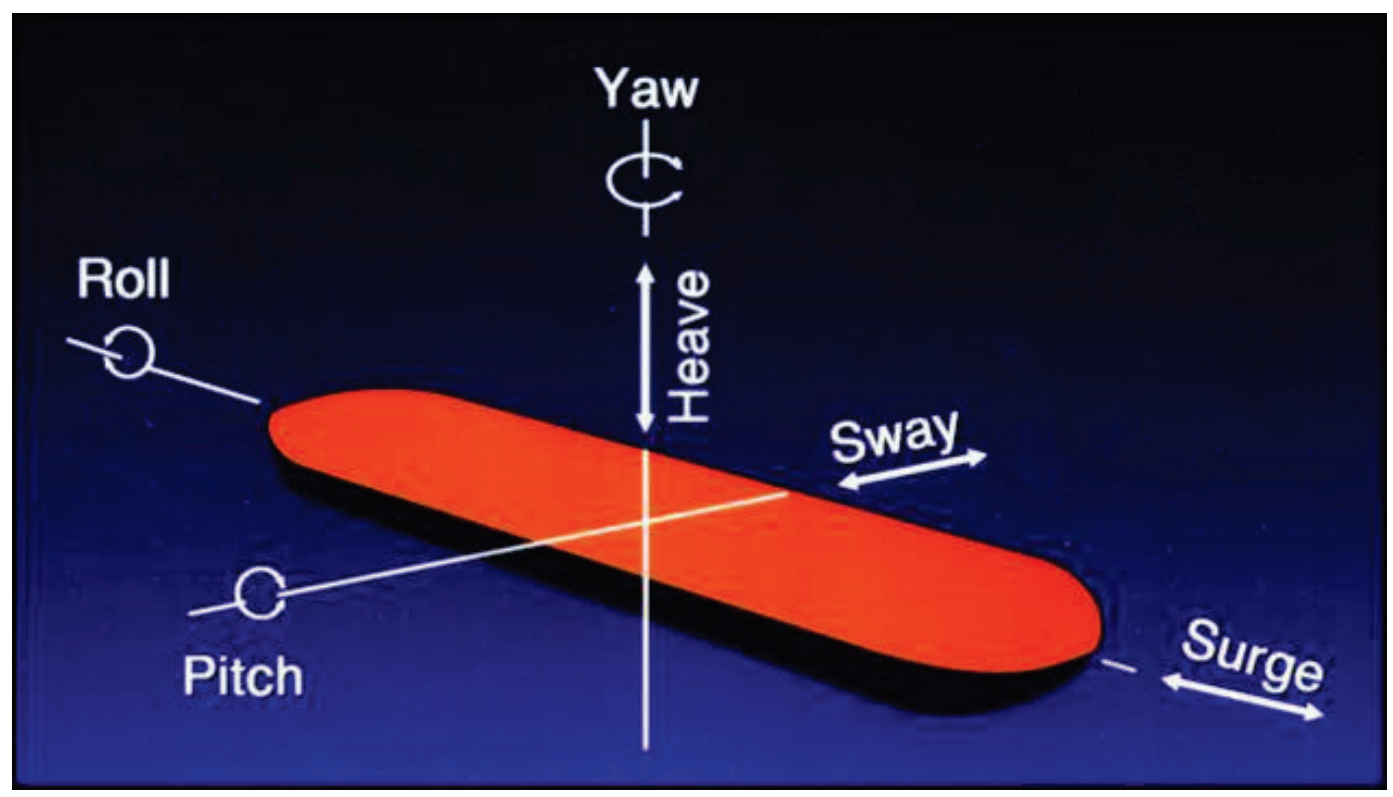

The three degrees of horizontal motion are surge, sway, and yaw. Surge is either a forward or astern motion of the vessel and is calculated by summing the forces along its longitudinal axis. Sway is a sideways or crabbing motion calculated by summing the forces along its lateral axis. Yaw is the rotation of the vessel calculated by summing the moments about its vertical axis.

Wave action is the primary force causing vertical ship movement. The three degrees of vertical motion are heave, pitch, and roll. Heave is the up and down motion of the vessel and is determined by summing the forces in the vertical direction. Pitch is bow-to-stern rotation computed by summing the moments about the vessel's lateral axis. Roll is the side-toside ship rotation calculated by summing the moments about its longitudinal axis.

Currently, CHL has three bridges in its facility and they can be operated in tandem during a simulation. This capability permits simulating ship-ship interactions, for example, to investigate if a wake propagating from one ship affects another's handling. This capability is applicable for evaluating, for example, whether wake effects induced by a formation of AAVs affect the rear vehicles as they are sailing towards shore. 


\subsection{Bridge/Visual scene}

The bridge and example visual scenes of the waters being navigated are shown in Figure 14. The simulator operates in real time and the visual scenes are updated continually throughout a simulation due to pilot control of the vessel and changing environmental conditions. The latter is illustrated in the visual scenes of the Port of Anchorage at high water and low water (Figures 15 and 16 respectively). The brown area shown at the water's edge in Figure 16 is the exposed mudflat fronting the Port. (The bright orange is sunlight reflecting off the mudflat.)

Visual scenes of land can be generated using satellite imagery and digital terrain elevation databases, permitting a pilot to view a virtual coastline and representative beachhead. As such, scenes can be generated for areas having restricted access. More exacting scenes can be generated if photographs of the coast are available. Also, the simulator can internally render scenes to display various conditions: daytime, twilight, or nighttime; fair, foggy or rainy weather; high or low tide (to display exposed mudflats, for example); ice; and lightning.

Figure 14. Ship simulator bridge.

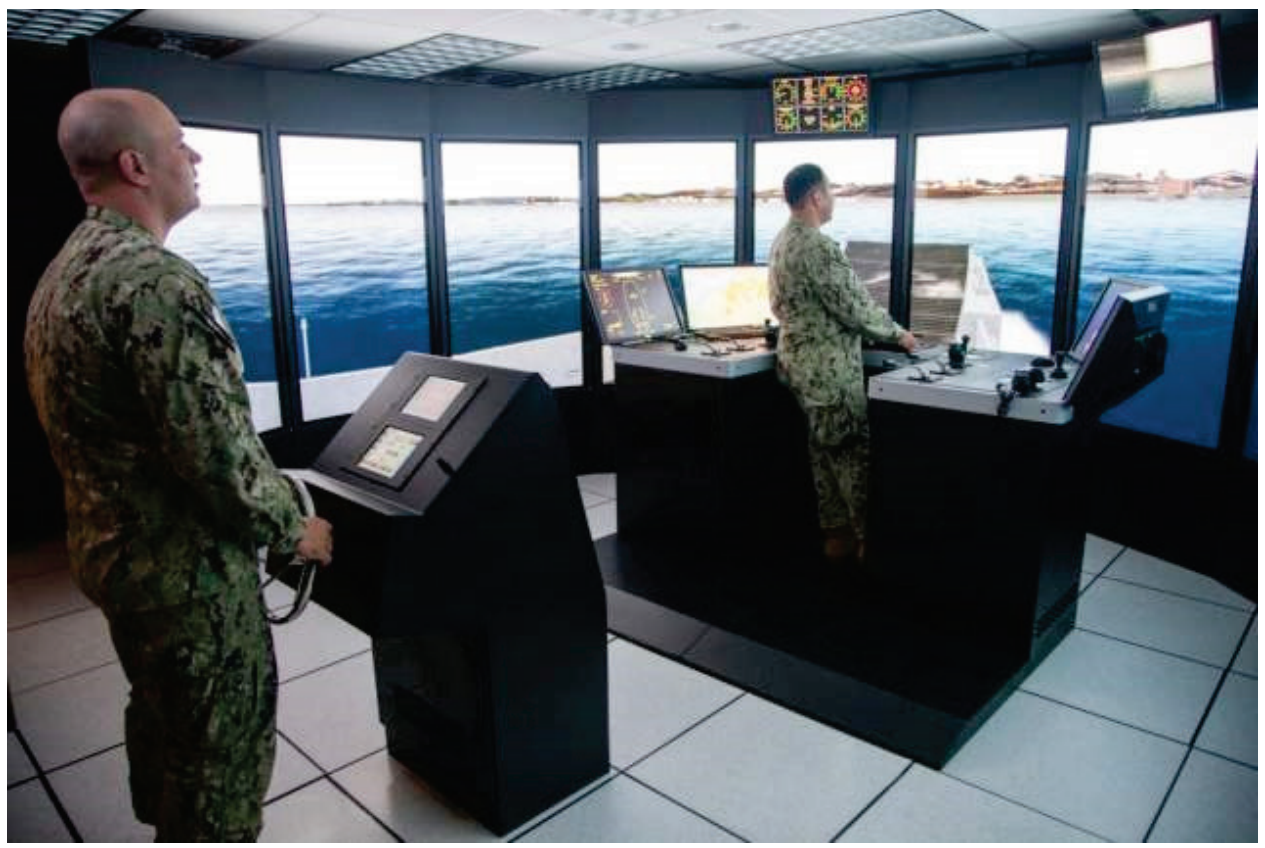


Figure 15. Port of Anchorage visual scene at high water.

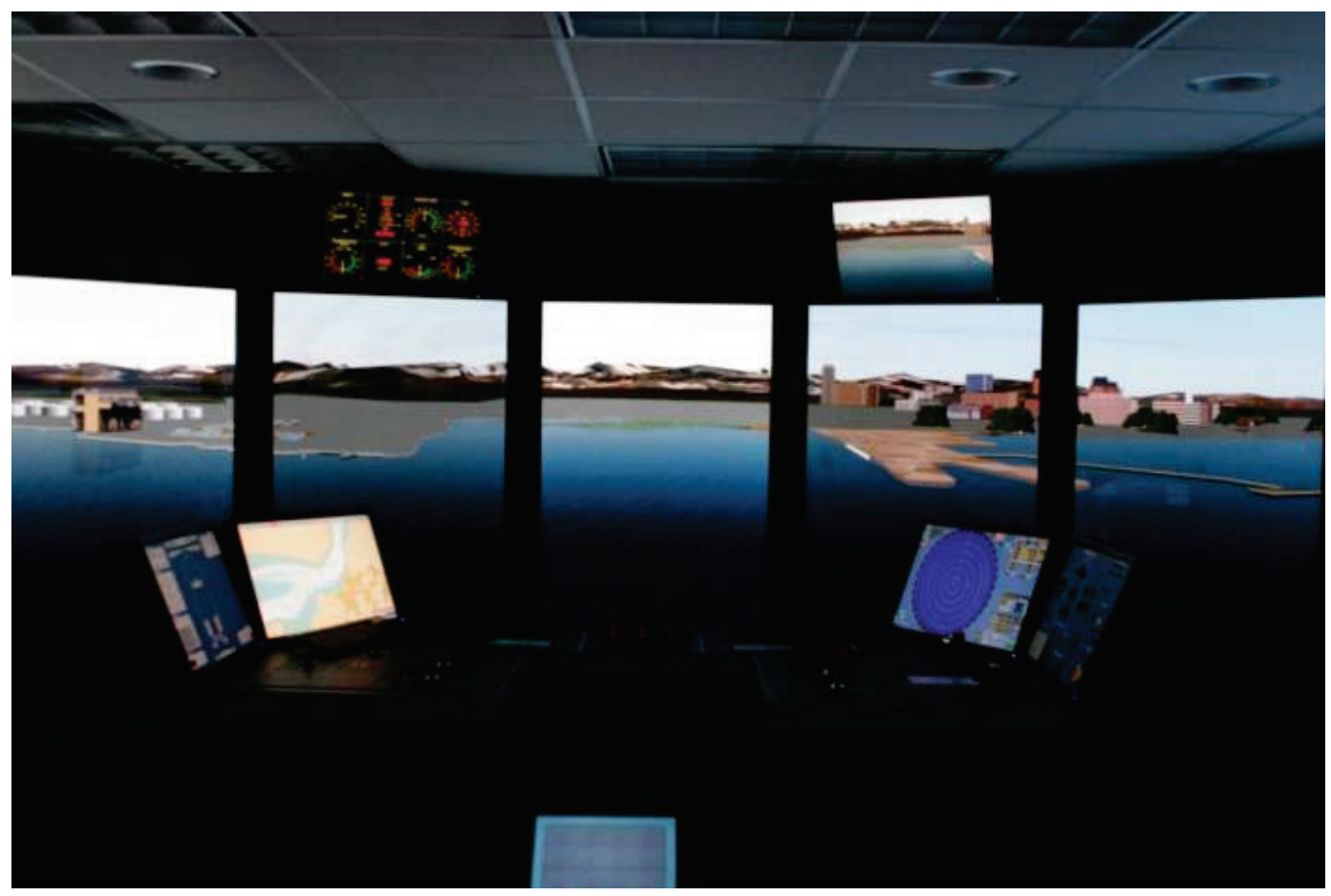

Figure 16. Port of Anchorage visual scene at low water.

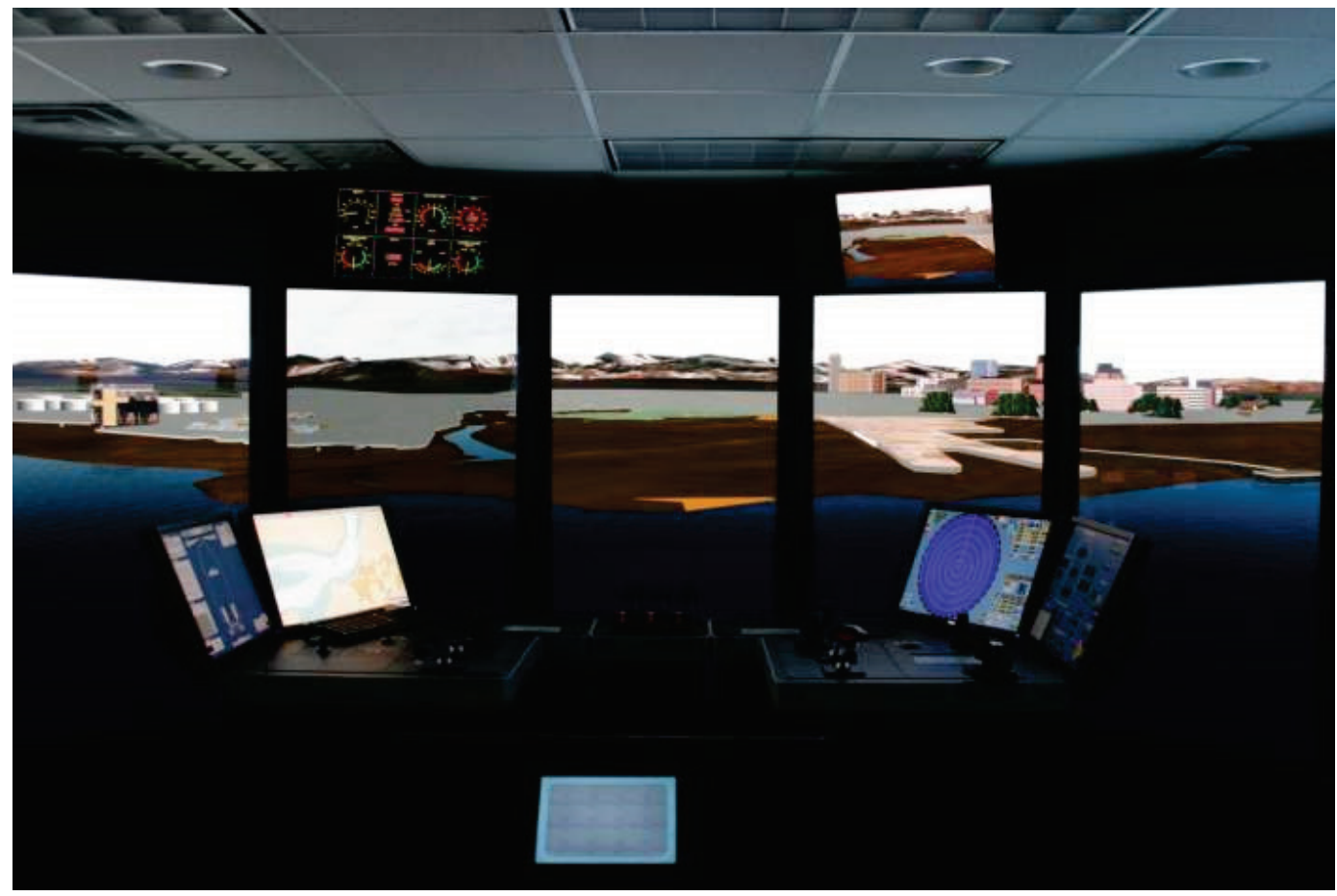




\subsection{Environmental library}

The environmental library consists of model-generated water levels, currents, waves, and winds. Environmental conditions input to the ship simulator can be time-varying or steady-state, depending on the need of the sponsor. For this proof-of-concept study, time-dependent water level and current output from the Port of Anchorage, Alaska, ADvanced CIRCulation (ADCIRC) model was used as a demonstration of the ship simulator under extreme tide conditions. This model is described in detail in Chapter 5 .

\subsection{Pilots}

Pilots operate the simulator by issuing engine, rudder, and tug-thruster commands. The engine and rudder commands are input to the vesselresponse model at the ship's console by either the pilot or a helmsman, whereas tug and thruster commands are input to the model by an operator stationed at the tug console. The model calculates the resultant vessel movement based on these inputs and the environmental conditions. The ship's motion is then shown on the visual and radar displays. If necessary, the pilot responds to this movement by issuing additional commands. This interaction of the pilot and the simulation process is known as "man-inthe-loop."

The ship simulator bridge is generic in that its layout is similar to that found in a variety of ships. As shown in Figures 17 and 18, the rudder and throttle controls in the LCU are in different positions than in the simulator. However, these controls are located on one console and are within reach of the craftmaster.

\subsection{Evaluation procedures}

There are three components of the evaluation procedures: output saved by the simulator during a simulation; a survey that each pilot provides at the conclusion of each simulation; and, an interview conducted at the conclusion of the testing period. 
Figure 17. LCU console (Image courtesy of U.S. Navy).

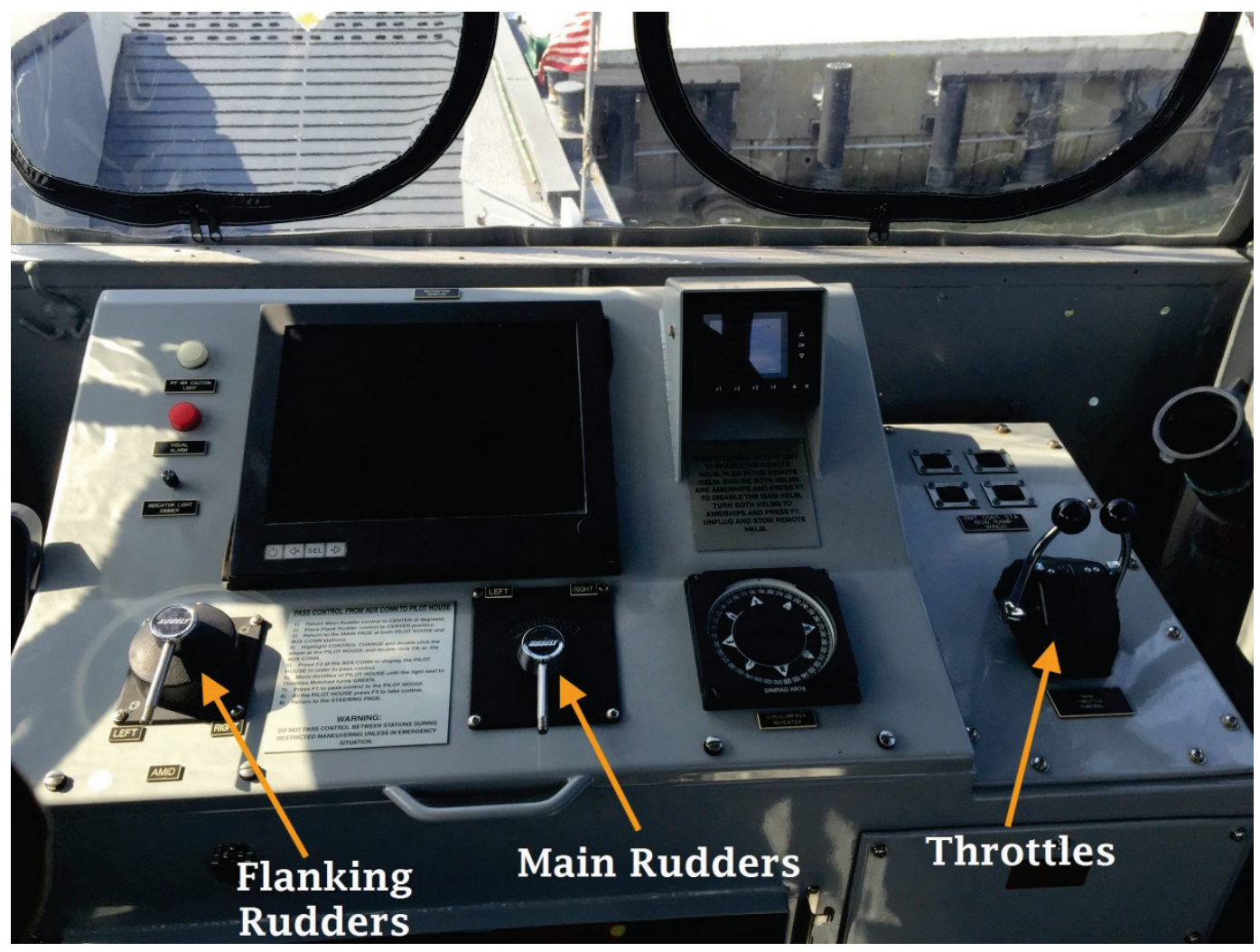

Figure 18. Ship simulator console.

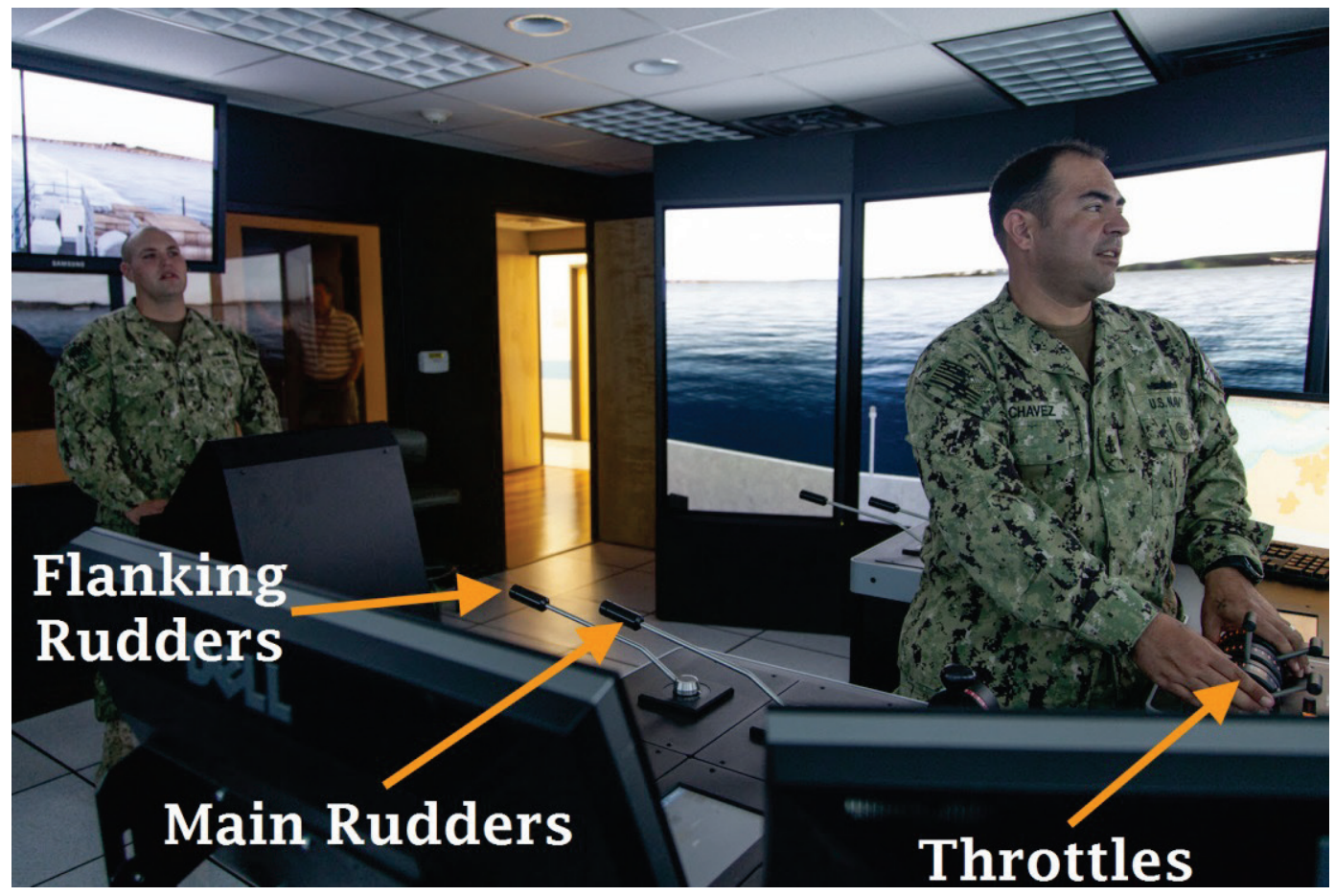


Every five seconds during a simulation, the simulator outputs the control, positioning, and orientation parameters of the vessel to a file. These parameters include the $\mathrm{X}$ - and Y-position of the center of the vessel and the vessel's heading, speed, propeller Revolutions Per Minute (RPM), rudder angle, and rate of turn. Additional data being saved include vessel speed, propeller RPM, rudder angle, drift angle, rate of turn, and port and starboard clearance (from the channel, another vessel, or structure). The distance along track is calculated by projecting the position of the ship's center of gravity perpendicular to the centerline of the channel. For military applications, such as here, the departure from the defined axis-ofassault is used instead of a channel centerline.

Each parameter listed above is then reviewed by the simulator staff to determine whether any of their values are outside recognized bounds of safe operation (e.g., is the rudder angle so great that the vessel is crabbing). The output is then converted to shapefiles for display in ArcMap-based Tracking Analyst for additional review as well as for archiving the data. Within Tracking Analyst, the simulation can be animated with the vessel symbol being displayed using a "traffic light" schema: green, denoting that all parameters fall within normal operating limits; yellow, denoting that at least one parameter is approaching its normal operating limit; and, red, highlighting that at least one parameter has exceeded its operating limit.

At the conclusion of each ship simulation run or exercise, the pilot completes a survey detailing the results of the run and any issues that were encountered. At the end of the testing week, the pilots are interviewed and asked to complete an exit survey. 


\section{Environmental Library}

The environmental library consists of two components: tidal current velocities and water levels generated using the ADCIRC computer model; and wind-generated wave fields generated internally by the vessel-response model. The ADCIRC tidal model was developed in support of the Hydrodynamic Evaluation of Proposed Expansion of the Port Of Anchorage (Chapman et al. 2009). That study was initiated by the USACE Alaska District because the volume of sediment dredged from the Port's turning basin increased six fold in a single season due to on-going construction at the Port. With additional expansions being planned, the District wanted to determine if additional construction would further increase dredging requirements. A comprehensive approach was taken in that study, including field data collection, measurement, and monitoring program; modeling tidal circulation under pre-and post-construction configurations of the Port using ADCIRC; and, modeling sediment transport with the Multi-Block Geophysical Hydrodynamic and Sediment Transport System for pre-and post-construction configurations (Hayter et al. 2012).

\subsection{ADCIRC Model}

The ADCIRC model has been used extensively by CHL over the past two decades by federal entities and universities for studying tidal circulation and storm surge. Several geographic-scale ADCIRC models have been developed by CHL to provide MCIA with tidal current and water level information for regions having challenging environments and are of interest operationally. Models have been developed for the Yellow and Korean Seas; Southeast Asia, including the South China Sea; Persian Gulf and northern Arabian Sea; western South Atlantic Ocean; and Caribbean Sea.

One benefit in applying geographic-scale models such as ADCIRC is that tidal information is available for the entire Amphibious Operations Area (AOA), from the sea echelon areas to the disembarkation point to the landing site. As such, planners can determine the optimal location for positioning amphibious assault assets, the axis-of-assault, and the timing of an amphibious assault. Another benefit is that numerous AOAs can be highly resolved within a single grid. As such, water-surface elevations and current can be predicted throughout a theatre-of-operation in a single 
simulation, enabling informed decision making during crisis in areas of denied access.

In the aftermath of Hurricane Katrina devastating the City of New Orleans, Louisiana, and the surrounding region in 2005, the Interagency Performance Evaluation Taskforce, with CHL being one member, used ADCIRC in an exhaustive study to identify the vulnerabilities of the City to hurricane-induced flooding. Other storm surge applications include Louisiana, Texas, Chesapeake Bay, Lake Michigan, and Lake Saint Clair, all conducted by CHL in support of the U.S. Federal Emergency Management Agency's mission in developing flood insurance maps.

Federal entities that have funded ADCIRC's development and/or have used it extensively include the ERDC, Army Research Office, U.S. NavyNaval Research Laboratory (Stennis), Office of Naval Research, Naval Ocean Partnership Program, National Science Foundation, National Weather Service, and the Department of Homeland Security. A sampling of universities that are actively involved in upgrading the model and/or using it extensively include the University of Notre Dame, University of North Carolina, University of Oklahoma, Ohio State University, University of Texas, and University of Tokyo.

A detailed description of the governing equations of physics, formulations of the discreet form of the governing equations, and a user's manual for ADCIRC are available at http://www.adcirc.org.

\subsection{Grid development}

For background, a water body is represented in ADCIRC using a grid of variably-sized triangles, called elements. Differing-sized elements provide flexibility in resolving complex-shaped coasts, including islands, and bottom contours with the grid. Water depths are specified at each vertex in the grid, and the model computes the current and water levels at the vertices, as well (vertices are referred to as nodes). Current velocities and water levels are computed dynamically, producing tides and current that change in time. Specific time periods can be simulated and these periods can be one year long, or longer. Furthermore, simulations can include wind and atmospheric pressure fields for estimating the combined effects of astronomical tides and winds. Lastly, ADCIRC can be coupled with shallow-water wave models for incorporating wave-induced current in estimating their effects close to shore. 
For this proof-of-concept study, the ADCIRC grid extends from Cross Sound, which is in proximity to Juneau, Alaska, westward to the eastern Aleutian Islands (Figure 19). Northward, the grid encloses Kodiak Island as well as Cook Inlet and Knik and Turnagain Arms. Figure 20 displays the grid in the vicinity of the Municipality of Anchorage. With the grid's openwater boundary being located in deep water and far removed from the area of interest, tides specified at the open-water boundary are linear and thus free of non-linear oscillations induced by shallow water and headlands along the coast that would adversely impact the accuracy of tidal predictions. An additional benefit in having the open-water boundary far removed from the study area is in modeling storm-induced water levels and current. Storm systems in the Pacific Ocean are very broad, much broader than the entrance to Cook Inlet. With the grid extending well beyond the entrance to the Inlet, the model can estimate storm-induced filling and emptying during the entire passage of a storm.

Several tidal circulation studies have been conducted to support the Army Corps' mission of maintaining navigation at the Port of Anchorage, the first being documented in Raad ${ }^{1}$. Subsequent studies include Ebersole and $\operatorname{Raad}^{2}$, Chapman et al. (2009) and Hayter et al. (2012). Improvements were made to the model in each study, primarily to reflect construction at the Port. However, extensive testing was conducted in Chapman et al. (2009) to improve the representation of the massive mudflat located in Knik Arm, because the waters that wet and dry the mudflat impact the accuracy of water levels and current at the Port. The model developed in Chapman et al. (2009) and Hayter et al. (2012) was applied in this study, and model-generated tides and current were used in testing navigation at the Port using the ship simulator.

\footnotetext{
${ }^{1}$ Raad L. (2017) Assessment of circulation for Upper Cook Inlet, Alaska, using ADCIRC-2DDI Model. ERDC/CHL LR-17-3. U.S. Army Engineer Research and Development Center, Coastal and Hydraulics Laboratory, Vicksburg, MS.

2 Ebersole, B. A., and L. Raad. (2017) Port of Anchorage dredging study: Assessment and refinement of hydraulics. ERDC/CHL LR-17-2. U.S. Army Engineer Research and Development Center, Coastal and Hydraulics Laboratory, Vicksburg, MS.
} 
Figure 19. Numerical grid.

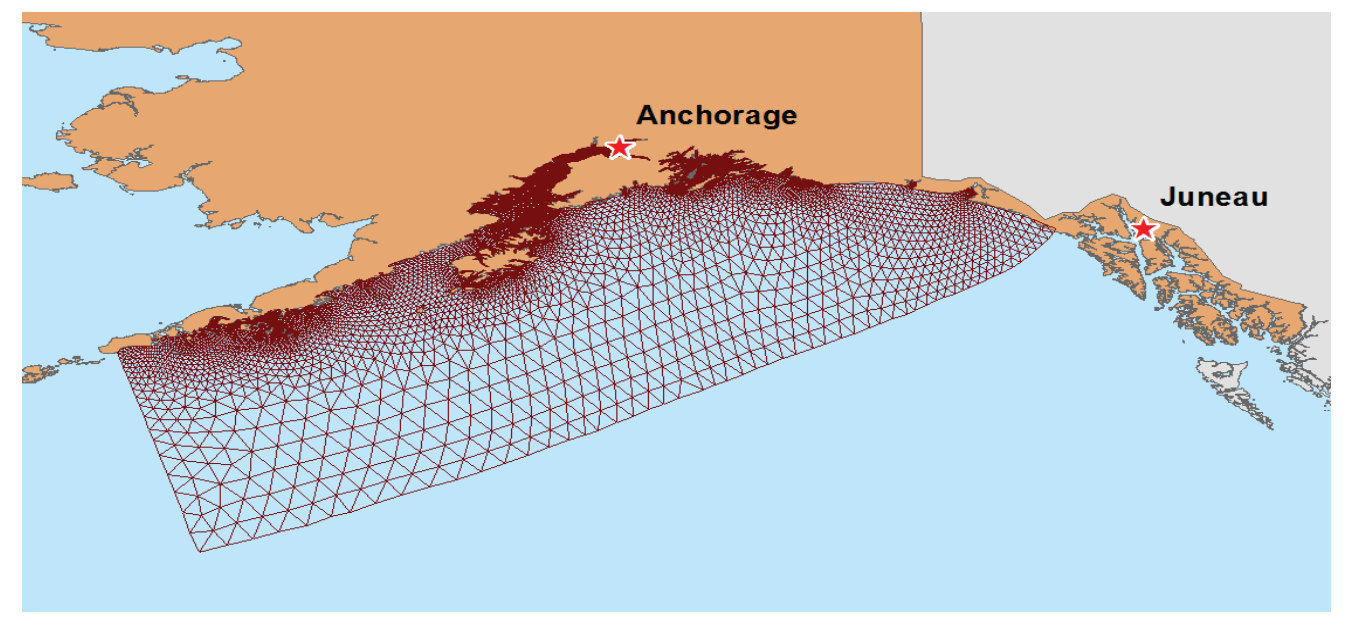

Figure 20. Numerical grid in vicinity of Anchorage, Alaska.

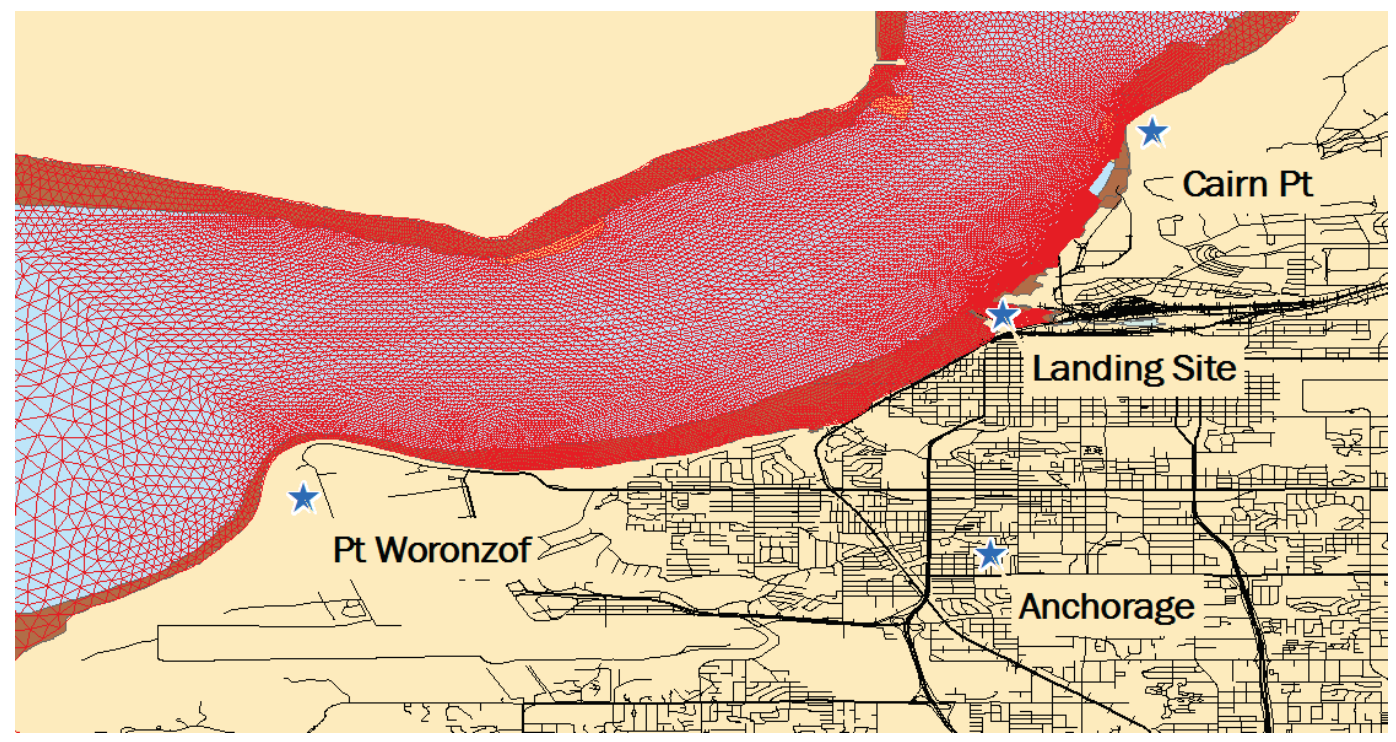

\subsection{Bathymetric data sources}

The grid consists of 47,037 computational nodes and 88,165 elements with an open-ocean boundary placed in the Gulf of Alaska. The largest elements are near the open ocean boundary, with nodal spacing of about $66 \mathrm{~km}$ (41 mi). The smallest elements resolve detailed geographic features in the vicinity of the Port of Anchorage, where nodal spacing is approximately $15 \mathrm{~m}$ (49 ft). The grid's coastlines were aligned with those published in the U.S. National Geospatial-Intelligence Agency's (NGA) Digital Nautical Chart (DNC). Furthermore, water depths specified in the grid are based on bathymetry extracted from the DNC database and District-sponsored bathymetric surveys. 
This grid included the refinement of the numerous mudflats in Knik and Turnagain Arms to allow for flooding and drying of these areas during each tidal cycle. The $6 \mathrm{~m}$ topographic contour was extracted from the United States Geological Survey (USGS) National Elevation Dataset (NED) $10 \mathrm{~m}$ resolution database in order to incorporate low-lying areas into the $\mathrm{ADCIRC}$ grid and to allow for flooding and drying of these areas during each tidal cycle.

\subsection{Forcing conditions}

The ADCIRC model was applied in this study to generate water levels and current under astronomical forcing conditions. Tidal forcing was applied at the open-ocean boundary and inflows were applied at two rivers up drift of the Port.

\subsubsection{Tidal forcing}

Tides specified along open-ocean boundary were synthesized using eight tidal constituents categorized as $\mathrm{M}_{2}, \mathrm{~S}_{2}, \mathrm{~N}_{2}, \mathrm{~K}_{1}, \mathrm{O}_{1}, \mathrm{Q}_{1}, \mathrm{P}_{1}$, and $\mathrm{K}_{2}$. Constituent amplitudes and epochs were obtained from a database published in the Oregon State University Tidal Inversion System (Egbert and Eroleeva 2010). Because the model domain is of sufficient size that celestial attraction induces tide within the grid proper, tide-generating potential functions were included in the simulations, and correspond to the constituents listed above.

\subsubsection{River inflows}

River inflows were included in the model simulations for the Matanuska and Knik Rivers. The mean daily flow rate, published by the USGS, for each river was specified as a constant in the model for the simulation.

\subsection{Model validation}

\subsubsection{General considerations}

Validation was performed to ensure ADCIRC accurately predicts the tidal processes in the study area. Various factors determine model accuracy including geometry of the study area which includes the bathymetry and coastline depicted in the grid; tides specified along the open-water boundary; values selected for model parameters, such as the bottom friction and lateral eddy coefficients; and the discrete form of the 
governing equations composing the computer model where the terms being computed are truncated from their analytic forms. A satisfactory comparison between predictions and measurements in the validation procedure provides confidence that the model replicates tidal processes. The validation procedure performed for this study consisted of watersurface elevation time series comparisons and a harmonic analysis to ensure that the model is responding correctly to astronomical forcing. Furthermore, formation and propagation of model-generated gyres were compared to those measured with Acoustic Doppler Current Profilers (ADCP) sensor during field surveys.

\subsubsection{Harmonic analysis}

A harmonic analysis was conducted using model-generated water levels to estimate tidal constituents at three locations within the study area; Kodiak Island, Nikiski, and Port of Anchorage. For this procedure, a 60-day simulation was performed, with the harmonic analysis being performed over the latter 45 days. Model-generated constituents were subsequently compared with those published by the National Oceanic and Atmospheric Administration's (NOAA) National Ocean Service (NOS) at the same locations for estimating model accuracy. Figure 21 displays a comparison of time-series synthesized using ADCIRC-generated tidal constituents and NOS-published constituents (top). This figure also compares amplitudes and epochs for the individual constituents in the lower two plots; symbols positioned along the line drawn at a 45 degree angle across the plots show perfect agreement between the ADCIRC-generated constituent and the value published by NOS.

\subsubsection{Time series comparisons}

The ADCIRC model developed for the Port was validated by comparing model simulated water level time series with NOS tide data for Cook Inlet and the northern Gulf of Alaska and with data from two month-long field data collection efforts in 2002 and 2006 (Chapman et al. 2009). The modelto-data comparisons indicate that the tidal amplitude, phase, spring/neap modulation, and diurnal inequalities were well represented (Chapman et al. 2009; Hayter et al. 2012). Details of the time series comparisons can be found in Chapman et al. (2009). Figure 22 compares ADCIRC-generated water-surface elevations with those measured at the NOS gage. 


\subsubsection{Transect comparisons}

Transect surveys to measure current in upper Cook Inlet and Knik Arm were conducted in 2002 by NOAA and in 2006 by ERDC using an ADCP. These data were used to assess model accuracy in representing spatial and temporal variations in current and eddy structures shed by the prominent headlands near the Port. The data were used in two ways: 1) to validate the model by comparing model-generated current to those measured directly throughout the surveyed region; and 2) to assess the bathymetric representation of the mudflats, as will be explained below.

Figure 21. Comparison of ADCIRC-generated and NOS-published tidal constituents.
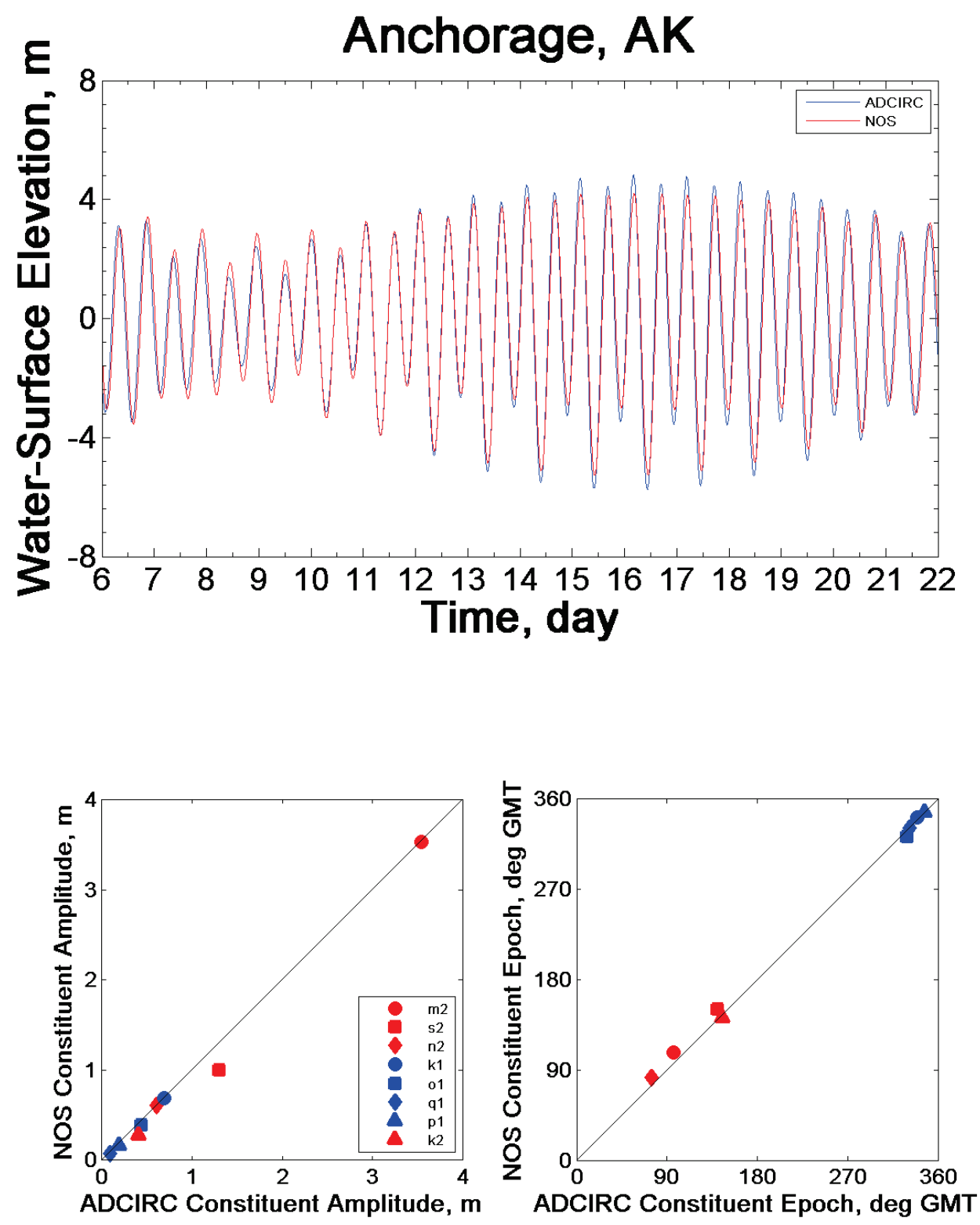
Figure 22. Comparison of ADCIRC-generated and measured water-surface elevations.

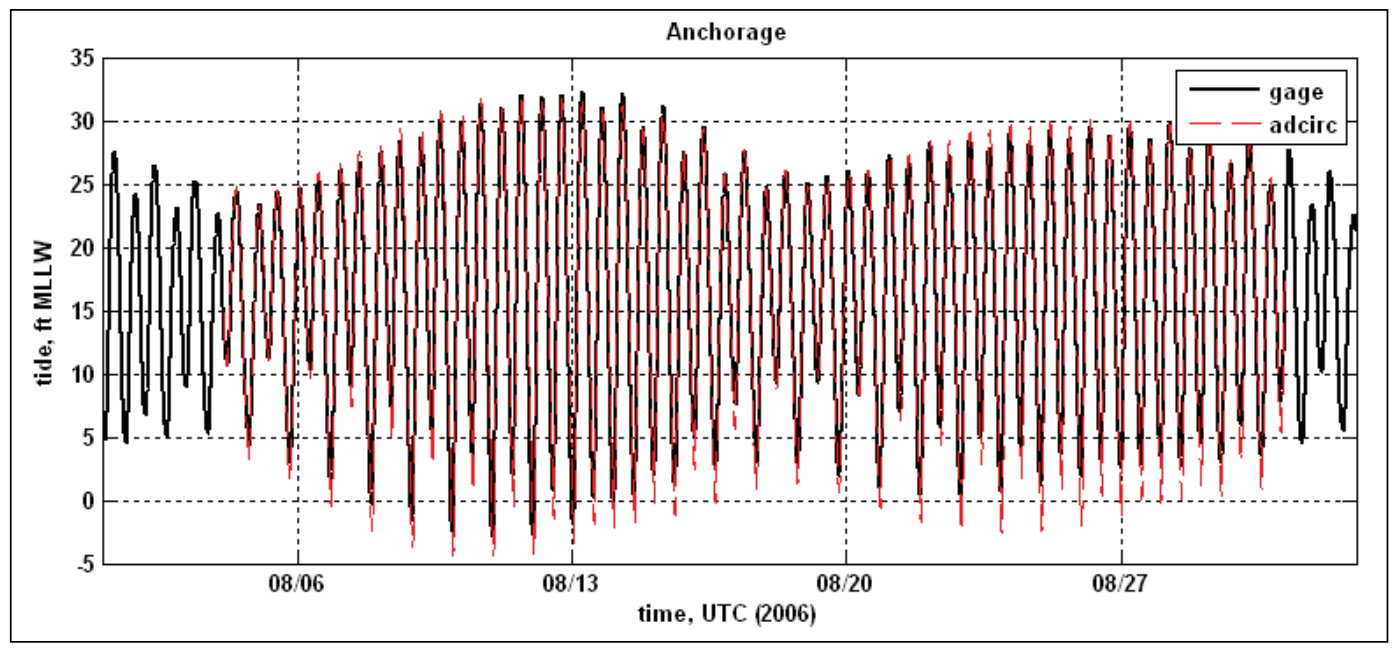

The direct comparisons between the ADCIRC model-generated current and ADCP-measured current indicate the model was able to replicate the complex hydrodynamic structures (gyres and shear layers) at the Port.

Broad mudflats can significantly influence the tides in areas having large tidal ranges, such as Knik Arm. Representing these features accurately in the grid is essential for the model to produce accurate water levels and current. Because no recent topographic surveys had been conducted of the mudflats in the Arm, a trial-and-error approach was taken to estimate their topography. The initial test used the historic topographic survey for estimating the mudflat's elevation, and a simulation was made with the model. Model-generated current were compared with those measured with the ADCP. The mean-tide level was estimated from the simulation, and topography was again estimated.

In the second and subsequent tests, the topography was estimated separately for areas below a breakline; initially this breakline was set to mean tide level. The basis for making this decision were visual observations conducted during the field data collection exercise where it was noted that the mudflat had a milder gradient above mean-tide level than below. Further tests were conducted with the model assuming different elevations of the breakline. In summary, the modified mudflat improved the tidal exchange represented in the model and correspondingly improves the quality of the hydrodynamic simulation at the study site.

Comparisons of ADCP and ADCIRC estimated water exchange are presented in Figure 23. The upper panel of this figure presents tide 
elevation (from ADCIRC) versus time; the lower panel presents time series of measured and ADCIRC-estimated water exchange. The initial representation of Knik Arm mudflats is denoted as "j5." The modified mudflat geometry is denoted as $\mathrm{k} 5 \mathrm{c}$. As shown, the modified mudflat geometry improves tidal exchange represented in the model and correspondingly improves the quality of the hydrodynamic simulation.

Figure 23. Comparison of measured and ADCIRC-generated water transport.

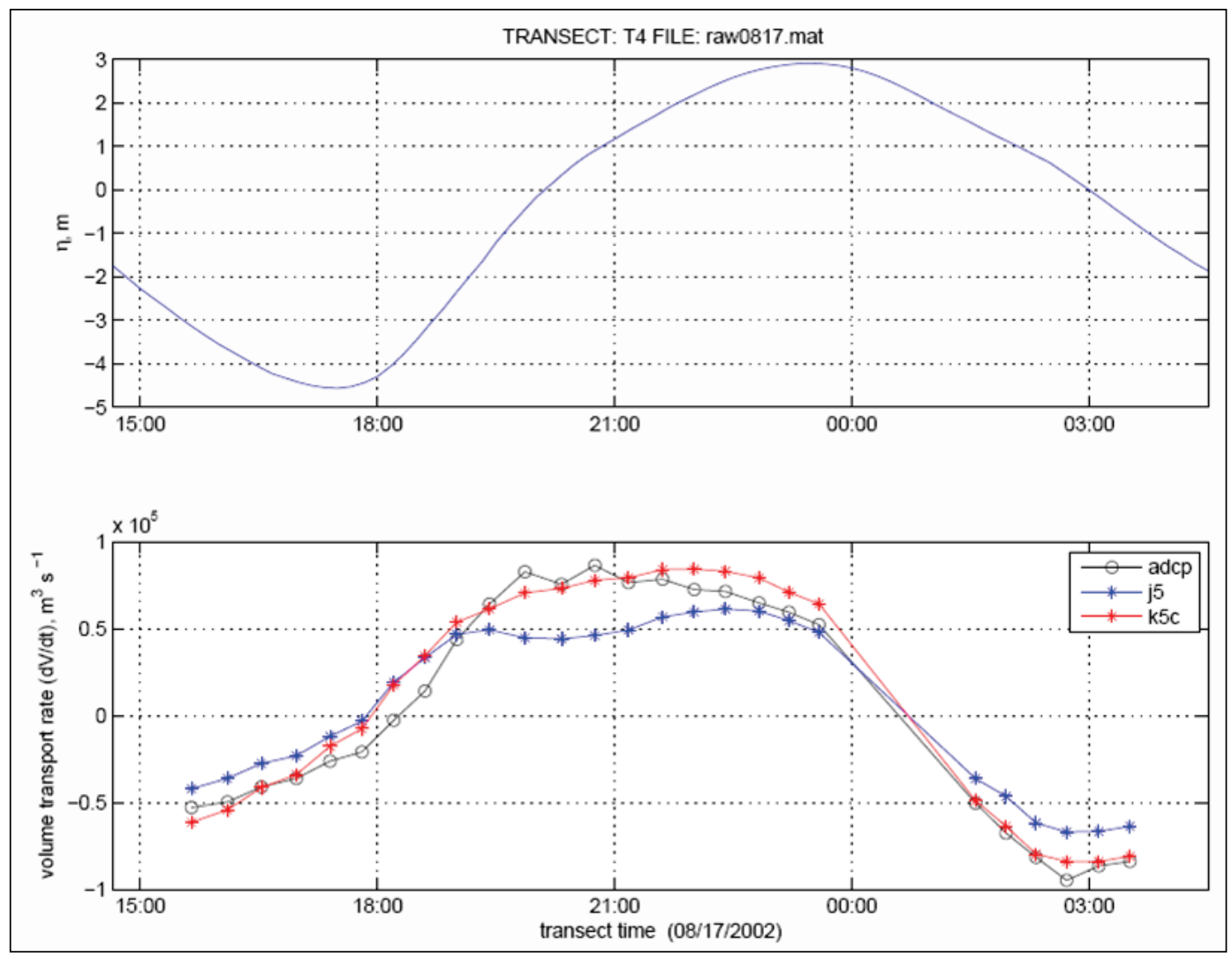

\subsubsection{Gyres}

The ADCP data discussed above were also used to evaluate the model accuracy in the formation and evolution of gyres at Point Woronzof and Cairn Point located southwest and northeast of the Port, respectively. Earlier studies by $\operatorname{Raad}^{1}$ and Ebersole and $\operatorname{Raad}^{2}$ suggested that the inferior comparisons of modeled and measured gyre formation indicated

\footnotetext{
1 Raad L. (2017) Assessment of circulation for Upper Cook Inlet, Alaska, using ADCIRC-2DDI Model. ERDC/CHL LR-17-3. U.S. Army Engineer Research and Development Center, Coastal and Hydraulics Laboratory, Vicksburg, MS.

2 Ebersole, B. A., and L. Raad. (2017) Port of Anchorage dredging study: Assessment and refinement of hydraulics. ERDC/CHL LR-17-2. U.S. Army Engineer Research and Development Center, Coastal and Hydraulics Laboratory, Vicksburg, MS.
} 
that the horizontal momentum exchange computed using a spatially and temporally constant eddy viscosity did not perform well. Chapman et al. (2009) adopted the Smagorinsky (1963) based approach, where the viscosity is computed at each node based on element size and strain rates within the current field. Through comparative simulations with current measurements, the ADCIRC model with the Smagorinsky scheme represented well the formation, size, structure, and evolution of the gyres.

Figure 24 compares the ADCIRC-generated current (red vectors) with current measured with a boat-mounted ADCP (blue vectors); note that the model captured the gyre well as it propagated in front of the Port.

Figure 24. Comparison of ADCIRC-computed and ADCP-measured gyre.

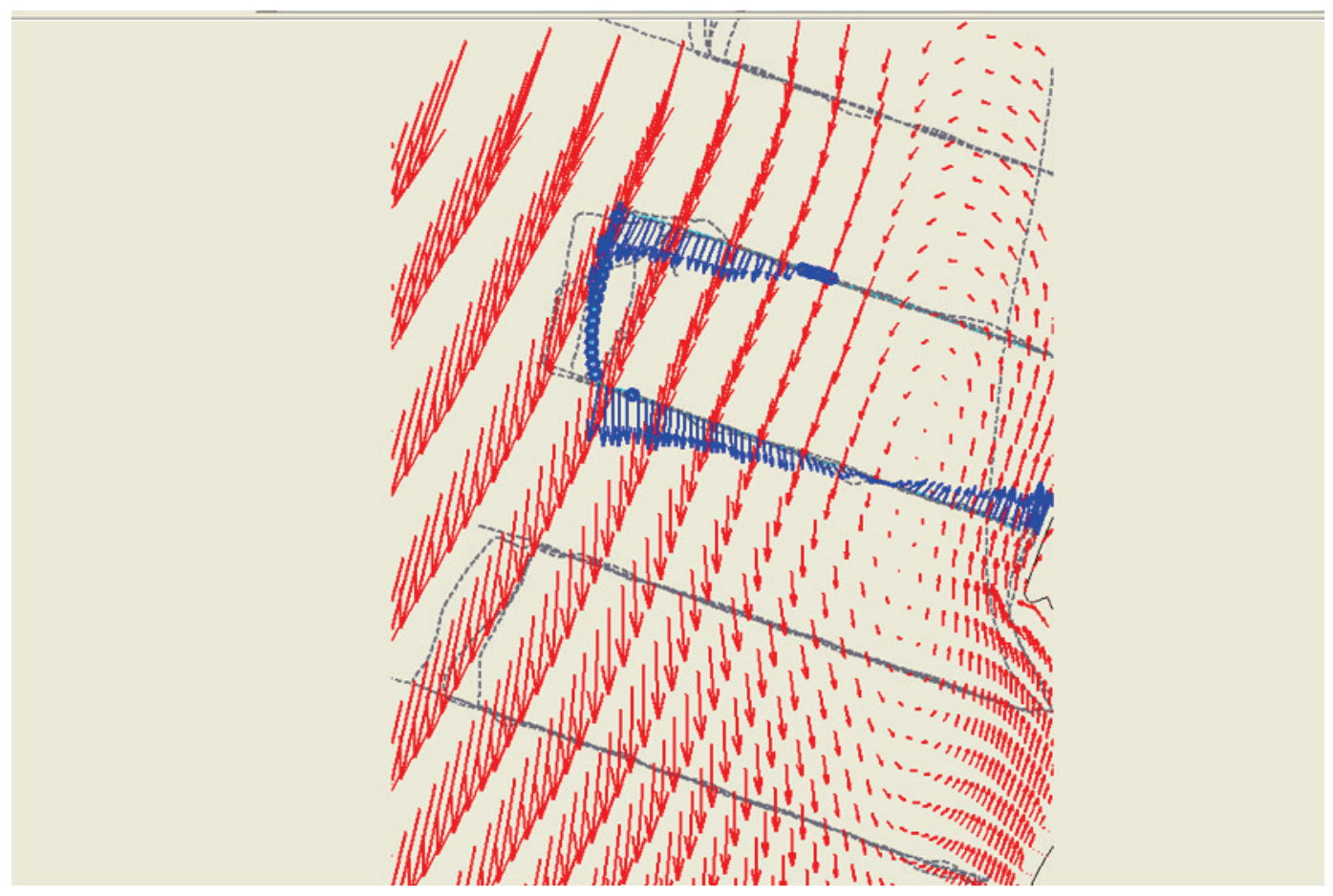

\subsection{Model application for ship simulator}

The validated model developed by Chapman et al. (2009) and Hayter et al. (2012) was applied in this study to provide water levels and current for inclusion into the ship simulator's environmental library. The time period chosen was 11-12 August 2006, during spring tide where its range was 11 $\mathrm{m}$. Water levels and current were saved at 15-minute intervals. Figure 25 shows the simulated current on 11 August 2006 16:15 Zulu. Tides were in flood and the current in the vicinity of the Port exceeded $2 \mathrm{~m} / \mathrm{s}$ (4 knots). Also, a gyre can be seen in the image east of Point Woronzof. 
Preceding inclusion into the environmental library, water levels and current were parsed to eliminate areas outside of the AOA, and then stored in the format required by the ship simulator software.

Figure 25. Tidal current on 11 August 2006 at 16:15 Zulu.

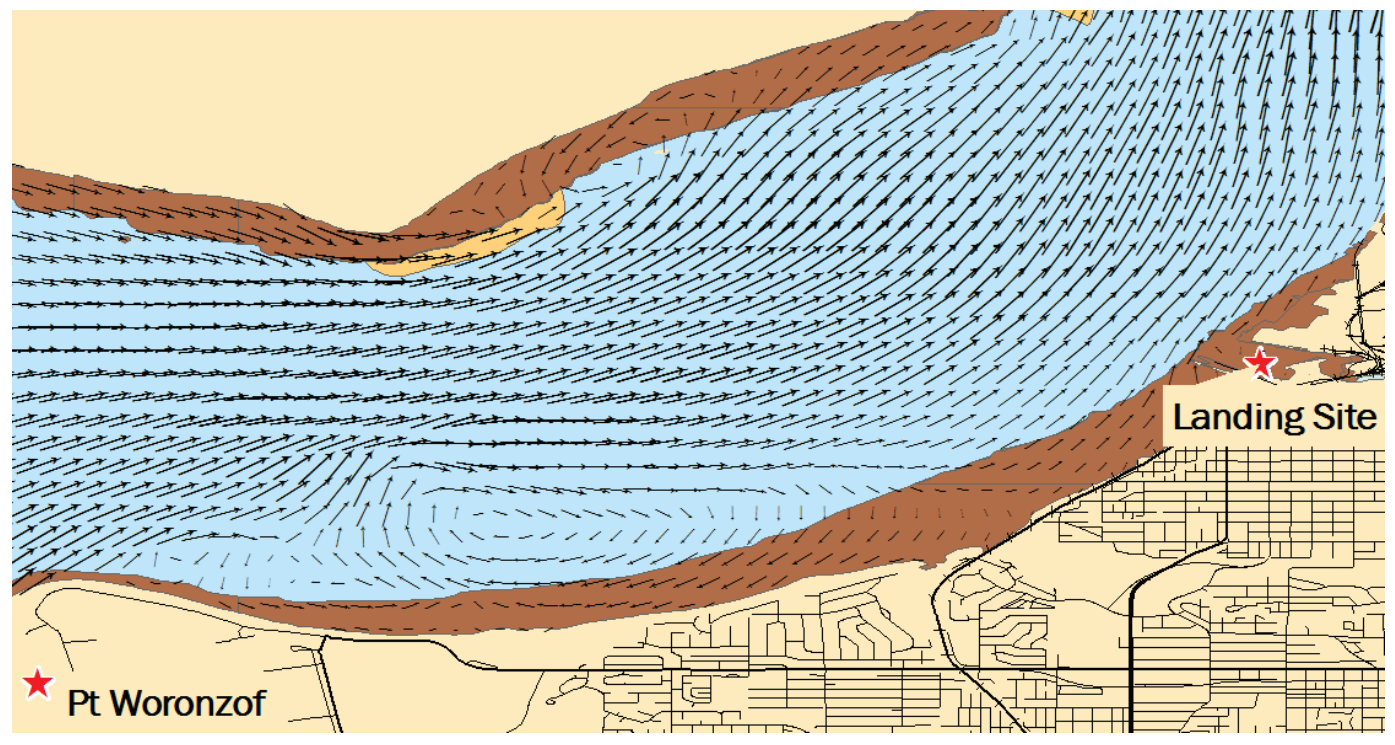




\section{Virtual Amphibious Assault}

Testing was conducted in the simulator facility over a three-day period from 11-13 August 2015. Exercises were conducted under a variety of environmental conditions, including three tidal conditions; three wind conditions, and two lighting conditions. Various aspects of this assault are described below.

\subsection{Testing personnel}

Operational plans executed in this study were developed by Mr. Thomas A. McKenna, Senior Amphibious Warfare Analyst, MCIA. Before joining the MCIA, Mr. McKenna graduated from the U.S. Naval Academy and served as a surface warfare officer throughout his 21-year career with the USN. For 15 of those years, his responsibilities included planning and executing amphibious operations from the assault-through-maritime prepositioning force operations and Joint Logistics-Over-The-Shore operations.

Craftmasters who piloted the virtual LCUs were BMCS Daniel Chavez, Assault Craft Unit Two, Joint Expeditionary Base Little Creek-Ft Story, Virginia; and QM1 Brandon M. Nelson, Assault Craft Unit One, Naval Amphibious Base, Coronado, California. Both are certified USN craftmasters, each having deployed operational experience in a variety of weather conditions and well deck operations, and were serving as instructors at their respective duty stations at the time this study was conducted.

\subsection{Amphibious Operations Area (AOA)}

The AOA for the virtual amphibious assault is shown in Figure 26. The LCUs began their assaults approximately $7.2 \mathrm{~km}(4.5 \mathrm{mi})$ west of the Port, in upper Cook Inlet. The landing site, shown in Figure 27, is a small cove immediately south of the Port proper. As can be seen in the figure, this cove almost completely dries at slack low water. During spring tide, maximum water depth is about $7.3 \mathrm{~m}(24 \mathrm{ft})$ at slack high water. 
Figure 26. Amphibious operations area.

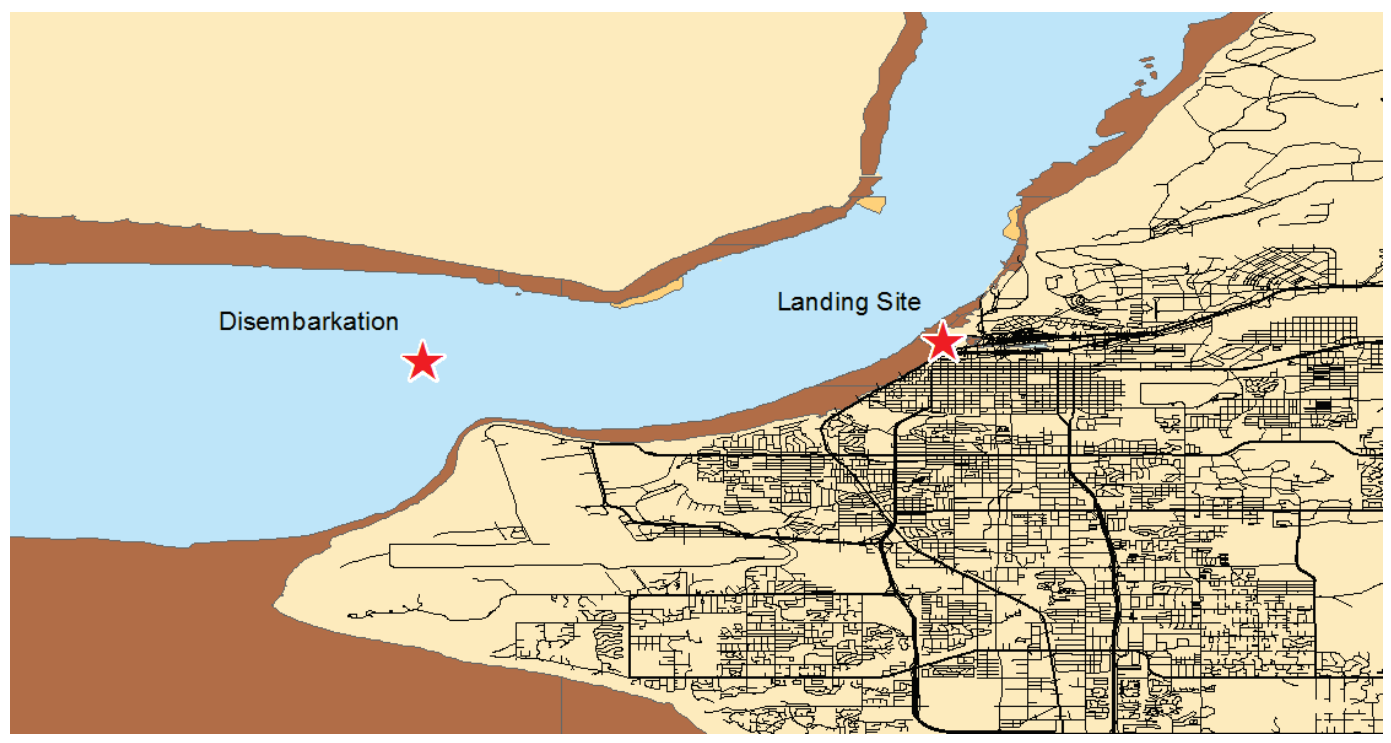

Figure 27. Landing site south of the Port of Anchorage (Google Earth Pro ${ }^{\circledR}$ ).

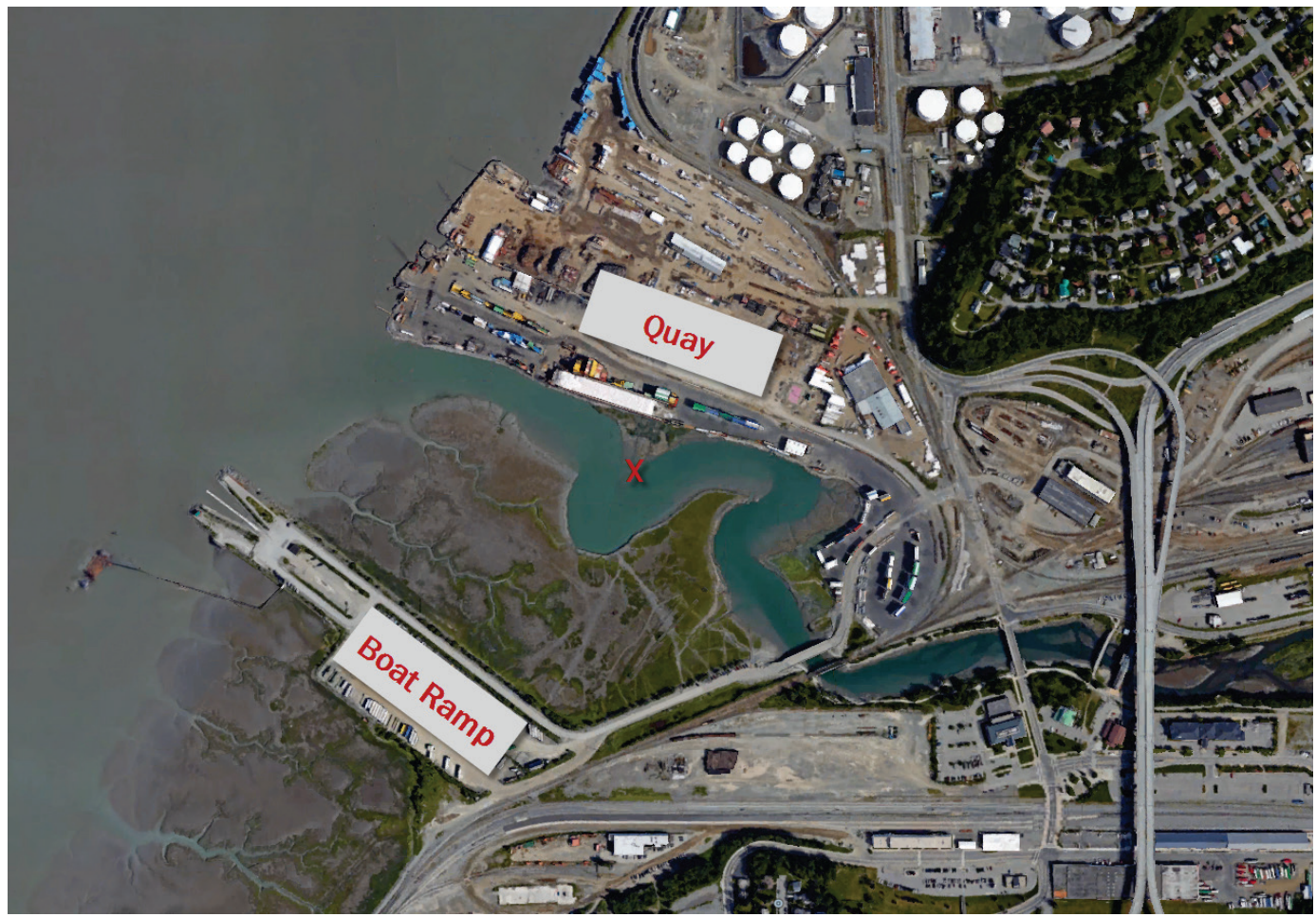

\subsection{Preliminary testing}

The craftmasters spent their first two days at ERDC familiarizing themselves with the simulator's bridge, piloting a newer class of virtual LCUs than they are accustomed, and conducting maneuverability exercises that they typically perform with the prototype vessel. The bridge layout in the ERDC facility is generic for freighters and container ships and not 
specifically designed for the LCU. As such, the craftmasters needed to become accustomed to the location of the controls in the simulator bridge.

The 1646-class LCU is a newer vessel than the 1600 -series vessels the craftmasters have been certified in using. Furthermore, Kongsberg Maritime constructed the digital 1646-class LCU specifically for this proofof-concept study, requiring the vessel to be vetted/calibrated before being used in the amphibious assault exercises. In this phase of testing, the craftmasters conducted a series of maneuvers to determine whether the vessel handled properly. If not, ship simulator personnel and the craftmasters described the issue to a naval architect at Kongsberg Maritime, who then promptly made adjustments to the digital vessel so it maneuvered to the craftmasters' specifications.

After vetting their vessels, the craftmasters were able to perform complicated maneuvers similar to those they perform with their prototype vessels, such as "walking" the craft. This maneuver involves using a combination of rudder and throttle commands to move the craft in a sideways fashion. In conclusion, they deemed the virtual vessels to be operating realistically and handled as expected.

\subsection{Overview of LCU exercises}

Exercises were conducted using conditions of 11-12 August 2006, and tides were in spring on this date. Tidal range was $11 \mathrm{~m}(36 \mathrm{ft})$ and the peak current exceeded $2 \mathrm{~m} / \mathrm{s}$ ( 4 knots) at the Port. Furthermore, exercises commenced at slack low water, slack high water, and one hour after slack high water. The latter tidal condition was added after testing the former two conditions in an attempt to optimize the conditions when the LCU would enter the cove.

Wind direction at the Port is significantly controlled by the orographic effects, or the steering of the winds, caused by the surrounding terrain. As such, a southerly wind is the predominant wind direction and therefore, the only wind direction that was tested. Two wind conditions were imposed with the above tidal conditions, one where its strength was 5 knots, the second was 12 knots.

Lighting conditions during the exercises were either full darkness or twilight. In one exercise the Municipality of Anchorage was under blackout 
conditions. For all others, lighting in the Municipality reflected typical nighttime conditions for a city.

\subsection{General exercise findings}

General findings are discussed below. Figure 28 displays the track of one of the exercises. A chevron is used for representing the LCU and the end consisting of a single tip is its bow. Also, a symbol is drawn at 1-minute intervals. Craftmaster surveys, summarizing their evaluation of an exercise, are contained in Appendix A.

Figure 28. Example LCU track.

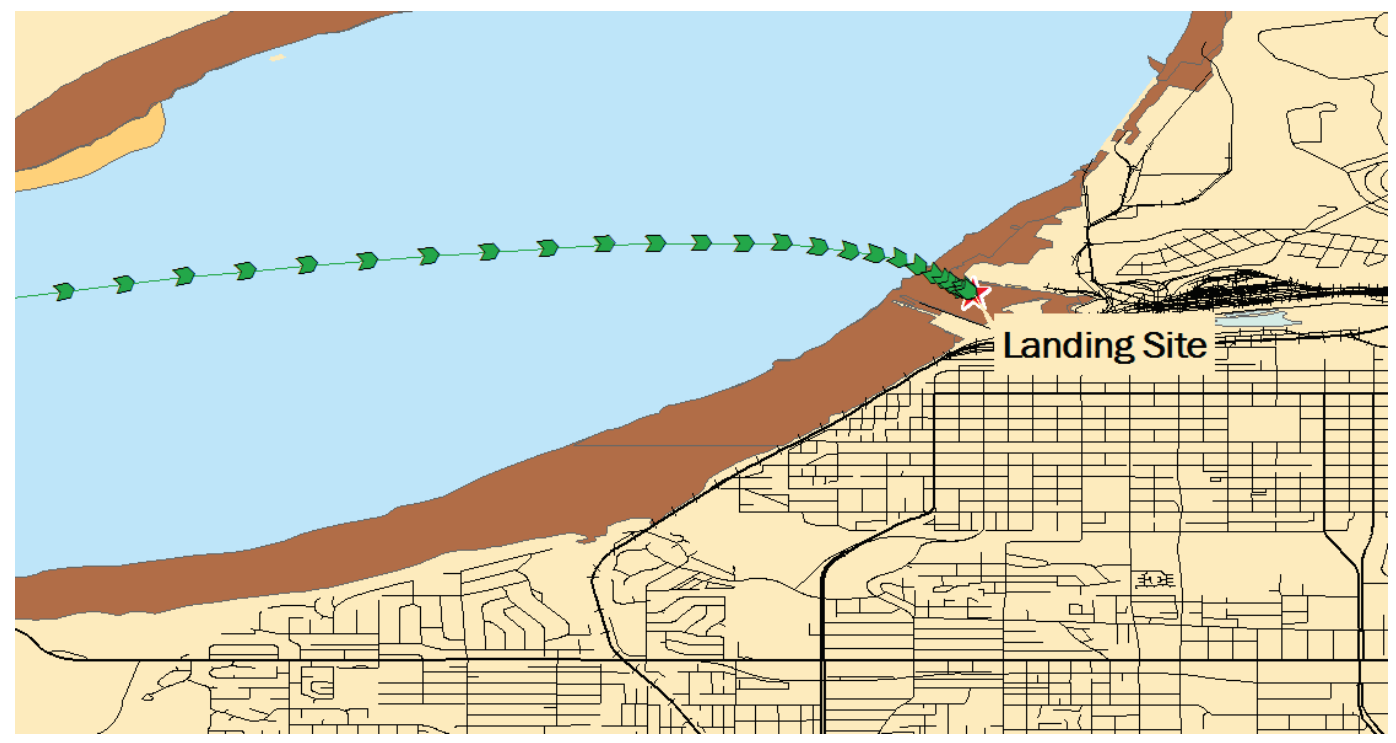

\subsubsection{Open-water transit}

Craftmasters noted no navigational difficulties during the open-water transit, from the disembarkation point to their approach for entering the small cove. However, the transit time while sailing with a rising tide and with the current was less than half that when sailing with a falling tide and against the current. The strong flood current did not result in the LCU becoming "rudderless," meaning that the vessel was swept along with the current leaving the craftmaster with minimal rudder control.

\subsubsection{Cove entrance}

On flood, the craftmasters found that the best method for entering the cove was to overshoot their approach northward of the entrance, swing their craft so that it is against the strong current, then enter the cove. 
Furthermore, once in the cove they had to immediately throttle down their controls in the weaker current or their vessel would run aground.

\subsubsection{Inside cove}

Craftmasters found that the best method for landing their vessel was to run as close to the quay wall on the north side of the cove as possible for both entering the cove and for backing out. (The digital vessel lacked a kedge anchor for turning a craft in tight areas.) Also, the craftmasters noted that the waters within the protected portion of the cove rotated clockwise, referring to it as "fish bowling."

The craftmasters were forced to back out because the turning radius of the vessels was greater than the area in the cove in which they could maneuver. Furthermore, they had grounded their vessels while backing out. One stated that under similar circumstances while sailing his prototype vessel, he would perform a kedging maneuver to help turn his vessel in the limited area, and exit the cove bow first.

One also noted difficulties while exiting the cove into the strong current, forcing the craft southward with little control.

\subsubsection{Lighting}

Both craftmasters had difficulty identifying landmarks for piloting their craft during nighttime conditions. Furthermore, they also had difficulty seeing the bow of their vessel under darkness.

\subsection{Demonstration assessment}

The craftmasters were asked to pilot their vessels in a very challenging environment without benefit of having sailed in these waters before, virtually or in real life. They had to contend with a strong current, on flood and ebb, light and moderate winds, a narrow entrance to the cove, and with limited or no lighting. Furthermore, once entering the cove, they had to contend with shoals and exposed mudflats within it.

Not unexpectedly, both craftmasters ran aground on their first exercise. At the conclusion of this exercise, as well as after the others, Mr. McKenna, BMCS Chavez, and QM1 Nelson gathered to discuss the difficulties in navigating through the entrance, shared their ideas for countering those 
difficulties, jointly developed a strategy, then implemented that strategy in the next exercise. In the second exercise, both craftmasters were successful in entering the cove.

By the end of the testing day, they were able to form a strategy for entering the cove during flood and ebb conditions, where the vessel should sail once inside the cove, location of shoals to avoid, and how to exit the cove on flood and ebb. As a result, both craftmasters were able to successfully navigate their vessel in each phase of the amphibious assault. Consequently, all parties involved concluded that using the ship simulator in developing and evaluating operation plans is effective.

\subsection{CHL recommendations}

For USACE civil works applications, channel designs are evaluated by as many as a dozen licensed pilots, and each pilot conducts testing over a week-long period. The exact number of pilots depends on the number of ship types that navigate the federal channel. Furthermore, alternative channel designs are tested over a variety of environmental conditions during the week. Because the pilots' skill at the simulator often increases over the course of that period, exercises are conducted in random order to avoid prejudicing results.

A similar approach for military applications is recommended should the simulator be used for evaluating operational plans. For example, a consensus of 4 craftmasters, piloting a particular vessel for identical exercises, would be more reliable than if that plan was tested with only 2 craftmasters. As above, exercises should be conducted in random order. A surface warfare officer, whether active or retired, with amphibious operational planning experience should be present to gain their insights and evaluate an operational plan.

Environmental libraries in USACE applications are generated for the "Maximum Credible Worst Case Scenario," which is defined as the worst conditions under which a ship or tow normally operates. Evaluation is limited to these conditions because of the time and costs associated with real-time simulation testing. The channel design is based on the assumption that if the design is acceptable for extreme conditions, it will be acceptable for less severe conditions. 
The military equivalent to the "Maximum Credible Worst Case Scenario" is the "Go/No-Go" condition. Unlike USACE applications, where that scenario is known by interviewing harbor pilots, the Go/No-Go conditions are guidelines based on technical manuals, standard operating procedures and assessment by the local commander. The greatest benefit that can be obtained from using the ship simulator is in evaluating an operation under marginal tide, wind, and river conditions to ensure that the operation is feasible under the Go/No-Go conditions in Table 1.

Table 1. Environmental conditions defining “Go/No-Go" decision.

\begin{tabular}{|l|c|c|c|c|}
\hline Craft & Wind Speed, kts & Sea State, ft & MSI & Beach Slope \\
\hline LCM 8 & 35 & 6 & $6 / 8$ & $1: 35$ \\
\hline LARC V & 25 & 6 & 9 & N/A \\
\hline LCU 1646 & 35 & 7.5 & $6 / 14$ & $1: 40$ \\
\hline
\end{tabular}

\subsection{Craftmaster recommendations}

While the digital vessel performed well, the pilots had suggestions to further improve the vessel and some aspects of the simulator itself which could not be implemented during testing. Two of the more important suggestions/requests were to be able to use the kedge anchor and the capability of soft grounding.

Soft grounding refers to the ability of the vessel to extricate itself once it has run aground. With respect to an LCU, a soft grounding would mean the bow has grounded and the pilot would simply back her off and either maneuver around the spot or build up significant momentum and plow through it. A complete listing of the suggested improvements is included in Appendix B. 


\section{Geographic Information System (GIS) Model}

Ship simulator exercises provide a qualitative assessment as to whether a proposed ship-to-shore operation is feasible. The Geographic Information System-based (GIS) model developed with the track output and data extracted from the environmental library compliments the craftmasters' assessments by providing military planners the information they need for determining the timing and logistics of an operation. This model provides planners the ability to graphically display each exercise and the environmental conditions under which it was conducted; query vessel performance parameters at any time during an exercise; and, generate figures and reports, as well as tabularize the parameters for export to other software packages, such as Microsoft Excel, for additional analyses.

This model uses the ArcMap system developed by the Environmental Systems Research Institute (ESRI). ArcMap is widely used by entities within the U.S. Department of Defense and allied counterparts for displaying and analyzing geographic information and has become the de facto standard platform. Model components are described below and Appendix $\mathrm{C}$ displays the vessel tracks and current for each exercise.

\subsection{Base map}

The base map, shown in Figure 29, was constructed from coverages, or data sets, extracted from the DNC published by the NGA. The DNCs are digital versions of standard paper nautical charts that the NGA and other agencies such as the National Oceanographic and Atmospheric Administration and foreign hydrographic offices publish and are intended for conducting both mission planning and vessel navigation purposes. The DNC database is divided into 29 regions and data for each individual region is segmented into four libraries; General, Coastal, Approach, and Harbor. Each contains a wealth of data, including soundings, contours, coastline, foreshore/mudflats and a variety of other maritime features. 
Figure 29. Base map.

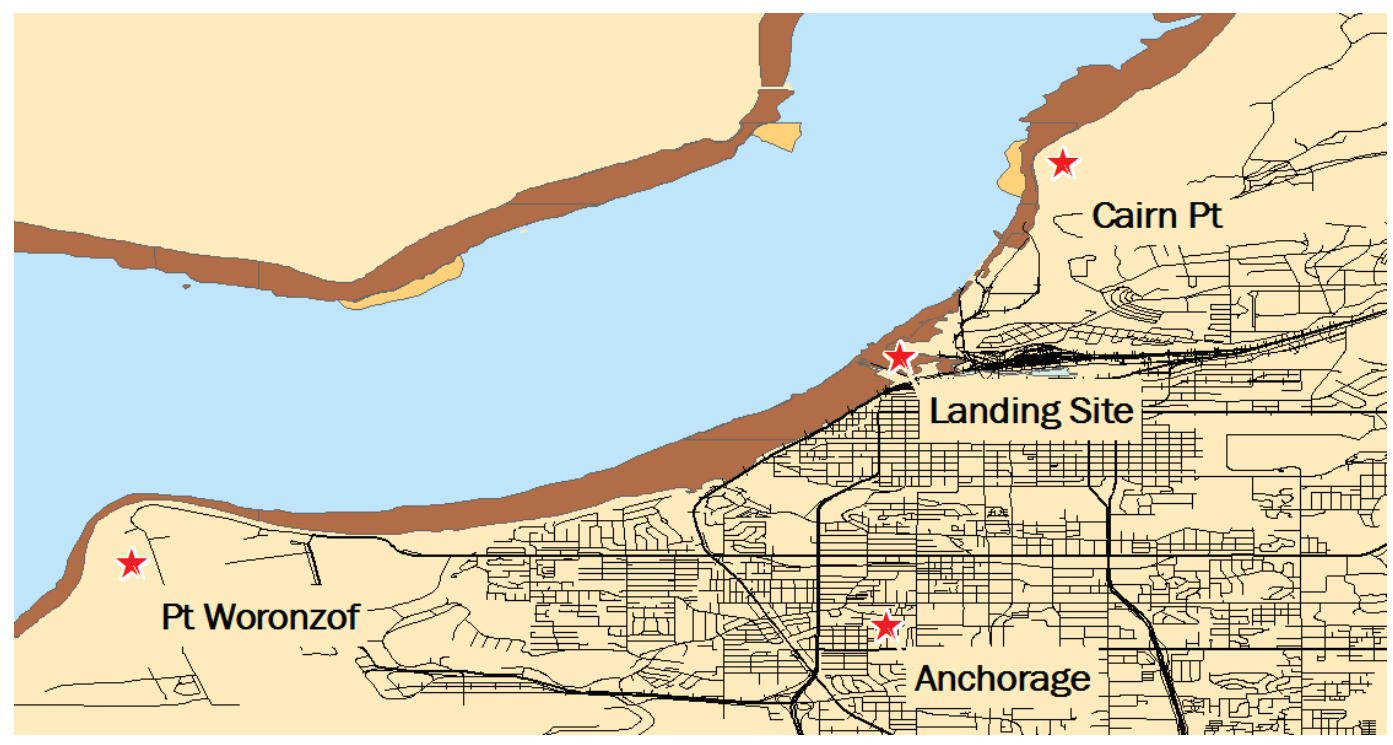

General libraries, which cover the largest areal extent, support open-ocean navigation. Coastal libraries are designed to support navigation along the open-coast, whereas Approach and Harbor libraries are intended to support navigation in inshore areas and harbors. As such, the entire AOA, from the sea echelon areas to the disembarkation point to the landing site can be resolved in a single GIS model. ArcMap automatically switches to higher resolution libraries as the user zooms in on an area. Figure 29 depicts the Port of Anchorage using the Approach library.

Data extracted from the DNCs were augmented with additional GIS products obtained from the Municipality of Anchorage for displaying its infrastructure. Roadways, railroads, trails, as well as rivers can be incorporated into the map to assist in planning an operation after reaching the landing site. Geo-referenced imagery can also be imported into the base map to display features not contained in the DNC, such as the channel that runs through the embayment containing the landing site.

\subsection{Track output}

Every five seconds during an exercise, the simulator outputs the control, position and orientation of the vessel, as well as the environmental conditions that are acting on it, to a log file. As many as 50 parameters can be saved during each exercise. For this proof-of-concept study however, 18 parameters were saved and they are listed in Table 2. 
Table 2. Track output parameters.

\begin{tabular}{|c|c|}
\hline Longitude & Latitude \\
\hline Heading & Speed \\
\hline Course & Course through Water \\
\hline Rudder Angle & Drift Angle through Water \\
\hline Lateral Speed Aft & Lateral Speed Forward \\
\hline Squat Aft & Squat Fore \\
\hline Drift Angle & Depth \\
\hline Current Speed & Current Direction \\
\hline Wind Speed & Wind Direction \\
\hline
\end{tabular}

Vessel tracks can be animated using the Tracking Analyst add-on residing in ArcMap. The symbol representing the vessel is displayed during an animation using a "traffic light" schema: green, denoting that all parameters fall within normal operating limits; yellow, denoting that at least one parameter is approaching its normal operating limit; and, red, highlighting that at least one parameter has exceeded its operating limit. As such, an area where navigation is hazardous is readily apparent to a military planner and analyzed to determine if craftmaster maneuvering or environmental factors caused the craft to go into danger.

\subsection{Environmental conditions}

The GIS model contains the environmental library that was supplied to the ship simulator and is stored as a file geodatabase. Data contained in the file includes water depths and terrain elevations, tidal current, and winds. The latter two items are viewed as vectors and can also be symbolized using a traffic-light schema. Environmental conditions can be viewed and animated simultaneously with the vessel in ArcMap.

Also included in the geodatabase are contour lines of water depth to delineate areas where an LCU can run aground. Positions of these contours are time dependent, reflecting changing depth due to the tide. Contours are symbolized using a traffic-light schema: green for the $3 \mathrm{~m}$ depth contour; yellow for the $2.5 \mathrm{~m}$ depth contour; and, red for the $2 \mathrm{~m}$ depth contour. Figure 30 provides an example of this capability. 
Figure 30. Traffic contours along coastline.

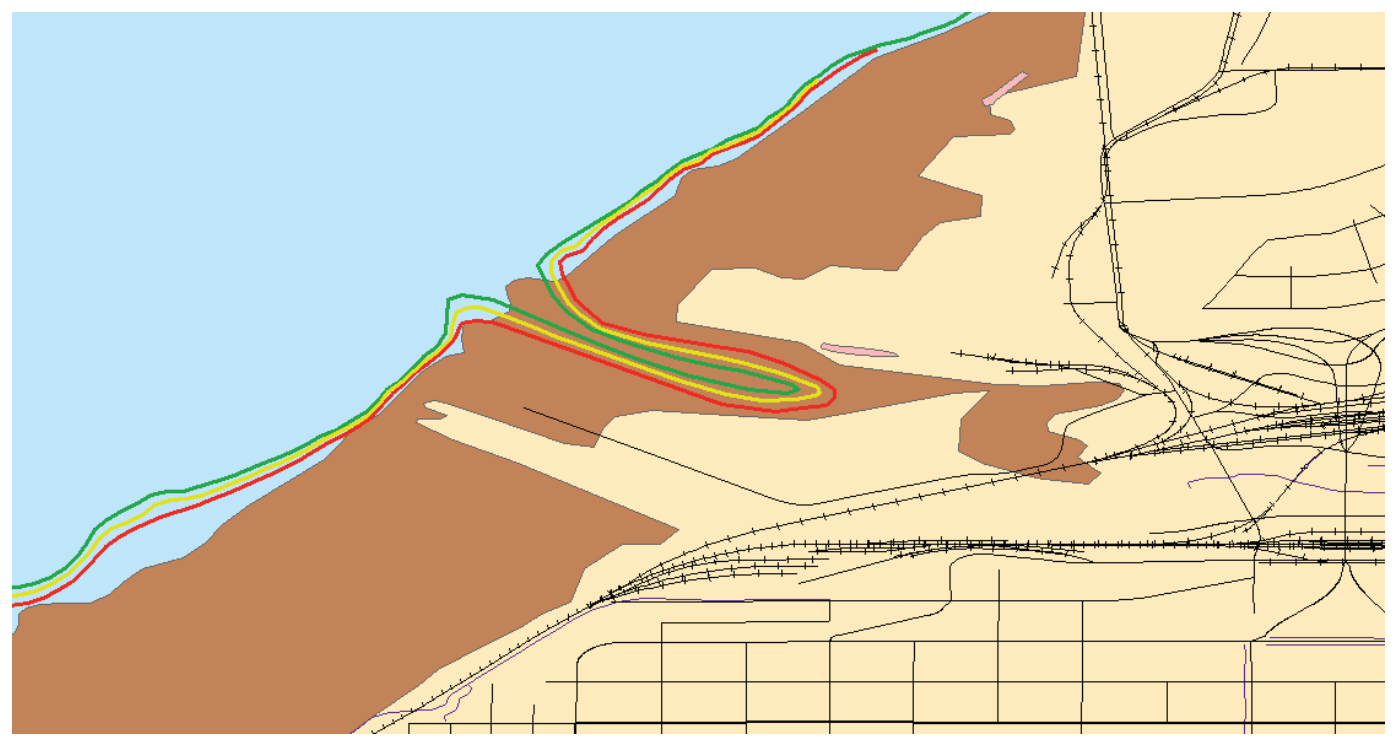

\subsection{Querying data}

ArcMap provides military planners several methods for displaying and outputting information stored in the geodatabases. The Hyper-Text Markup Language (HTML) capability built into ArcMap permits a planner to click on a vessel track and have a table of output parameters displayed on the screen. Figure 31 displays this capability and this feature permits the planner to compare, for example, the vessel course and its coursethrough-water. The course-through-water is the actual track the vessel takes and reflects the vessel drift induced by waves, wind, and tidal current. Course, or ordered course, is the actual heading that the craftmaster steers to account for the drift. Analyzing these factors enables a planner to develop an axis-of-advance that a vessel can easily maintain, as well as to reduce the travel time from the disembarkation site to the landing site.

Another built-in capability is to generate summarized reports. Track output parameters can be summarized in a report that can be saved as a text file or in a Microsoft Excel spreadsheet for additional processing. 
Figure 31. HTML capability to display vessel performance.

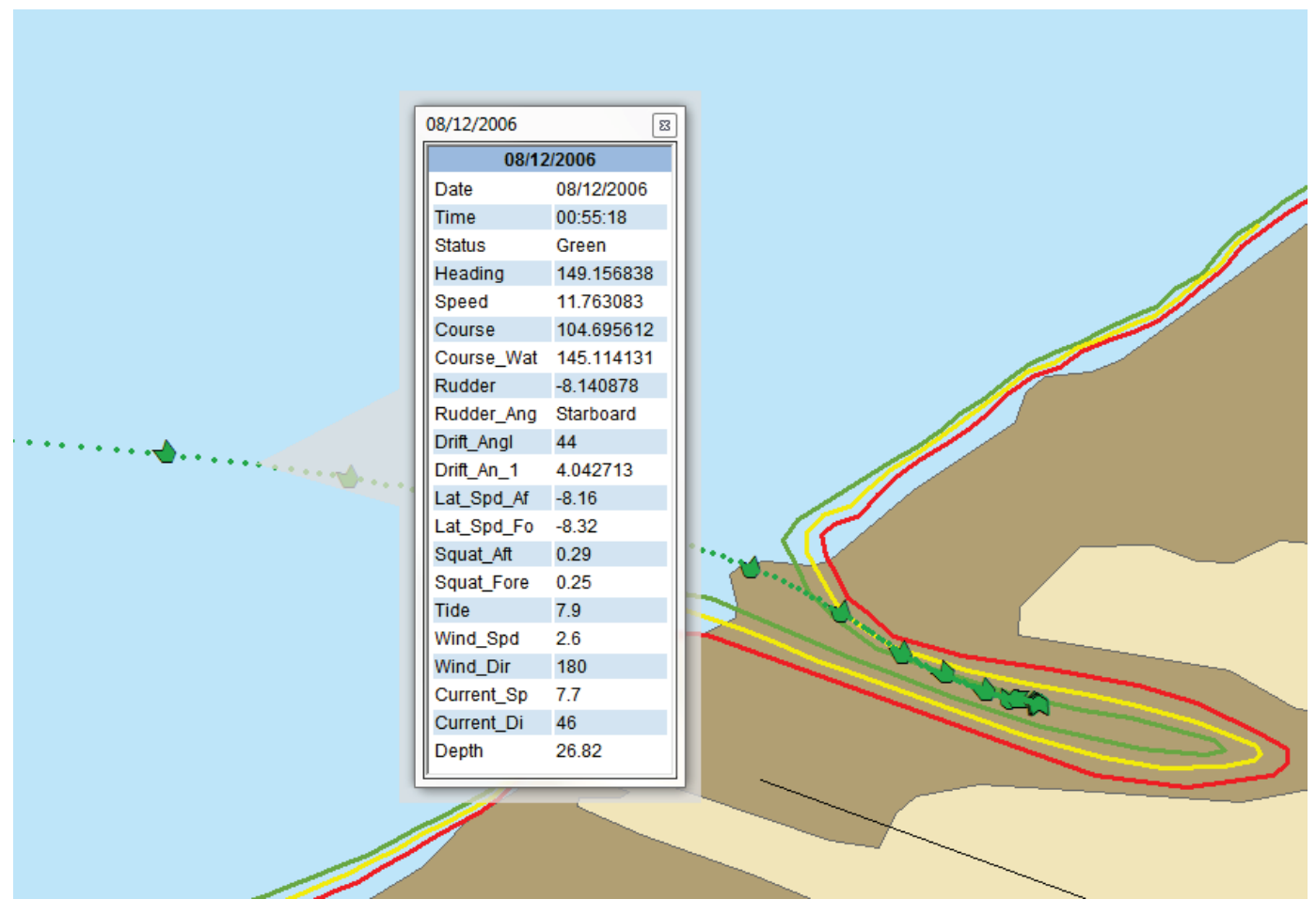




\section{Summary}

This proof-of-concept study demonstrated that a ship simulator can address two critical factors in evaluating amphibious operational plans: 1) the navigability of waters from the sea echelon area to the beachhead by the landing craft; and, 2) the timing of that operation. These factors are most acute in areas of extreme tidal range, strong current and shear zones, and in areas having limited maneuverability.

Additional benefits in applying circulation models together with a ship simulator in planning amphibious assaults include: 1) minimizing operational risk by testing the feasibility of the navigability of an area; 2) determining the logistics and timing of that operation; 3) defining the optimal axes-of-assault that best ensures navigational safety; and 4) developing a training platform for executing a plan.

A virtual amphibious assault was conducted near the Port of Anchorage, Alaska. This site was chosen because the environmental conditions at the Port are as challenging as those experienced during the Invasion of Inchon, Republic of Korea, in September 1950. Currents in Knik Arm, where the Port of Anchorage resides, exceed $2 \mathrm{~m} / \mathrm{s}$ (4 knots) during spring tide and the tidal range exceeds $10 \mathrm{~m}(32 \mathrm{ft})$. Massive mudflats front the Port, and at lower-low water are about $500 \mathrm{~m}$ (1640 ft) wide.

The ERDC has supported the USACE Civil Works mission in evaluating federally-maintained navigation channels since the early 1980's in its ship simulator/vessel-response facility. Currents used in this study were generated using a tidal circulation model developed in-house to support the USACE Alaska District for investigating sediment transport at the Port. A sampling of federally-maintained channels that have been evaluated by CHL include Port of Alaska; San Diego Harbor; Mayport, Florida; and Chesapeake Bay (Thimble Shoals Channel and Elizabeth River Reach).

The vessel used in the virtual assault was the 1646-class Land Craft Utility (LCU). The USN provided two craftmasters for piloting the LCU, and each is certified in their use. These craftmasters were serving as instructors stationed at the USN's Naval Amphibious Bases in Coronado, California and Little Creek, Virginia. The operational plan executed in the ship 
simulator was developed by a retired USN surface water officer who has over 15 years of experience in planning amphibious assaults and maritime prepositioning of naval assets to support those assaults.

Developed specifically for this study, the craftmasters first vetted the 1646class LCU. Each found that the virtual vessel matched the performance and maneuverability of the prototype vessel. Thereafter, they conducted a series of exercises of piloting their vessels from the disembarkation point to a cove located in proximity to the Port, a distance of about $10 \mathrm{mi}$. The craftmasters had to pilot their LCUs in a very challenging environment without benefit of having sailed in these waters before, virtually or in real life. They had to contend with a strong current, on flood and ebb, light and moderate winds, a narrow entrance to the cove, and with limited or no lighting. Furthermore, once entering the cove, they had to contend with the shoals and exposed mudflats within it.

Not unexpectedly, both craftmasters ran aground on their first exercise. At the conclusion of this exercise, as well as after the others, testing personnel gathered to discuss the difficulties in navigating through the entrance, shared their ideas for countering those difficulties, jointly developed a strategy, then implemented that strategy in the next exercise. By the end of the testing day, they were able to form a strategy for the following:

entering the cove during flood and ebb conditions; where the vessel should sail once inside the cove; location of shoals to avoid; and, how to exit the cove on flood and ebb. As a result, both craftmasters were able to successfully navigate their vessel in each phase of the amphibious assault. Consequently, all parties involved concluded that using the ship simulator in developing and evaluating operation plans is effective.

The greatest benefit that can be obtained from using the ship simulator is in evaluating an operation under marginal tide, wind, and river conditions to define the metrics of the Go/No-Go condition. 


\section{References}

ADvanced CIRCulation (ADCIRC). 2014. ADvanced CIRCulation User's Manual. http://adcirc.org.

Boose, Jr., D. W. 2008. Over the beach: U.S. Army amphibious operations in the Korean War. Fort Leavenworth, KS: Combat Studies Institute Press.

Builder, C. H., S. C. Bankes, and R. Nordin. 1999. Command concepts: A theory derived from the practice of command and control. Santa Monica, CA: RAND Corporation. http://www.rand.org/pubs/monograph_reports/MR775.

Chapman, R. S., K. J. Eisses, and T. O. McAlpin. 2009. Numerical modeling studies supporting Port of Anchorage deepening and expansion; Part III: measuring physical processes. In Proceedings of Estuarine and Coastal Modeling Conference, American Society of Civil Engineers. Seattle, WA.

Clark, E. F. 2002. The secrets of Inchon: The untold story of the most daring covert mission of the Korean War. New York, NY: G.P. Putnams Sons.

Egbert, G. D., and L. Eroleeva. 2010. Oregon State University (OSU) Tidal Data Inversion. http://volkov.oce.orst.edu/tides/. Retrieved on 2 February 2017.

Frey, R. W., J. S. Hong, and W. B. Hayes. 1988. Physical and biological aspects of shell accumulation on a model macrotidal flat, Inchon, Korea. Netherlands Journal of Sea Research. 22(3):267-278.

Hayter E. J., R. S. Chapman, P. V. Luong, S. J. Smith, and D. B. Bryant. 2012. Demonstration of predictive capabilities for fine-scale sedimentation patterns within the Port of Anchorage. AK. Final Report prepared for U. S. Army District, Anchorage, AK.

Kim, J. L., and S. C. Park. 1985. Intertidal flat sediments and characteristic sedimentary structures in the Changgu Bay, west coast of Korea. Journal of Oceanological Society of Korea. 20:43-49

Schwartz, M. I. 2005. Encyclopedia of coastal science, encyclopedia of earth science series. The Netherlands: Springer.

Smagorinsky, J. 1963. General circulation experiments with primitive equations, I. The basic experiment. Monthly Weather Review 91:99-164. 


\section{Appendix A: Craftmaster Surveys}

Craftmaster exit and testing surveys are provided in this Appendix.

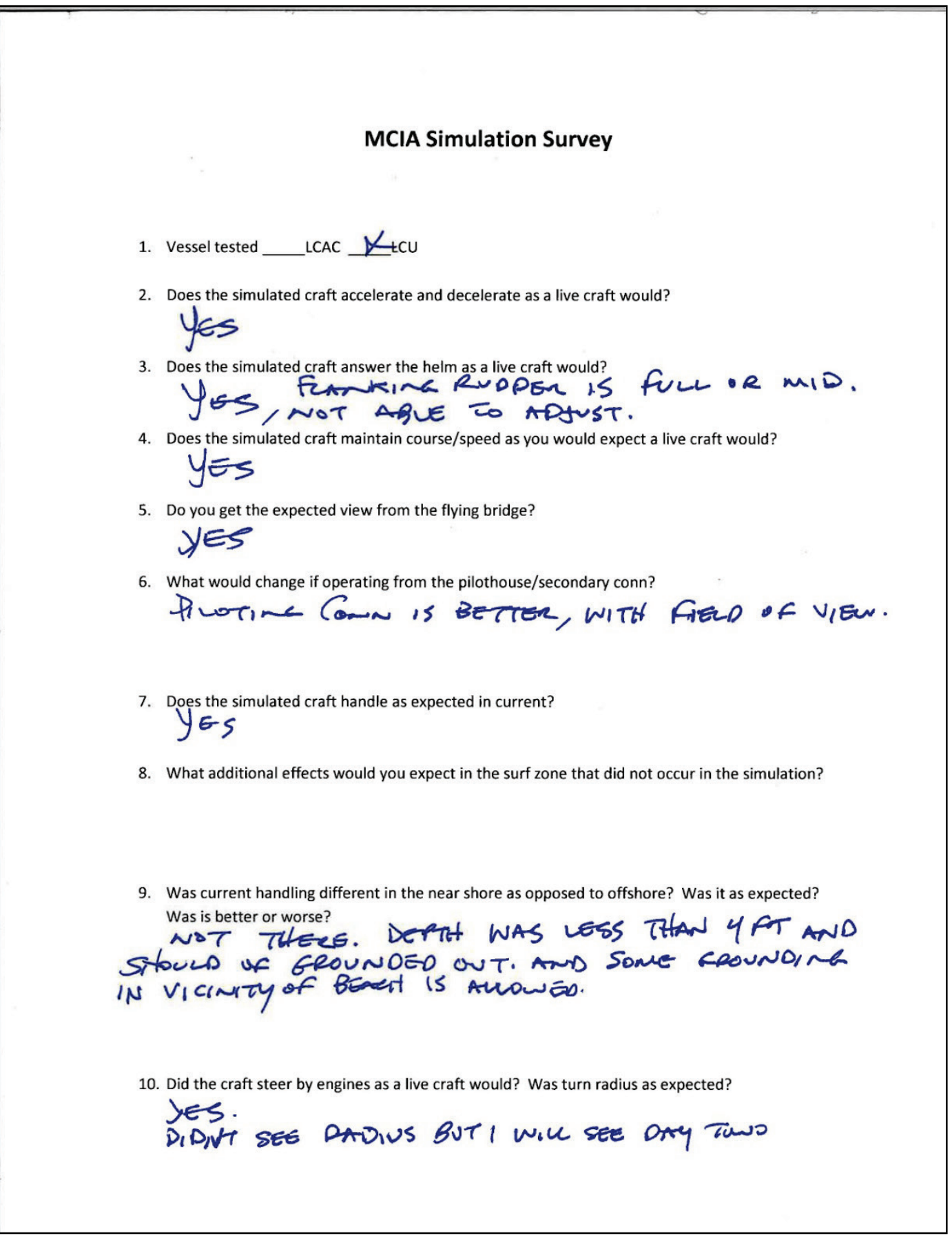


ERDC/CHL TR-17-4

49

11. Did the craft operate as expected in the surf zone? Requirements for a kedge anchor (per SOP)? testing in broaching maneuver -Did craft handle as expected (Rudder/throttle)? NA. ANCHOR IS AT CRAPTMUSTER DISCRESSION BUT RUDDERS \& FEAT RUDDER WORKED AS SSPECTED.

12. Did the craft ballast as expected? Timing? Deballast as expected? Timing? Maneuverability changes? As expected/slower/faster/more sluggish/crisper?

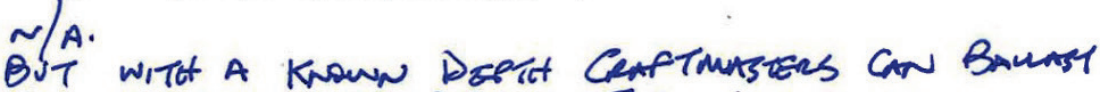

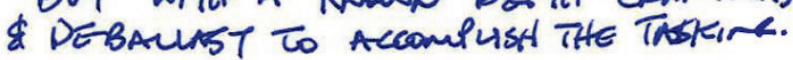

13. Sail area accounted for? Changes when ballasted?<smiles>C1CCCCC1</smiles>

14. Use of VMS/AADS requirements - Same? Better? Worse?

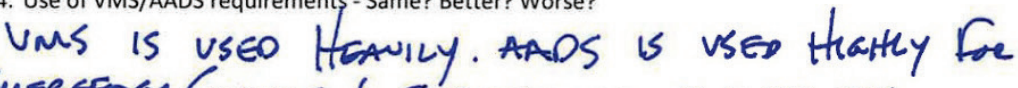

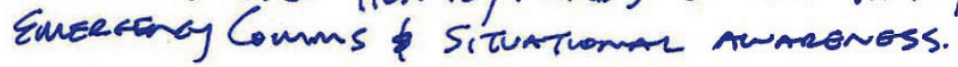




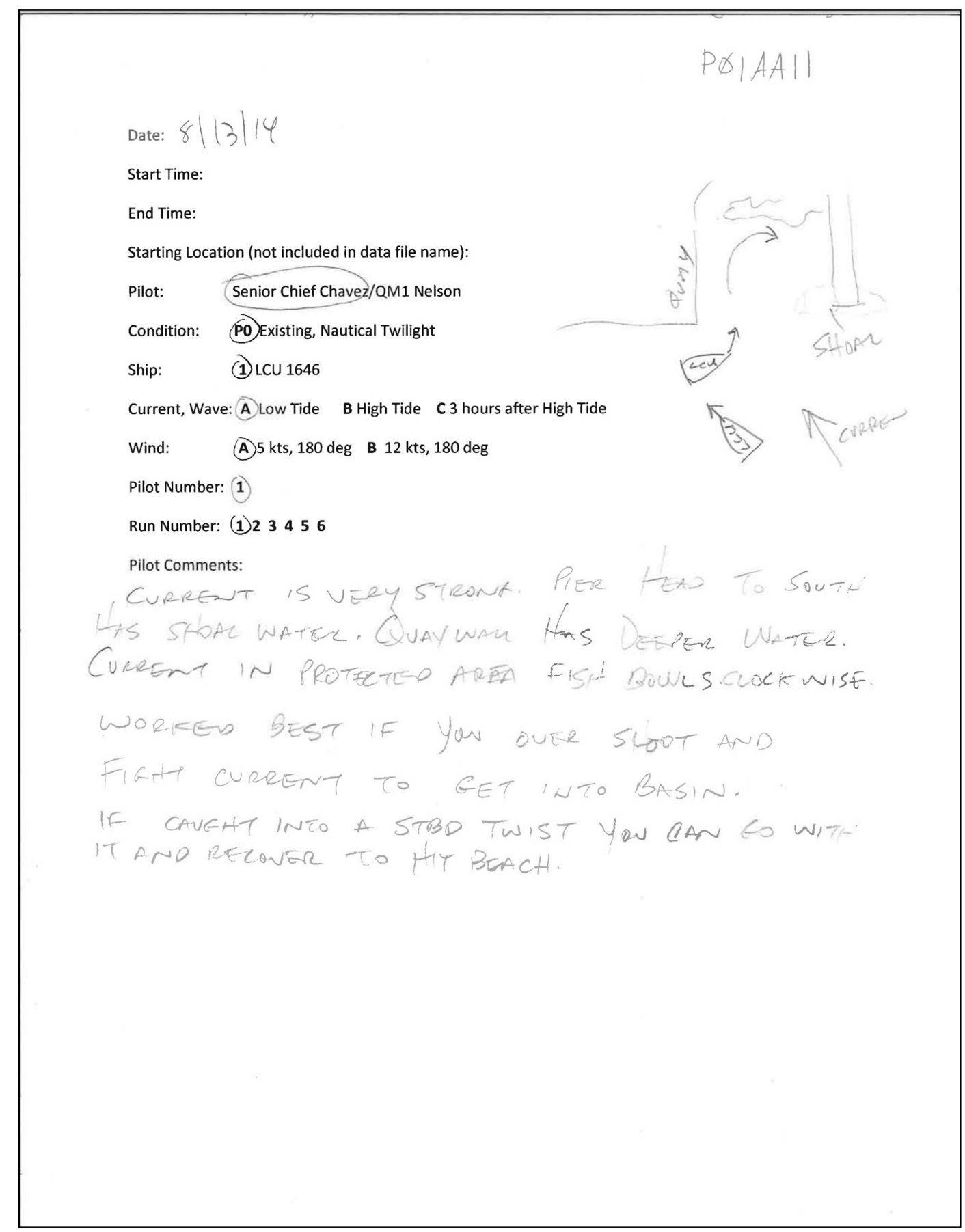




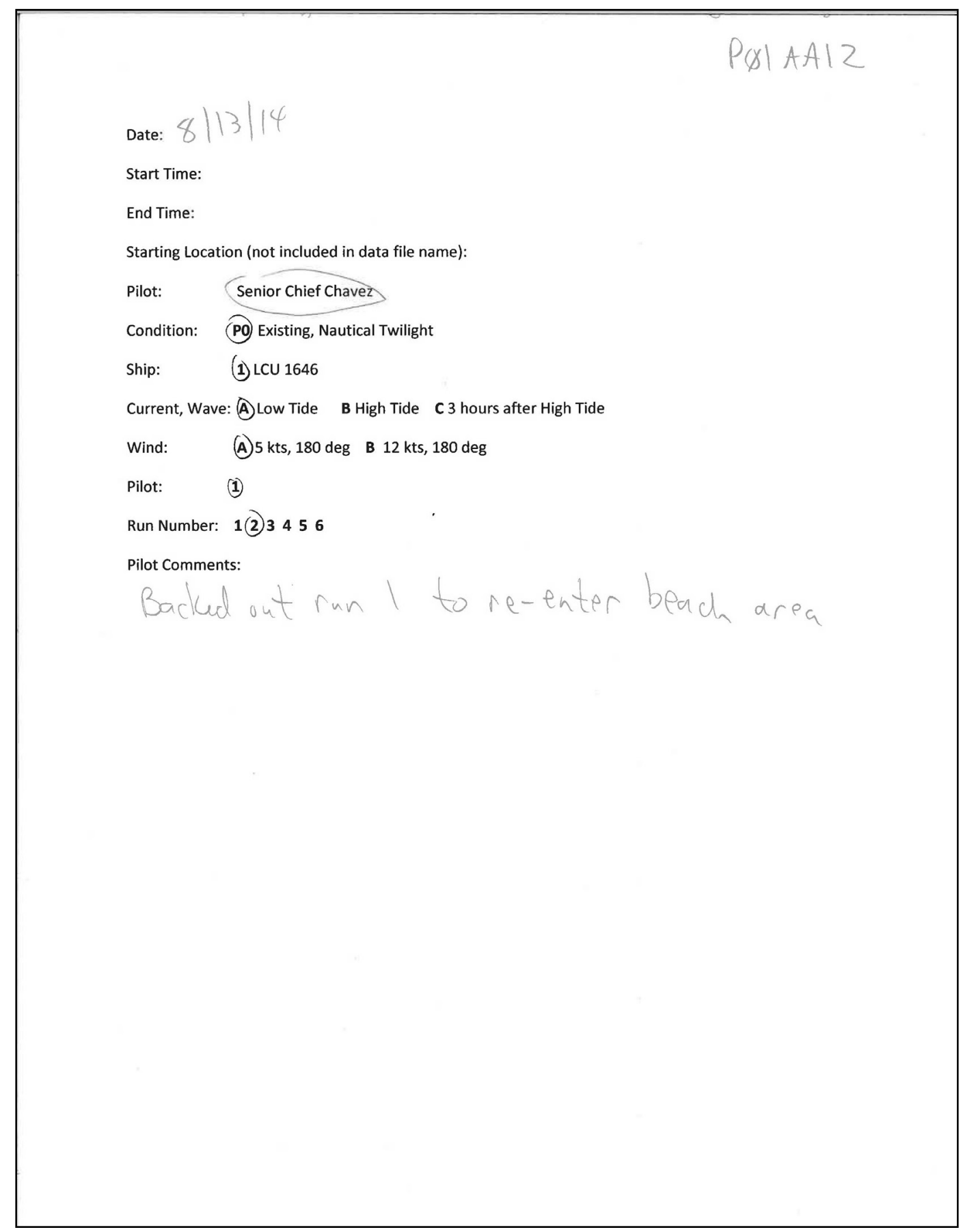


Date: $8 / 12 / 15$

Start Time: 1623

End Time:

Starting Location (not included in data file name): $61^{\circ} 14.199^{\prime} \mathrm{N}, 149059.700^{\prime} \mathrm{W}$

Pilot: $\quad$ Senior Chief Chavez/QM1 Nelson

Condition: Po Existing, Nautical Twilight

Ship: (1) LCU 1646

Current, Wave: A Low Tide (B) High Tide C 3 hours after High Tide

Wind: (A) $5 \mathrm{kts}, 180 \mathrm{deg}$ B $12 \mathrm{kts}, 180 \mathrm{deg}$

Pilot Number: (1)

Run Number: 1)23456

Pilot Comments:

Wind Waves funchedued

Grounded while backins out 


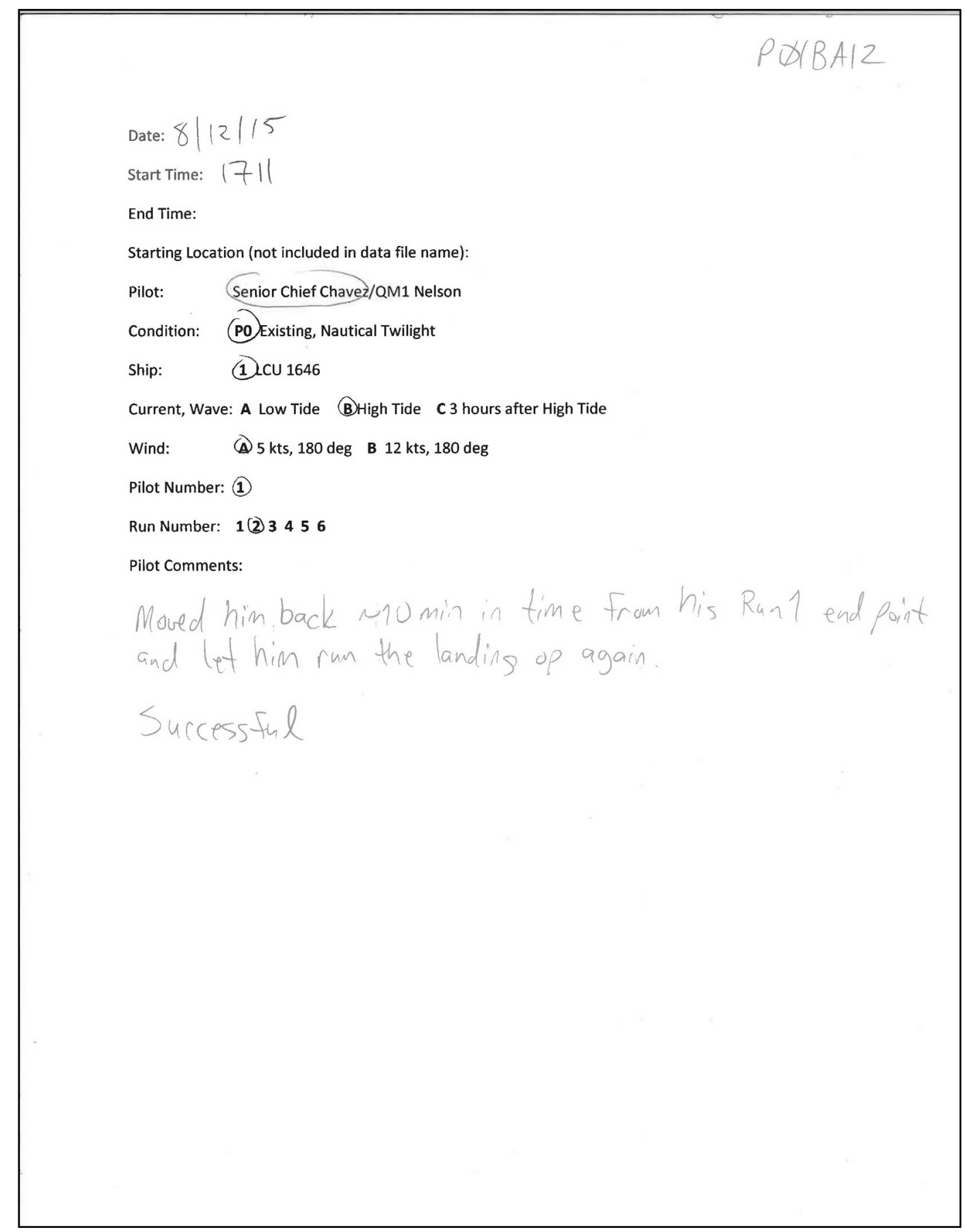



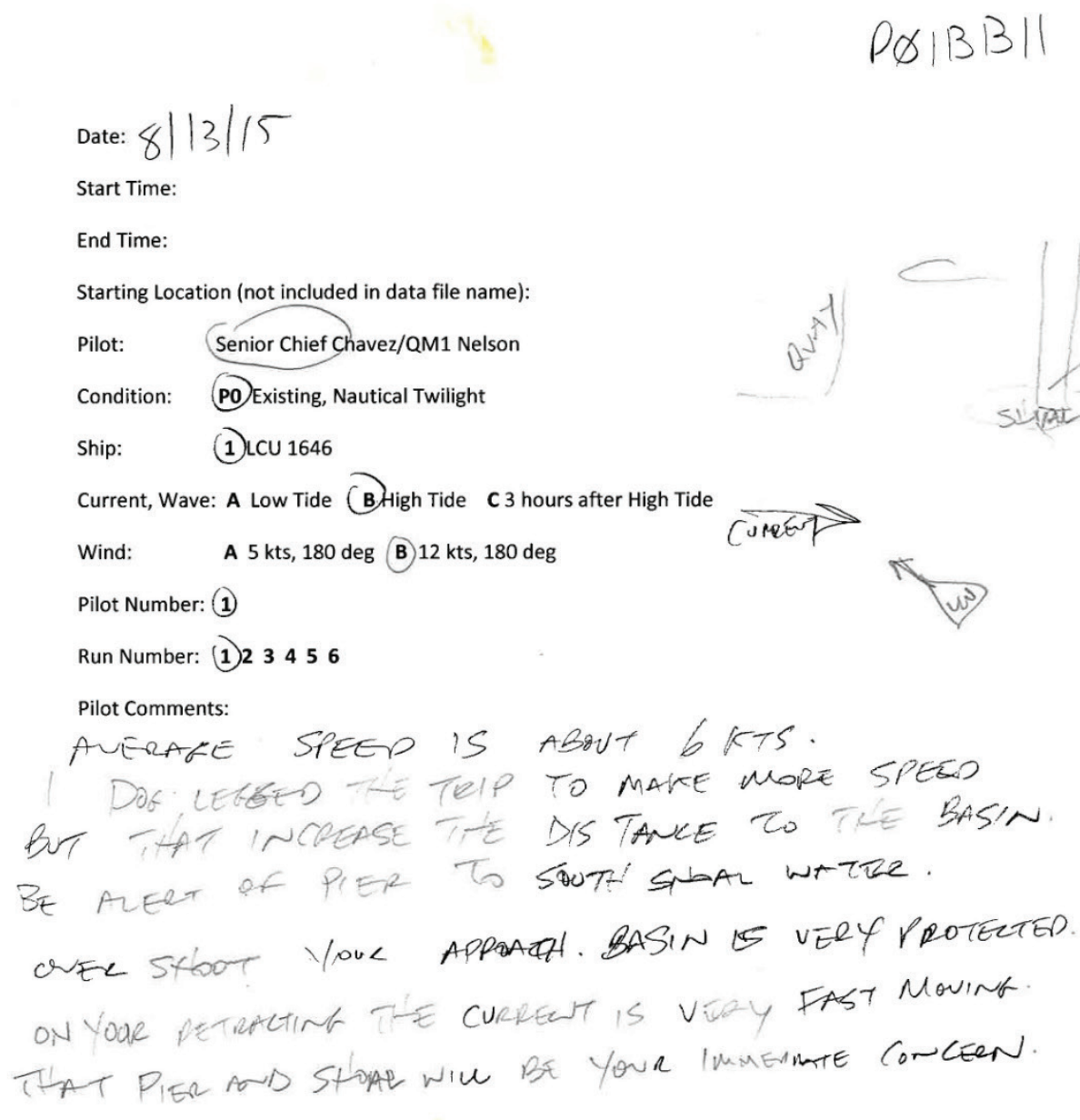


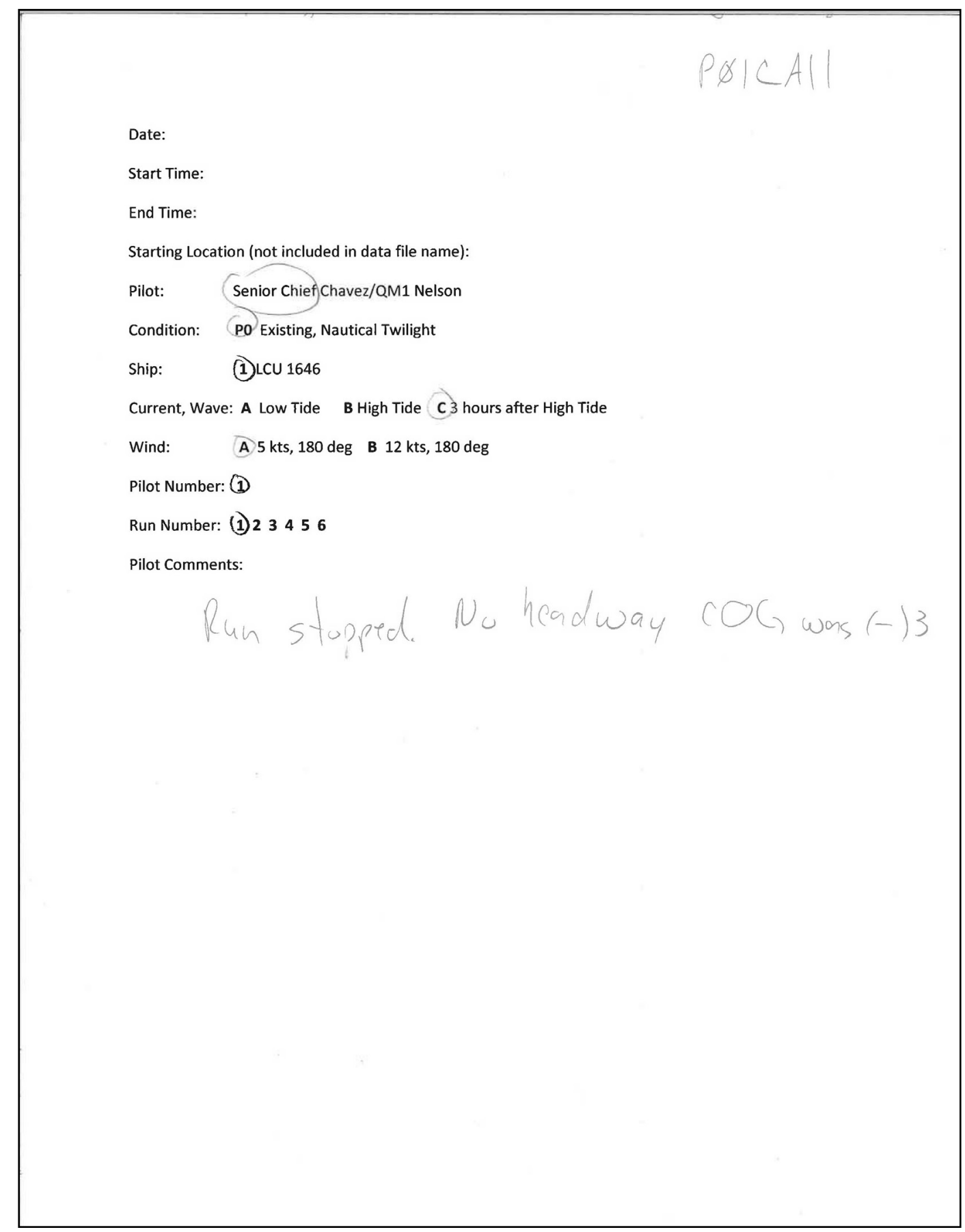


Date:

Start Time:

End Time:

Starting Location (not included in data file name):

Pilot: Senior Chief Chayez/QM1 Nelson

Cońdition: Po Existing, Nautical Twilight

Ship: (1) LCU 1646
Current, Wave: A Low Tide B High Tide c3 hours after High Tide D High Tide, Dark

Wind: A $5 \mathrm{kts}, 180 \mathrm{deg}$ B $12 \mathrm{kts}, 180 \mathrm{deg}$

Pilot Number: [1]

Run Number: (1)2 3456

Pilot Comments: THES LCU MERGES WITH OCEAN MAKING

IT ALMOST NOT VISABLE. THE MONITOR THEN BECAME GRAINEY

AND DIFFICUIT TO MARE OUT MY BOW. SIMULATOR HANDLE CORRECTLY,

VMS (ENTC) WAS A NOEDED DOOL ON THIS RUN, YOU MUST COME

NORTM AND HAVE YOUR REAR QUARTER NORT H OR EVEN WITH THE

END OF TOUR QUAM WALC PRIOR TO ENTERING THE COVE, YOV

MUST HUE THE QUAY WAK OUT TO CCEAR TME MUD]

FCAT TO STARBUARD. 


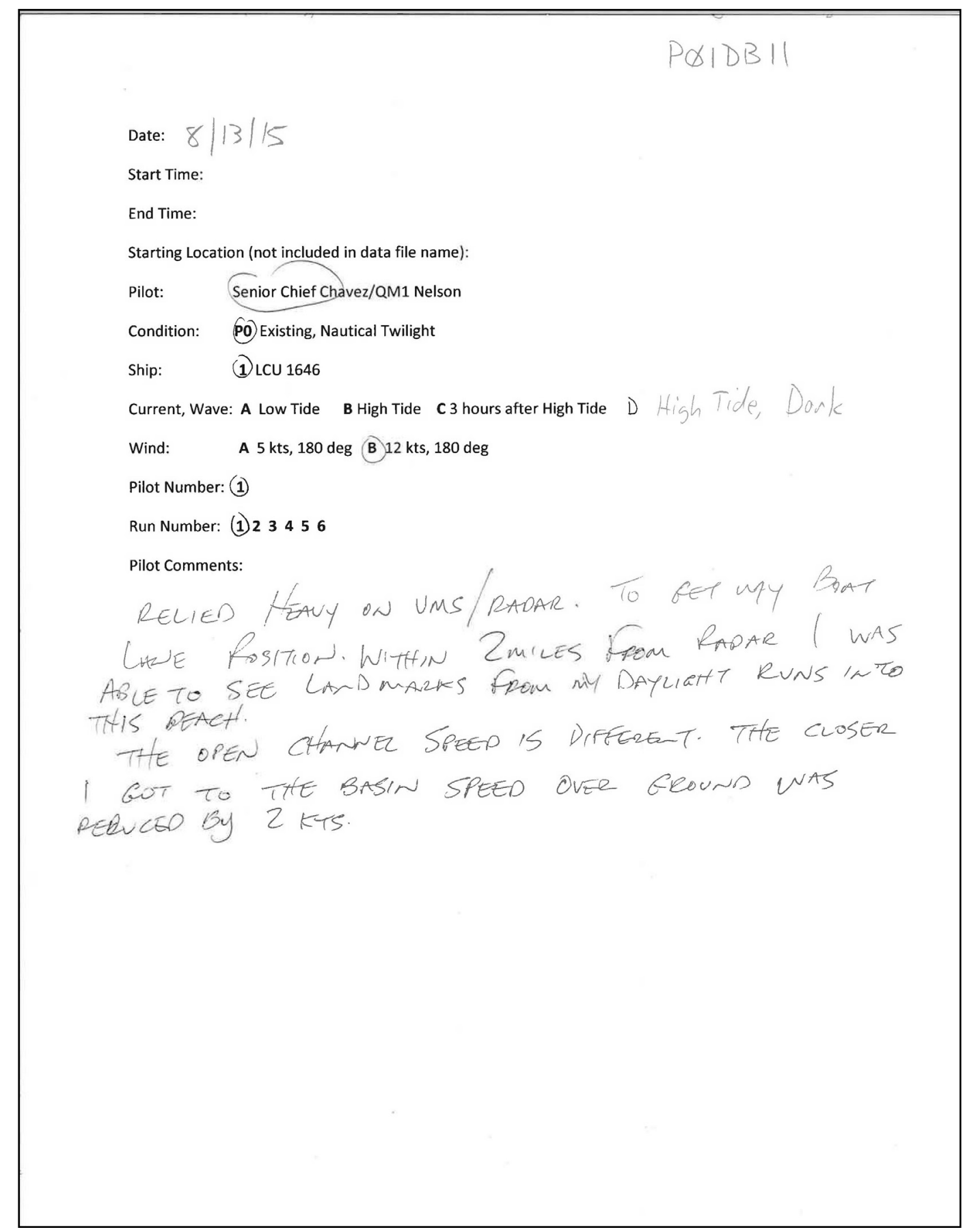




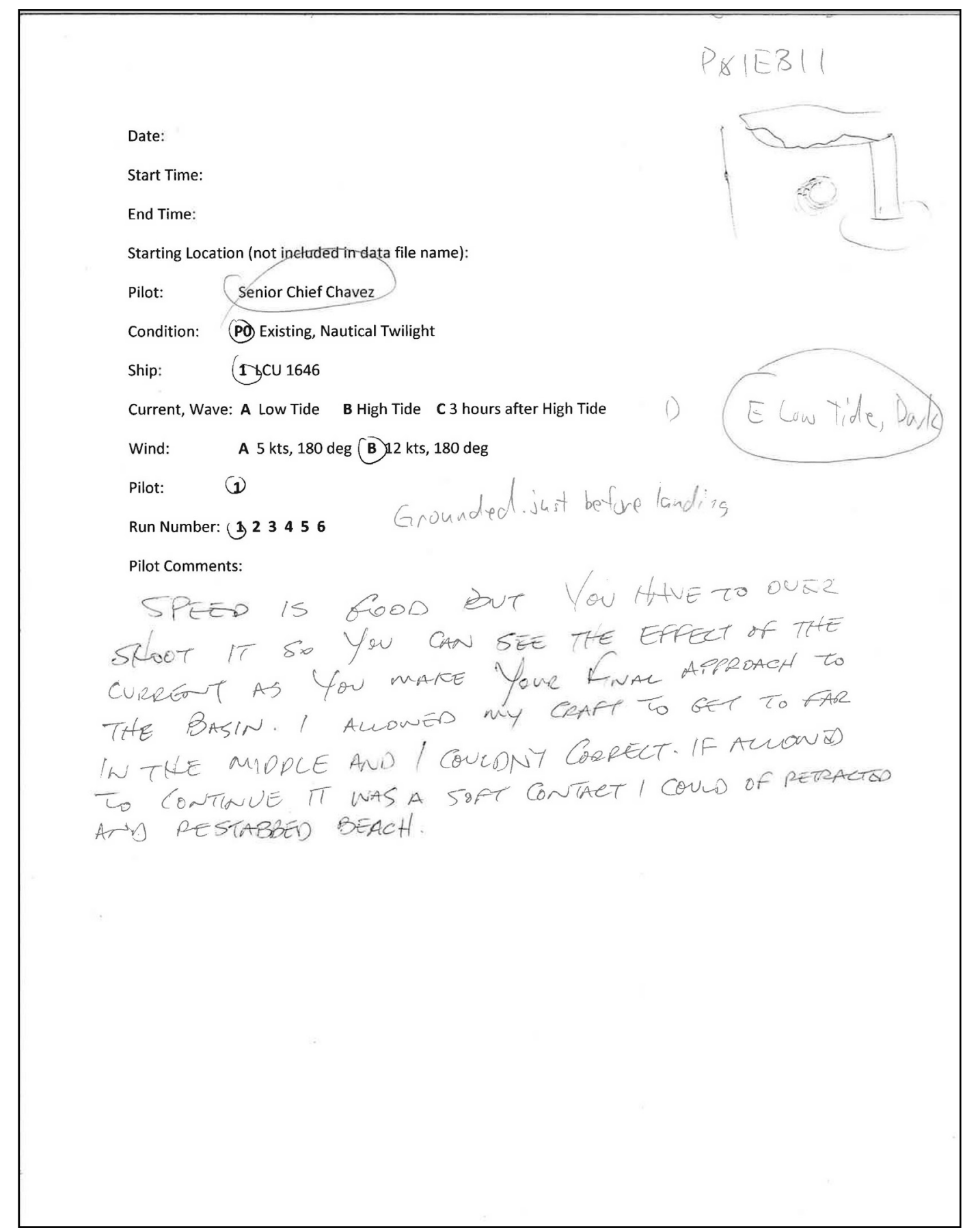




\section{Simulation Survey}

1. Vessel tested LCAC Х $\chi_{\text {LCU }}$

2. Does the simulated craft accelerate and decelerate as a live craft would? Yes

3. Does the simulated craft answer the helm as a live craft would? Yes

4. Does the simulated craft maintain course/speed as you would expect a live craft would? Yes

5. Do you get the expected view from the flying bridge? Yes

6. What would change if operating from the pilothouse/secondary conn? CONTROS IN THE SIMULATER

7. Does the simulated craft handle as expected in current? Yes

8. What additional effects would you expect in the surf zone that did not occur in the simulation? $N / A$

9. Was current handling different in the near shore as opposed to offshore? Was it as expected? Was is better or worse?

Yer, IT WAS REAUSTIC AS I EUTERED A cove.

10. Did the craft steer by engines as a live craft would? Was turn radius as expected? YES MINUS NO FLANKINGE RUDDERS 
11. Did the craft operate as expected in the surf zone? Requirements for a kedge anchor (per SOP)? testing in broaching maneuver -Did craft handle as expected (Rudder/throttle)?
$N \mid A$

12. Did the craft ballast as expected? Timing? Deballast as expected? Timing? Maneuverability changes? As expected/slower/faster/more sluggish/crisper?
$N \mid A$

13. Sail area accounted for? Changes when ballasted?

N/A

14. Use of VMS/AADS requirements - Same? Better? Worse? SAME ONCE OMINE

15. Other Comments

OVERALL Great Experine for AN LCU SIMULATOR. 
Date: $8 / 13 / 2015$

Start Time: 0838

End Time: $\quad$ 9:00

Starting Location (not included in data file name):

Pilot: QM1 Nelson

Condition: Po Existing, Nautical Twilight

Ship: 1 ICU 1646

Current, Wave: A Low Tide B High Tide C 3 hours after High Tide

Wind: A $\mathrm{kts}, 180 \mathrm{deg}$ B $12 \mathrm{kts}, 180 \mathrm{deg}$

Pilot Number: 2

Run Number: (1)23456

Pilot Comments:

Grounded but able to got off. 
Date: $8 / 12 / 2015$

Start Time: 1625

End Time:

Starting Location (not included in data file name): $\quad 6 i_{0}^{\circ} 14.199^{\prime} \mathrm{N} \quad 149^{\circ} 59.7^{\prime} \mathrm{W}$

Pilot: Senior Chief Chavez/QM1 Nelson

Condition: Po Existing, Nautical Twilight

Ship: $\quad 1$ LCU 1646

Current, Wave: A Low Tide Bhigh Tide C 3 hours after High Tide

Wind: A $5 \mathrm{kts}, 180 \mathrm{deg}$ B $12 \mathrm{kts}, 180 \mathrm{deg}$

Pilot Number: 1

Run Number: (1) 23456

Pilot Comments:

Grounded 


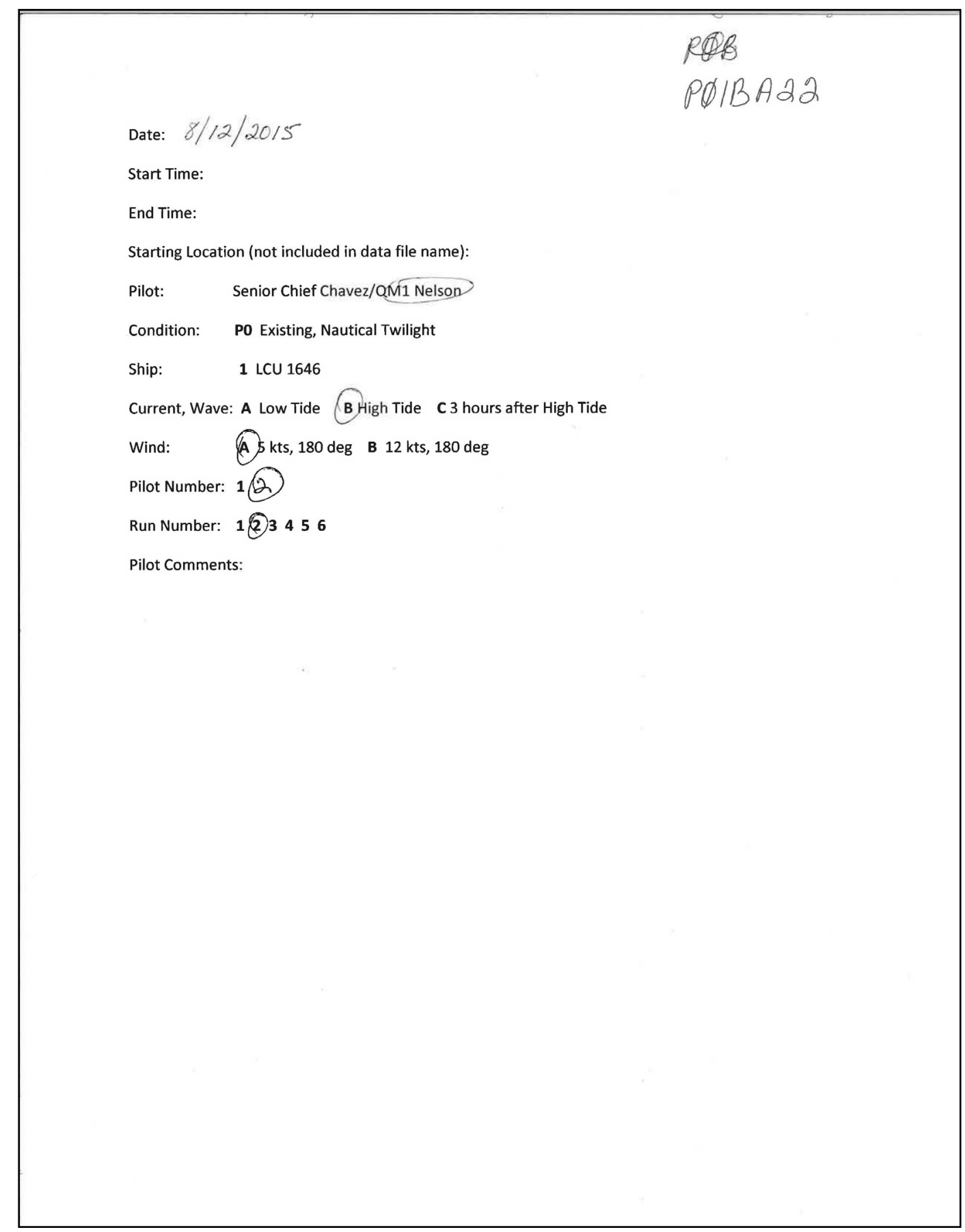


Date: $8 / 13 / 2015$

Start Time:

End Time:

Starting Location (not included in data file name):

Pilot: QM1 Nelson

Condition: Po Existing, Nautical Twilight

Ship: 1 LCU 1646

Current, Wave: A Low Tide BHigh Tide C3 hours after High Tide

Wind: $\quad$ A $5 \mathrm{kts}, 180 \mathrm{deg}$ (B) $12 \mathrm{kts}, 180 \mathrm{deg}$

Pilot Number:( 2

Run Number: (1) 23456

Pilot Comments: THE CURRERT AND WINDS WERE REALISTIC. ANA THEY MAD THE CORRECT EFFECT ON THE CAAFT. THE VISUALS WERE WASN'T STRAIGRT WENOUOUM APRIOACH INTO THE COVE, FEEL HANDLE SAFELY. CRAFTT, BUT NOTHINK I COULD NO QUAY WACL. THE CRAFT SHOULD EMTER CLOGOR TO THE ASTERN PROPULSION REQUIREA SIMPCE ONLY MINOR VES REL. RECCOMEM D CKAET BECAURS THE CURREMT UNAM NEAR THE QUAY WALL TME CRAFT WOUTH QUICKLY UNCE YOU EXIT WIL FORCE WITH LITTLE CONTBOL. 
Date: $8 / 13 / 2015$

Start Time:

End Time:

Starting Location (not included in data file name): $611^{\circ} 13.231 \mathrm{~N} 150^{\circ} \mathrm{ol} .774$

Pilot: QM1 Nelson

Condition: Po Existing, Nautical Twilight

Ship: 1 LCU 1646

Current, Wave: A Low Tide B High Tide $\mathcal{C}_{3}$ hours after High Tide

Wind: A $5 \mathrm{kts}, 180 \mathrm{deg}$ B $12 \mathrm{kts}, 180 \mathrm{deg}$

Pilot Number: (2)

Run Number: (1)23456

Pilot Comments:

CURRENT WAS TOOSTRONZE TO OPGRATE CRAFT
AGAINST IT. CRAFT WOULD NOT

AGAINST IT. CRAFT WOULD NOT RESPOND WITH

ACC AHEAD AND STIL DRIFED AFT. 


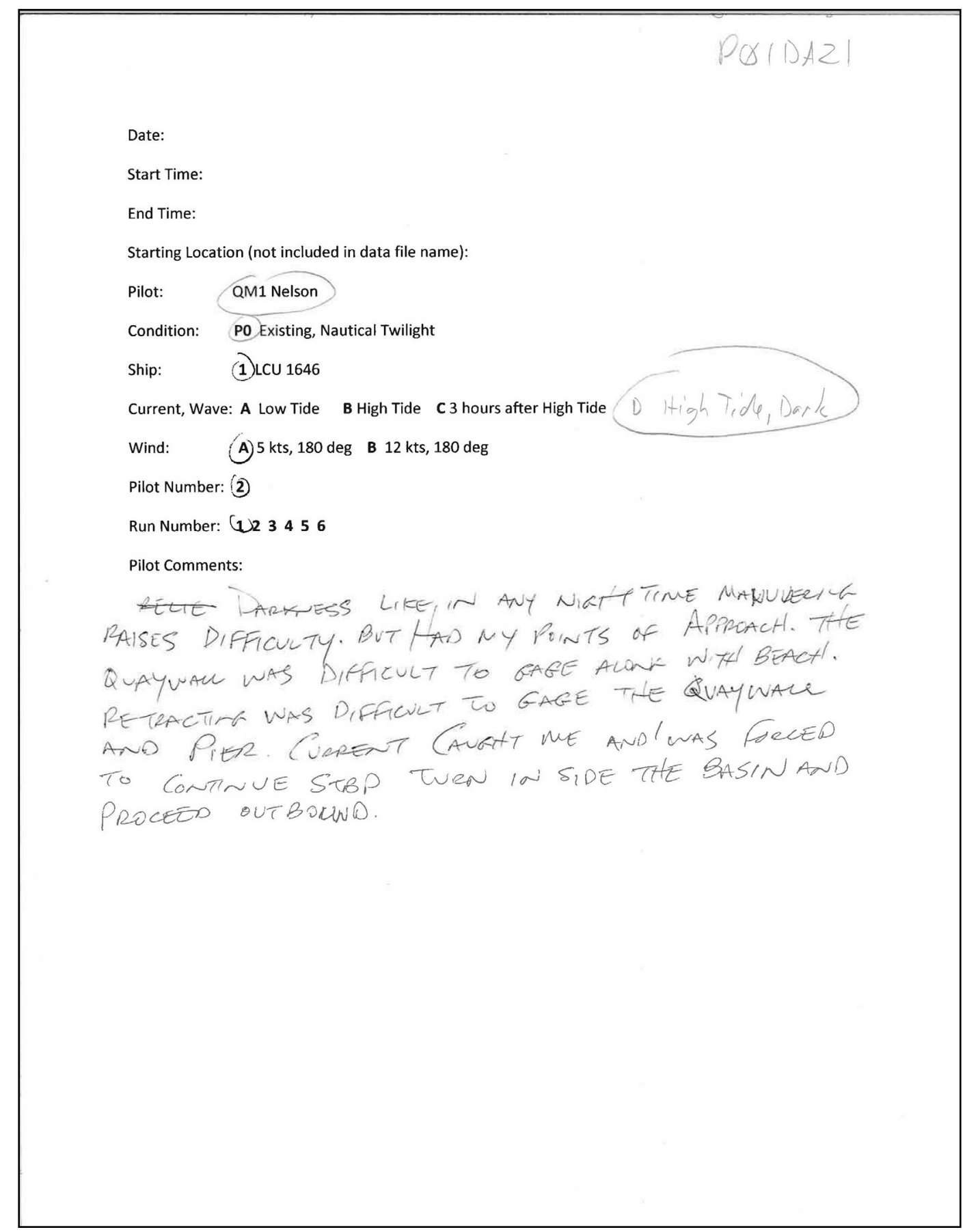




\section{$P \phi|D B 2|$}

Date: $8 / 13 / 20 / 5$

Start Time:

End Time:

Starting Location (not included in data file name):

Pilot: $\quad$ QM1 Nelson

Condition: (P) Existing, Nautical Twilight

Ship: (1) LCU 1646

Current, Wave: A Low Tide B High Tide c3 hours after High Tide (D) ktigh Tide, Dark ( $84 \%$ )

Wind: $\quad$ A $5 \mathrm{kts}, 180 \mathrm{deg}$ (B) $12 \mathrm{kts}, 180 \mathrm{deg}$

Pilot Number: 2

Run Number: 123456

Pilot Comments:THE DISPCAM was Geniney Accarn. IT was MAQU TO SEE ThE BOWRAMP. WHEN APPRONCMIANC THE COVE YOU NEED B BE NORTM AMS MAKe The CONN PARACLE WITH THE END OP THE QUAY WACL. WHEN HEHD ING IN THE IS A SUCGHT CURRENT THAT SETS YOU TO STAKBOARD. I RECOMAMONS

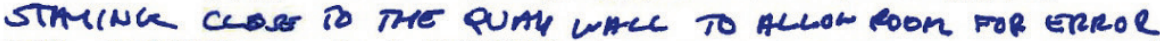

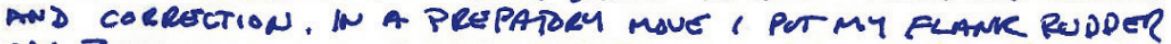
ON BUT THIS MOVED THE CRAAT WITH NO ASTERN PROPULTON WHICM IS NOT CORRECTMOVEMONT. THIV CAUSED The CRAFT TO

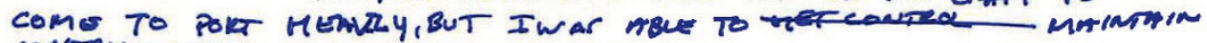
CONTROL. THE EXIT/RETURN WAS JUST LIRE LAST TIME. PIERS TME QUAY WHLL OUT ONCE CCOAR OF THE MUD AND CURRENI. STARBOARD TWIST TO STARBARD WITHE THE 
Date:

Start Time:

End Time:

Starting Location (not included in data file name):

Pilot: QM1 Nelson

Condition: PO Existing, Nautical Twilight

Ship: 1 LCU 1646

Current, Wave: A Low Tide B High Tide c 3 hours after High Tide D High Tide Dark

Wind: A $5 \mathrm{kts}, 180 \mathrm{deg}$ (B) $12 \mathrm{kts}, 180 \mathrm{deg}$ (E) Low Tide Dark

Pilot Number: 2

Run Number: 1123456

Pilot Comments: You MUST ao North of THE QUAM wack TWUN

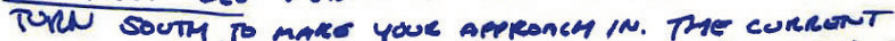

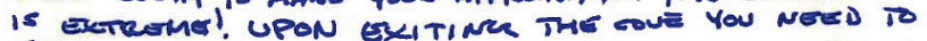

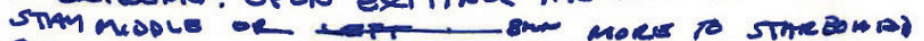

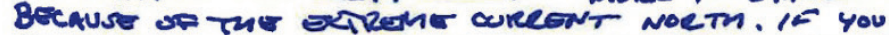
DONT You will END oponeup on Tre fury warl

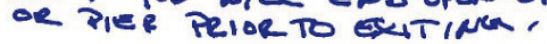




\section{Appendix B: Craftmaster Comments}

The craftmasters had several comments concerning the performance and handling of the digital LCU, as well as improvements to the ship simulator facilities.

1. They stated that they need a minimum of 120-degree view aft to properly judge whether a vessel is maneuvering correctly. The simulator does not meet this minimum requirement. Adding additional screens, which requires additional visual channels, is required. Kongsberg Maritime has provided a cost estimate for upgrading the number of visual channels.

2. Engine sounds, especially the revving up and down to throttle movements, was not audible during the exercises. The craftmasters requested that sound effects be included in the ship simulator software package. This issue was resolved with the latest upgrade of the simulator in February 2016.

3. The visuals for night runs were grainy and the image of the vessel became transparent on the screens in the simulator bridges. The image quality may be directly related to the plasma monitors currently installed in the simulator. The simulator manufacturer will test whether LED monitors will improve the image quality in low-light environments. Additionally, the craftmasters requested that "lighting" or hue of the visuals be changed to that seen when wearing night vision goggles. The request for the night vision goggles effect has been fulfilled.

4. Using the flanking rudders during an all-ahead motion of the vessel caused the digital vessel to modify course. This is not the case in a prototype vessel. This issue needs to be addressed by Kongsberg Maritime.

5. For this particular naval vessel, the digital LCU should not become grounded when its bow touches bottom. The craftmasters asked that the bow of the vessel be "desensitized" to reflect this. Grounding when any other portion of the keel touches bottom is appropriate. This capability, soft grounding, will be part of the next simulator software upgrade which is scheduled for release in early 2017.

6. The craftmasters requested the capability to raise and lower the bow ramp and the ability to drop a kedge anchor.

7. Throttles stop increasing at about $80 \%$ on the bridge console. 
8. The RPM readout does not match the speed of vessel. Craftmasters can discern approximately how fast the vessel is going by the RPMs of the engine. Engine revolutions were "estimated" by the craftmasters. A table of throttle commands and associated engine RPMs would aid in judging craft speed (as ordered).

9. Maximum speed of vessel should be about 12 knots, but the maximum speed of the digital vessel was 10.7 knots.

10. Port and starboard throttles do not match. The starboard throttle runs slightly faster. 


\section{Appendix C: Vessel Tracks}

Vessel tracks are provided in this Appendix. The following table provides a key for the environmental conditions under which each exercise was conducted.

\begin{tabular}{|c|c|c|}
\hline Exercise & Tide Condition & Wind Strength, kts \\
\hline P01AA11 & Peak Flood Current & 5 \\
\hline P01AA21 & Peak Flood Current & 5 \\
\hline P01BA11 & Slack High Water & 12 \\
\hline P01BB11 & Slack High Water & 12 \\
\hline P01BB21 & Slack High Water & 5 \\
\hline P01DA11 & Slack High Water & 12 \\
\hline P01DB11 & Slack High Water & 12 \\
\hline P01DB21 & Slack High Water & 12 \\
\hline P01EB21 & Peak Flood Current & \\
\hline
\end{tabular}

Figure C1. Exercise P01AA11.

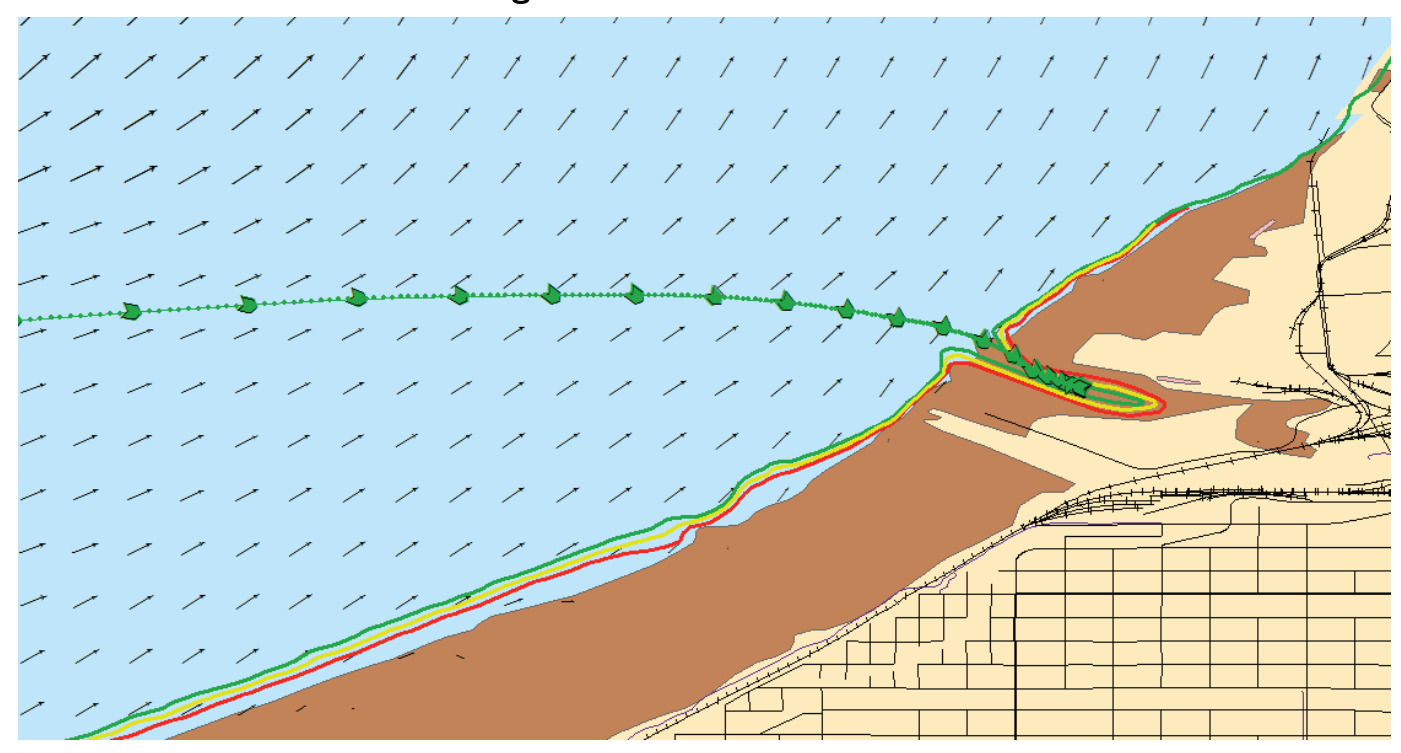


Figure C2. Exercise P01AA21.

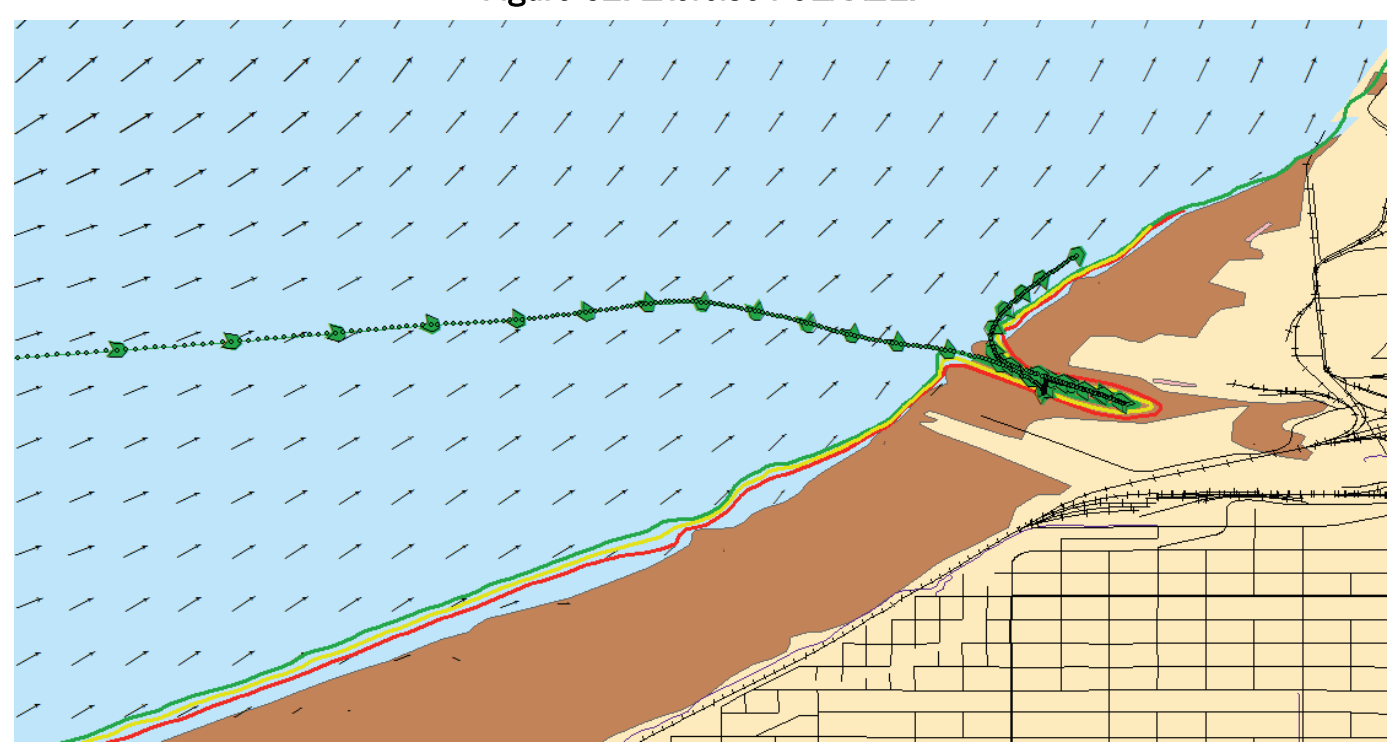

Figure C3. Exercise P01BA11.

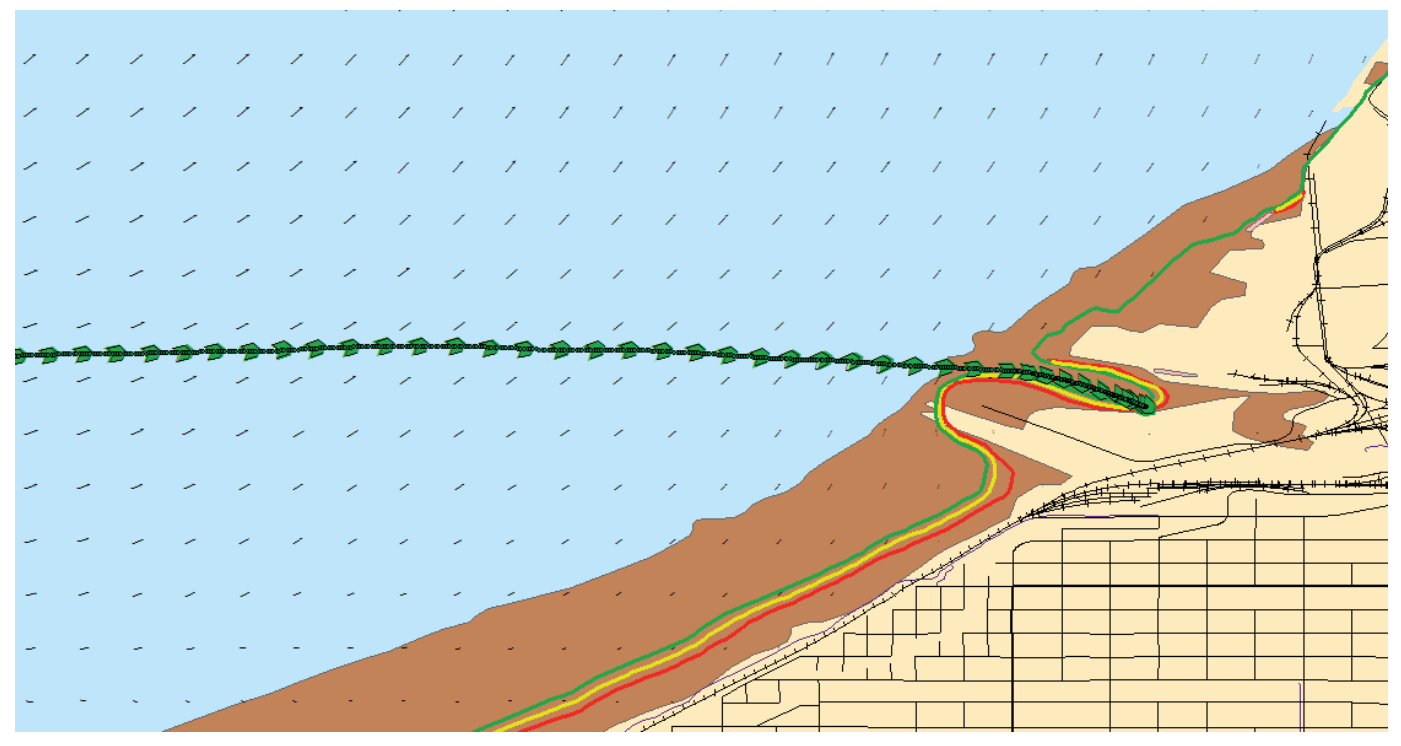


Figure C4. Exercise P01BB11.

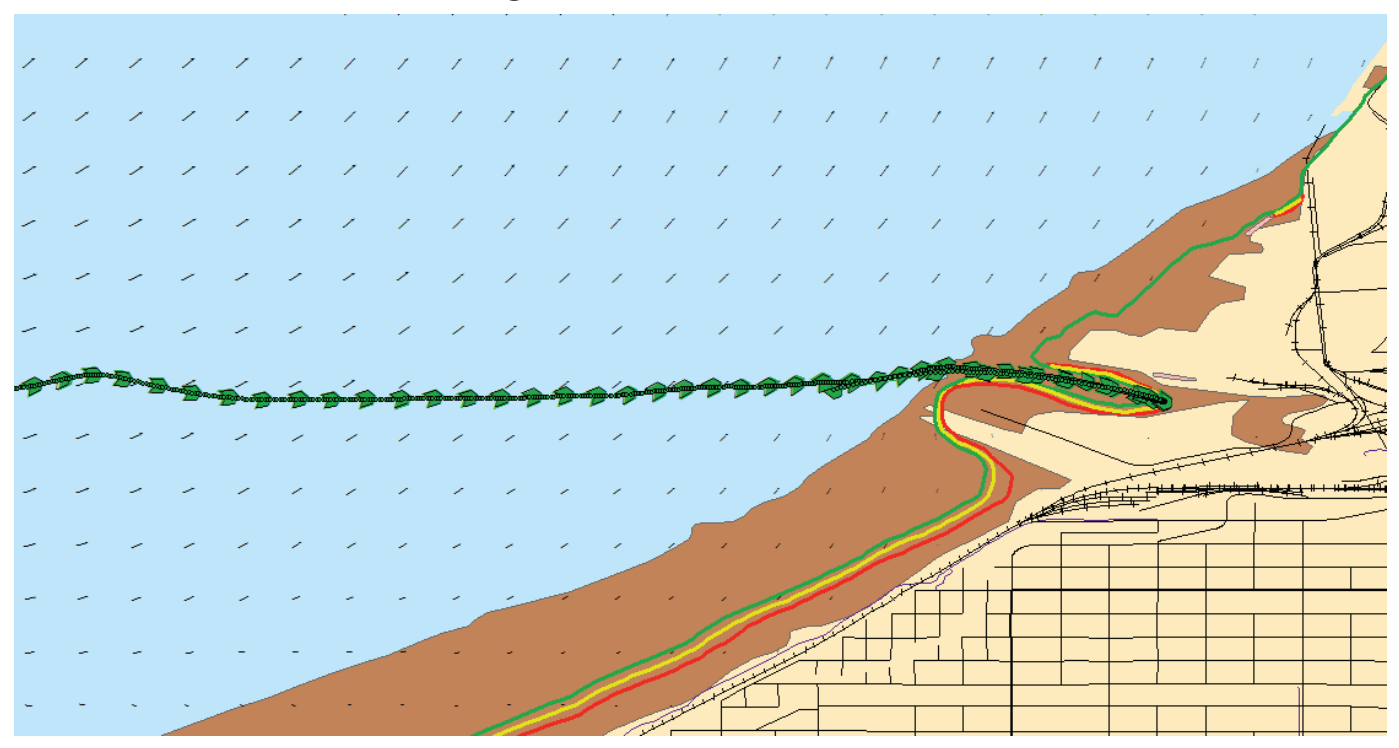

Figure C5. Exercise P01BB21.

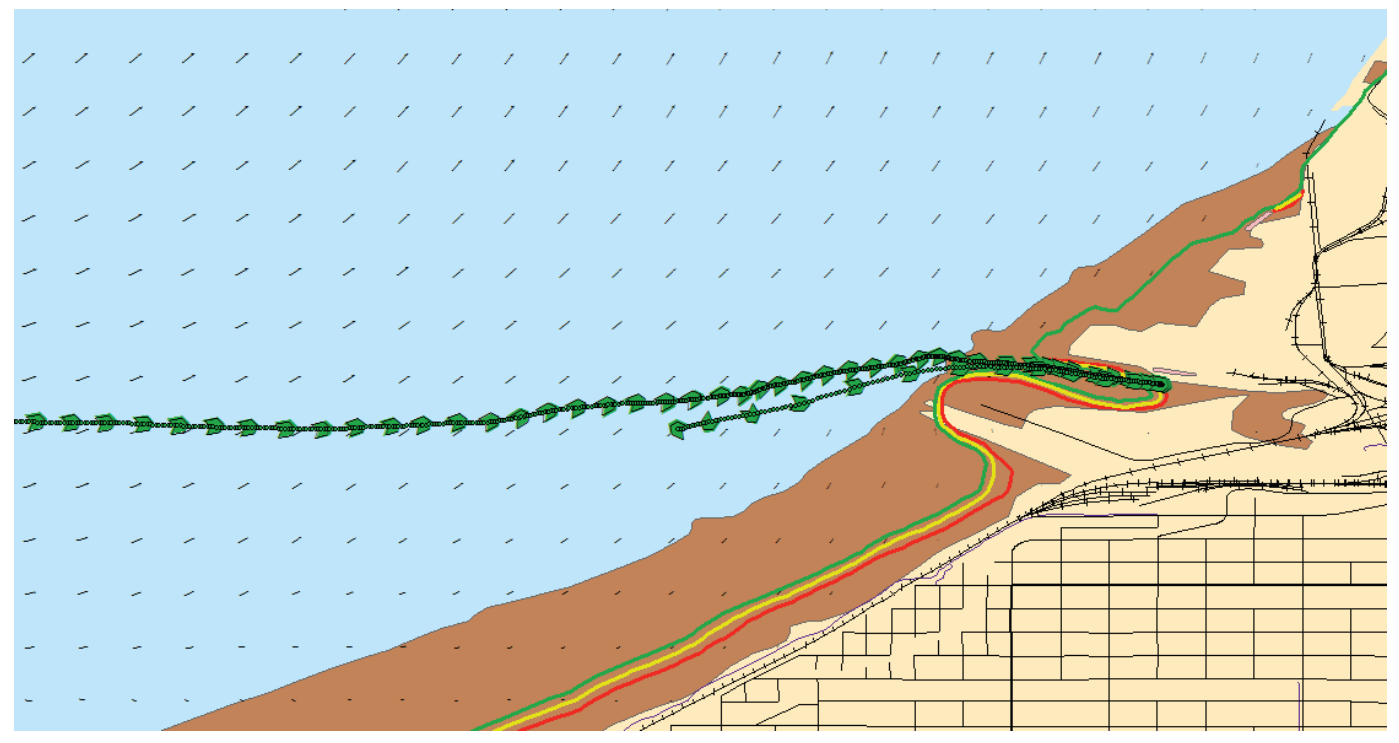


Figure C6. Exercise P01DA21.

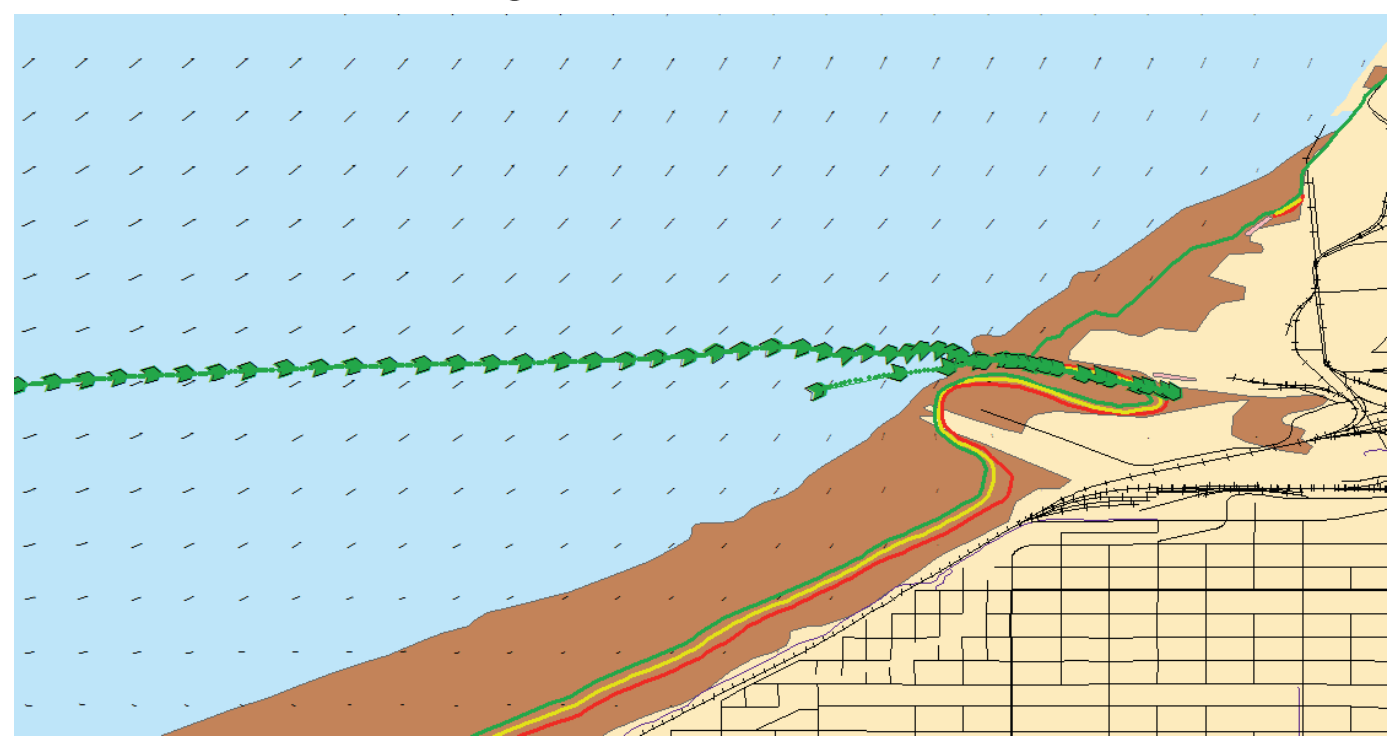

Figure C7. Exercise P01DB11.

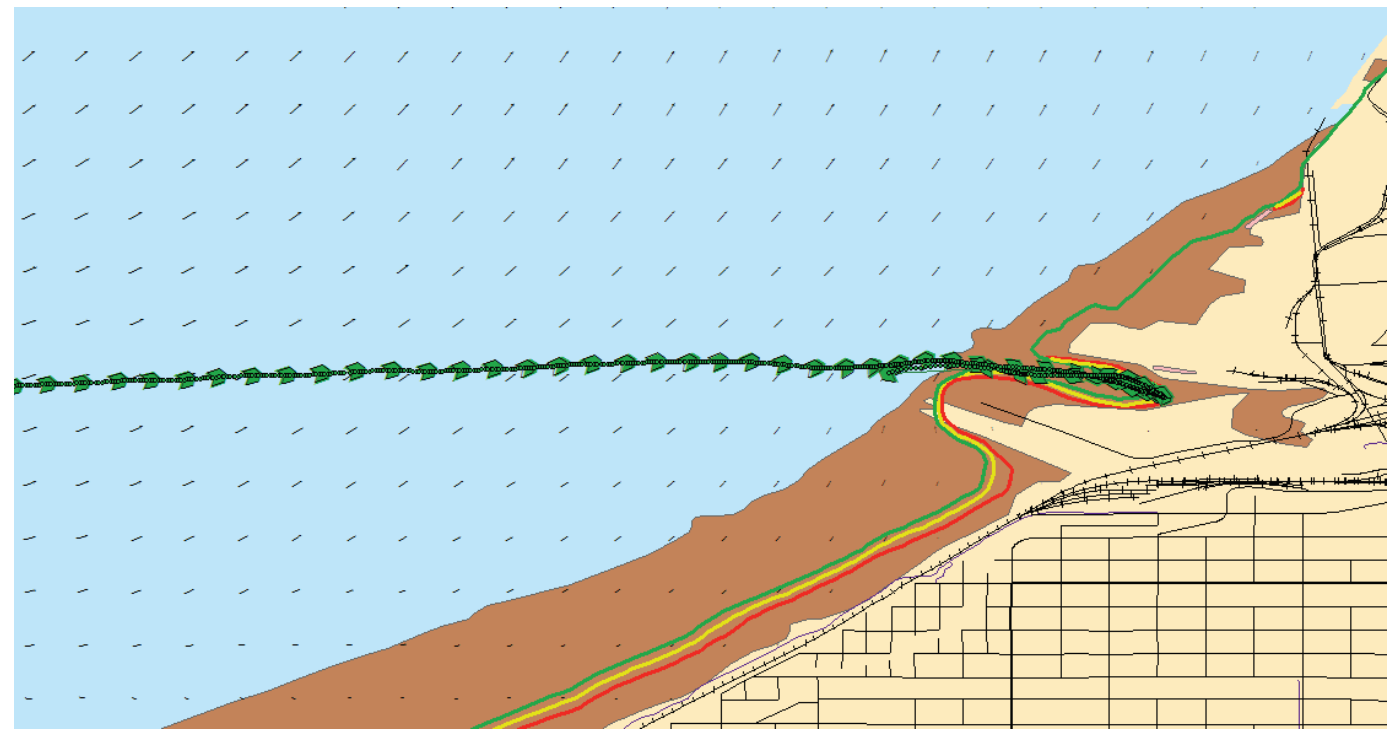


Figure C8. Exercise P01DB21.

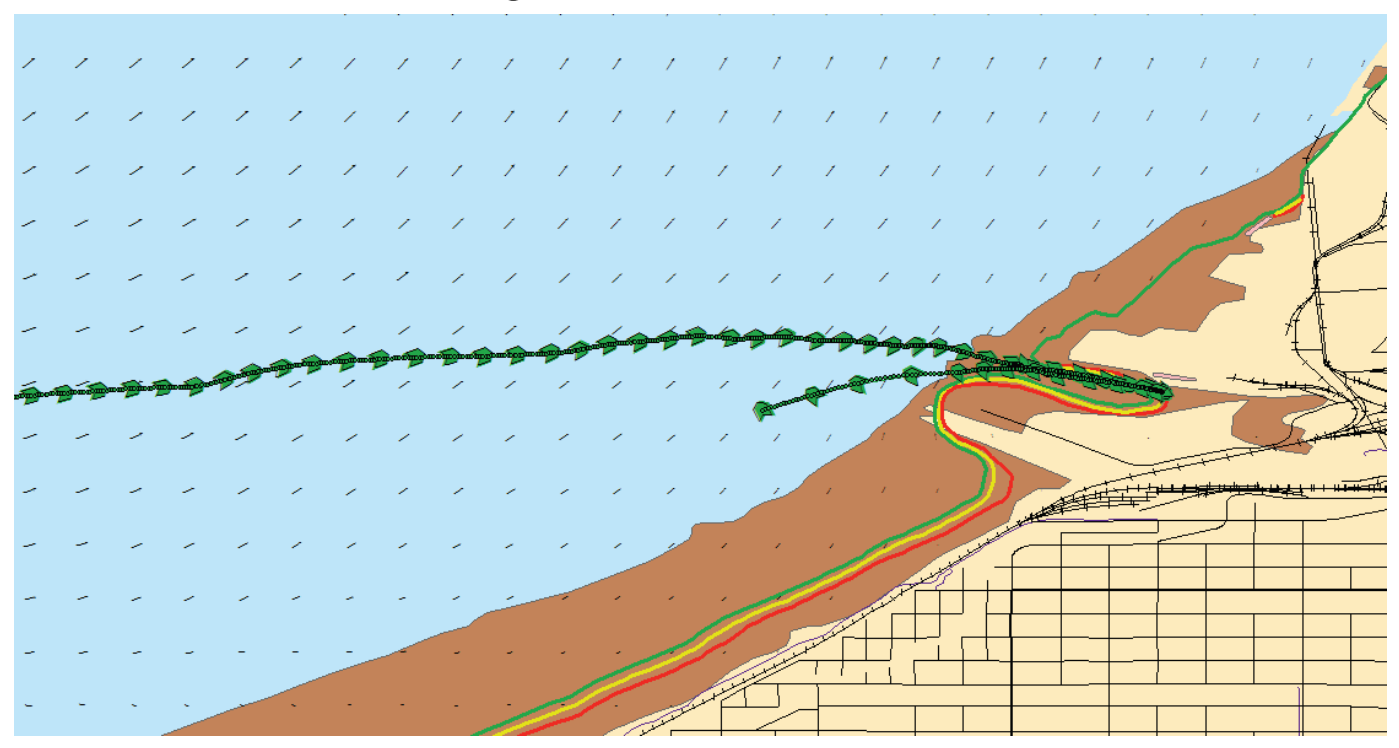

Figure C9. Exercise P01EB21.

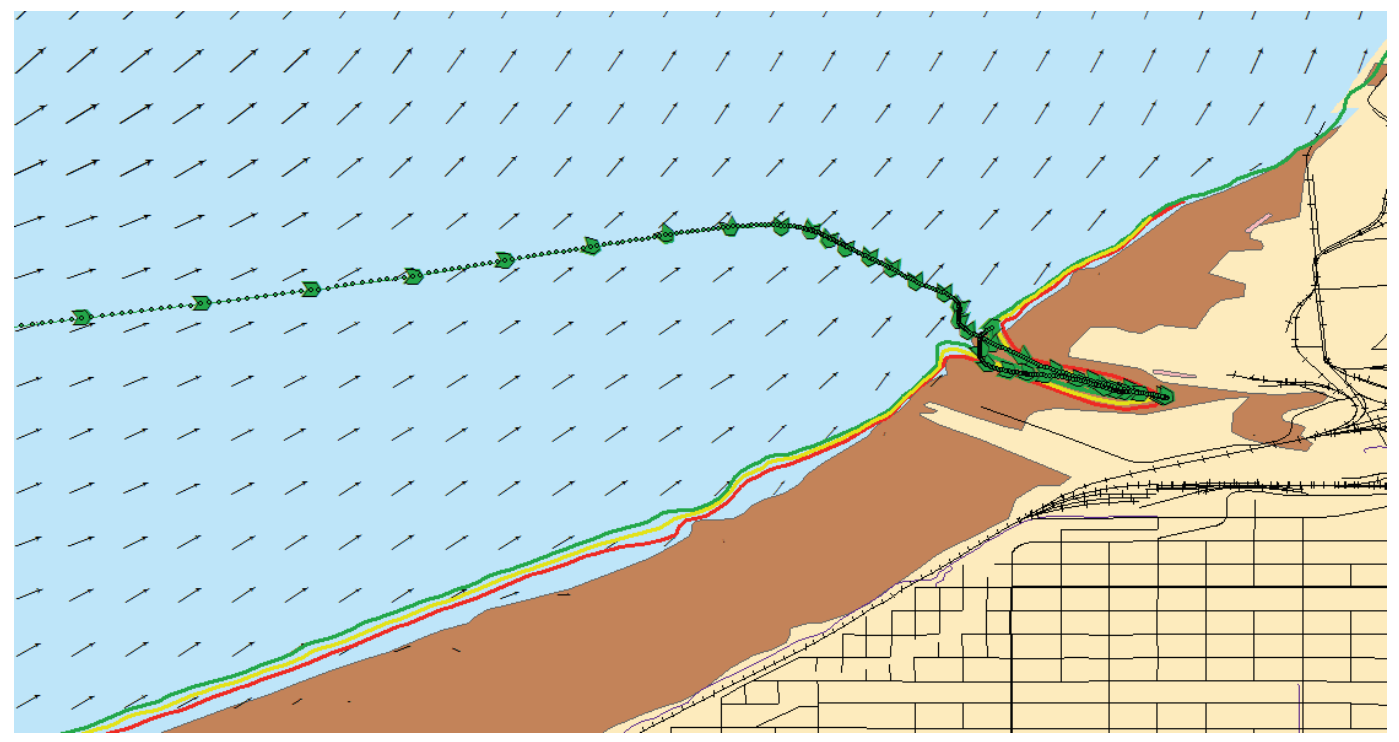




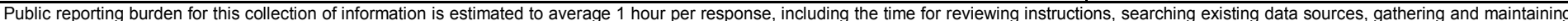

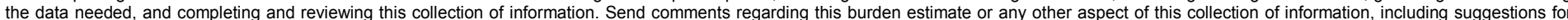

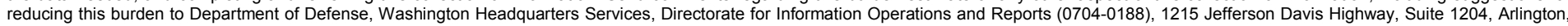

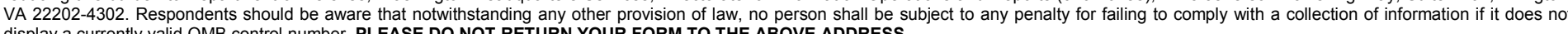
display a currently valid OMB control number. PLEASE DO NOT RETURN YOUR FORM TO THE ABOVE ADDRESS.
1. REPORT DATE (DD-MM-YYYY) 2. REPORT TYPE
May 2017 Final report

3. DATES COVERED (From - To)

\section{TITLE AND SUBTITLE}

Analysis of the Effect of Environmental Conditions in Conducting Amphibious Assaults Using a Ship Simulator/Vessel-Response Model Proof-of-Concept Study

5a. CONTRACT NUMBER

5b. GRANT NUMBER

5c. PROGRAM ELEMENT NUMBER

\section{AUTHOR(S)}

Mary A. Cialone, David J. Mark, S. Keith Martin, Dennis W. Webb, Mary C.

Allison, Rhonda D. Taylor, Thomas A. McKenna, and James R. Hill

5d. PROJECT NUMBER

5e. TASK NUMBER

5f. WORK UNIT NUMBER

\section{PERFORMING ORGANIZATION NAME(S) AND ADDRESS(ES)}

8. PERFORMING ORGANIZATION REPORT NUMBER

U.S. Army Engineer Research and Development Center

Coastal Hydraulics Laboratory

ERDC/CHL TR-17-4

3909 Halls Ferry Road, Vicksburg, MS 39180-6199

9. SPONSORING / MONITORING AGENCY NAME(S) AND ADDRESS(ES)

10. SPONSOR/MONITOR'S ACRONYM(S)

Headquarters, U.S. Army Corps of Engineers

Washington, DC 20314-1000

11. SPONSOR/MONITOR'S REPORT

NUMBER(S)

\section{DISTRIBUTION / AVAILABILITY STATEMENT}

Approved for public release; distribution unlimited.

\section{SUPPLEMENTARY NOTES}

\section{ABSTRACT}

Significant technological advances have been made in estimating tidal current and water levels using numerical models as well as in estimating vessel maneuverability using ship/tow simulators. Benefits in applying these technologies to planning an amphibious assault include: 1) minimizing operational risk by testing the feasibility of the navigability of an area; 2) determining the capacity and timing of that operation; 3) defining the optimal axes-of-assault that best ensures navigational safety; and 4) developing a training platform for executing a particular plan.

This report summarizes a proof-of-concept study for demonstrating the application of these technologies to allow commanders to determine the feasibility of surface amphibious operations and their use in a virtual amphibious assault near the Port of Anchorage, Alaska. This site was chosen because the environmental conditions at this location dictate that only a narrow window of time is available for conducting surface ship-to-shore operations.

The vessel used in the virtual assault is the 1646-class Landing Craft Utility (LCU). The U.S. Navy (USN) provided two experienced craftmasters for piloting the LCU. Their assessment was that the simulator provided a realistic environment and the handling of the virtual LCU closely resembled that of a standard displacement landing craft.

$\begin{array}{lll}\text { 15. SUBJECT TERMS } & \text { Coastwise navigation } & \text { Tidal currents } \\ \text { Amphibious warfare--Environmental } & \text { Amphibious assault ships } & \text { Anchorage Bay (Alaska) } \\ \text { aspects } & \text { Ship simulators } & \end{array}$

Landing craft

16. SECURITY CLASSIFICATION OF:

\begin{tabular}{|l|l|l|}
\hline a. REPORT & b. ABSTRACT & c. THIS PAGE \\
UNCLASSIFIED & UNCLASSIFIED & UNCLASSIFIED \\
\hline
\end{tabular}

17. LIMITATION
OF ABSTRACT

\begin{tabular}{|c|} 
18. NUMBER \\
OF PAGES \\
\cline { 2 - 2 }
\end{tabular}

19a. NAME OF RESPONSIBLE PERSON

19b. TELEPHONE NUMBER (include area code) 